Documents de travail du Département des Affaires économiques de l'OCDE No. 18

\title{
Base de données compatibles sur le commerce et la production de I'OCDE
} Derek Blades, Wendy Simpson 


\section{OCDE \\ DEPARTEMENT DES \\ AFFAIRES ECONOMIQUES ET STATISTIQUES}

\section{DOCUMENTS DE TRAVAIL}

NO. 18 : BASE DE DONNEES COMPATIBLES SUR LE COMMERCE ET LA PRODUCTION DE L'OCDE

$$
\text { par }
$$

Derek Blades,

Wendy Simpson

Division des Statistiques Economiques

et des Comptes Nationaux

Janvier 1985

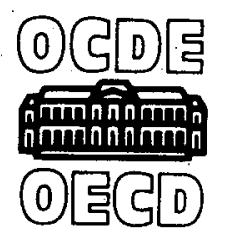



DEPARTEITET DES AFEAINES ECOINOINQUES

ET STATISTIQUES

DOCU: EHTS DE TRAVAIL

La série "Documents de Travail" a pour but de permettre $a$ un plus grand nombre de lecteurs de disposer de certaines études menées au sein du Département pour les besoins de I'OCDE. Ils sont sénéralement étebjis par un groupe d'auteurs dont les principaux sont mentionnés. Ces docunents sont disponibles en anglais et en franceis.

Tout commentaire sur ces documents sera apprécié et pourre être adressé à I'OCDE, Département des Afraires Economiques et Statistiques, 2 rue André-Pascal, 75775 Paris Cédex 16. Des exemplaires supplémentaires peuvent être fournis en noribre limité sur demande.

ORGAIISATIOIN DE COOPERATIOIN ET DE DEVELOPPEIEITT ECONOIITQUPS

Copyright OCDE, 1985 

(i)

BASE DE DONIEES COIPATIDLES SU: Li

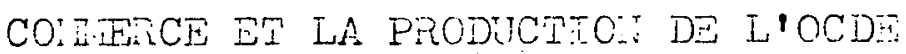

\author{
by \\ Derek Biaces \\ Wendy Simpson
}

Division des Statistiques Economiques et des Comptes Nationaux*

* Administrateur principal et administreteur, respectiverent, dans la Division des Statistiques Economiques et des Comptes IVationaux. Les vues exprimées reflètent l'opinion des auteurs et ne représentent pas nécessairement celies de I'OCDE ou des gouvernements des pays Membres. 



\section{Table des iratières}

paracrephe

Introduction

Contenu de la base de données

Utilization

Qualité des données

Taux de pénétration du marché dans

11 pays de I'OCDE
$1-2$

$3-5$

$6-7$

$8-14$

$15-28$

page

Tableaux résumés des taux de pénétration des importations

$9-1 ?$

15

Annexe Statistique

16-19

Production des produits nanufacturés

$19-21$

$22-24$

$25-72$ 

BASE DE DONNEES COMPATIBLES SUR LE COMMERCE ET LA PRODUCTION

\section{Introduction}

1. La Base de données compatibles sur le commerce et la production (COMTAP) de TrOCDE a été etablie par la Banque mondiale, sous la supervision générale du Professeur Jean Waelbroeck de I'Université Libre de Bruxelles. La Division des Statistiques Economiques et des Comptes Nationaux du Département des Affaires Economiques et Statistiques est maintenant responsable de la gestion de cette base de données.

2. Ce document décrit le contenu de la base de données, ainsi que certaines des exploitations analytiques auxquelles elle peut donner lieu. En suite, il examine certains problèmes que posait la constitution de cette base. Il donne enfin des exemples de l'utilisation de COMTAP pour, ie calcul d'un indicateur déterminé de la "pénétration du marché". Les annexes jointes présentent sous forme résumée certaines des données figurant dans les fichiers COMTAP.

\section{Contenu de la base de données}

3. La Base de données compatibles sur le commerce et la production (COMTAP) comprend des statistiques annuelles relatives à la production, aux importations et aux exportations de produits manufacturés. Sa caractéristique essentielle est de classer toutes ces statistiques selon une même nomenclature, la Classification internationale type, par industrie, de toutes les branches d'activité économique (CITI) (1).

4. La partie de COMTAP consacrée au commerce extérieur comprend les exportations et les importations, en valeur, de 24 pays Membres de l'OCDE. Ces données sont entièrement ventilées par pays partenaires, qu'il est possible de regrouper selon les besoins, de meme que les pays déclarants. Dans la plupart des cas, ces statistiques sont disponibles à partir de 1961. Les statistiques de production sont disponibles à partir de 1970 pour 11 dés pays les plus industrialisés de l'OCDE : Australıe, Belgique (2), Canada, France, Allemagne, Italie, Japon, Pays-Bas, Suède, Royaume-Uni et Etats-Unis, qui, bien que représentant moins de la moitié du nombre total de pays Membres, sont responsables de plus de 90 pour cent de la production des industries manufacturières de cette zone.

5. Tant le fichier du commerce extérieur que celui de la production font l'objet d'une mise à jour continue, encore que, dans le cas de la production, le délai dépasse trois ans et demi, les derniers chiffres actuellement disponibles étant ceux de 1980. Toutes les données figurant dans les fichiers COMTAP sont exprimées en valeur courante, convertie en dollars des Etats-Unis sur la base du taux de change courant. 


\section{Utilisation}

6. On définit ci-après quatre indicateurs analytiques d'usage courant, parmi ceux qui peuvent etre établis à partir de COMTAP (les symboles $X, M, P$ désignant respectivement les exportations, les importations et la production d'un pays déclarant déterminé et les indices $i, j$, les pays partenaires et les branches d'industrie) :
a) $\frac{X i j-M i j}{P j+M j}$ :
- Balance commerciale vis-à-vis du pays $i$ pour les produits de la branche j, rapportée aux ressources totales de $j$;
b) $\frac{\mathrm{Mij}}{\mathrm{P} \dot{j}}$
c) $\frac{M i j}{P j+M j}$
: Importations de produits j en provenance du pays $i$, rapportées à la production de $j$;
: Importations de produits $j$ en provenance du pays $i$, rapportées aux ressources totales de $j$;
d)

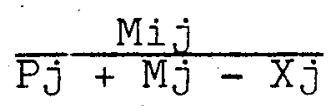
: Importations de produits $j$ en provenance du pays i, rapportées à la consommation intérieure de $j$.

7. On peut calculer des rapports de ce genre à divers niveaux de la CITI et définir les partenaires, soit comme des pays ou territoires distincts, soit comme un regroupement quelconque, tel que I'OPAEP, Ies pays du Pacifique, les pays les moins développés, le COMECON, etc. Dans les indicateurs b) et c), on peu remplacer $M$ par $X$ au numérateur, de manière à calculer la "performance des exportations". On peut calculer ces rapports pour toutes les années de 1970 à 1980, la période couverte sialiongeant continuellement.

\section{Qualité des données}

8. Dans l'établissement des fichiers COMTAP, qu'il s'agisse du commerce extérieur ou de la production, on s'est heurté à plusieurs difficultés, qui ont des incidences sur la fiabilité et 1 'interprétation des données collectées. En ce qui concerne les statistiques du commerce extérieur, la difficulté fondamentale est I'absence d'une correspondance univoque entre la classification par produits (CTCI) (3) qui leur sert de base et la classification par branches (CITI) adoptée pour COMTAP: Méme au niveau des rubriques à 4 ou 5 chiffres, de nombreux produits définis par la CTCI peuvent etre issus de deux ou plusieurs branches de la CITI. Il existe en principe deux méthodes pour surmonter cette difficulté : attribuer en totalité chaque rubrique douteuse à la branche de la CITI que l'on considère comme la plus appropriée, ou bien la ventiler entre toutes les branches concernées. C'est la seconde solution qu'a adoptée le Département des Affaires économiques et statistiques, qui utilise actuellement un tableau de concordance établi par la Banque mondiale. Ce tableau répartit chacun des produits issus de plusieurs branches d'industrie entre les rubriques correspondantes de la CITI, en fonction de la composition par produits des échanges des pays du Marché Commun en 1975 (4). 
9. Ce tableau est critiquable, du fait qu'il applique les mémes facteurs de répartition à toutes les années et aux échanges de tous les pays (y compris ceux qui ne font pas partie de la $\mathrm{CEE})$. Si, de toute évidence, c'est là une méthode peu satisfaisante, elile semble néanmoins préférable à l'autre solution, qui consisterait à attribuer en totalité les produits issus de plusieurs branches d'industrie à une branche unique, considérée comme la plus appropriée. Il convient, en tout état de cause, d'observer que seule une minorité des rubriques de la CTCI ressortit de plusieurs branches d'industrie, la plupart des produits pouvant être affectés de manière univoque à une rubrique de la CITI.

10. Pour établir les statistiques de production, on est parti des recensements industriels, en convertissant en nomenclature CITI la nomenclature nationale qui leur sert de base. Bien entendu, il arrive souvent qu'il n'y ait pas de concordance univoque entre la nomenclature nationale et la CITI, ce qui oblige à adopter diverses solutions de fortune. D'autres difficultés naissent de la définition de la production, du traitement des

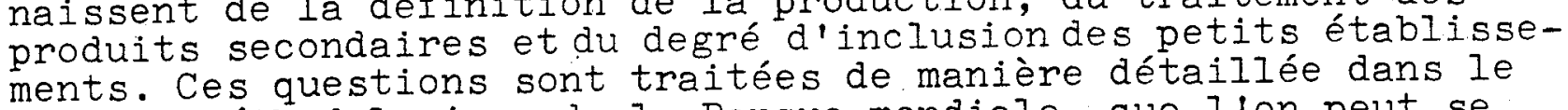
rapport méthodologique de la Banque mondiale, que lion peut se procurer auprès du Secrétariat ; toutefois, certaines remarques s'imposent ici pour éclairer les taux de pénétration du marché qui figurent à la section ci-après.

11. Dans la plupart des pays, la production est définie par la valeur des ventes ou des livraisons, mais la France, I'Italie, la Suède et l'Allemagne (cette dernière, uniquement dans le cas de certaines branches) utilisent la notion de "production brute" empruntée à la comptabilité nationale et comprenant, outre la valeur des biens livrés à des tiers, la production d'actifs fixes pour compte propre et la variation des stocks de produits finis. Dans ces pays, la "production" est d'habitude plus élevée que dans les autres.

12. La production secondaire fait problème du fait que les enquetes industrielles ont pour unité statistique l"établissement", qui souvent fabrique un ou plusieurs articles secondaires, en dehors de celui qui représente son activité principale. En Belgique, en France, en Allemagne et en Suède, on s'est efforcé d'affecter ces productions secondaires à la branche correspondante de la CITI, tandis que les sept autres pays les attribuent à la branche d'activité principale de l'établissement. Dans les statistiques de ce demier groupe de pays, par conséquent, des erreurs d'importance inconnue sont réparties de manière aléatoire entre les branches d'industrie, chaque rubrique de la CITI pouvant comprendre des produits afférents à d'autres et exclure des produits attribués par erreur à d'autres branches. 
13. Dans tous les pays, les enquetes ou les recensements relatifs à la production industrielle omettent les petits établissements, mais la définition en est variable, l'effectif maximal retenu dans les 11 pays de l'OCDE allant de 4 salariés (Australie) à 20 (Allemagne et Italie). Pour le Japon, le Canada et le Royaume-Uni, les données résultant des recensements ont été corrigées pour inclure la production estimée des petits établissements. Pour les autres pays, $I^{\prime}$ omission des petites unités risque d'entrainer une grave sous-estimation de la production, plus particulièrement en ce qui concerne les industries légères -- par exemple, habillement, articles en cuir, transformation des produits alimentaires -- où ces unités risquent d'être responsables d'une part importante de la production totale.

14. Les fichiers COMTAP conservent des données au niveau des rubriques à 4 ou 5 chiffres de la CITI. Cependant, du fait des difficultés évoquées ci-dessus, ce degré de détail risque de comporter des erreurs relativement importantes et ne devrait etre utilisé, le cas échéant, qu'avec beaucoup de prudence. Un regroupement des données a parfois pour efiet d'éliminer ces erreurs et presque toujours d'en réduire l'importance relative; c'est pourquoi les tableaux joints à la présente note ne descendent pas en dessous des rubriques à 3 chiffres ("classes") de la CITI.

\section{Taux de pénétration du marché dans 11 pays de I'OCDE}

15. En annexe à la présente note, on trouvera quatre tableaux. Les Tableaux A à C indiquent la valeur, en 1970 et en 1980, de la production, des importations et des exportations de la Branche 3 de la CITI (industries manufacturières) et de 27 classes de cette Branche. C'est à partir de ces données que sont calculés les taux de pénétration du marché figurant au Tableau D.

16. Ces taux correspondent à la formule:

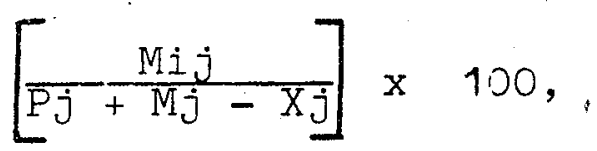

autrement dit, au pourcentage que représentent les importations du pays déclarant en provenance du pays i, pour les produits de la branche $j$, par rapport à sa consommation intérieure de ces produits. De manière générale, ces pourcentages devraient etre positifs et ne pas dépasser 100 pour cent. Cependant, le Tableau $D$ comporte plusieurs résultats supérieurs à 100 pour cent et I'on obtiendrait également des résultats négatifs en calculant, à partir de la base de données, des taux de pénétration au niveau des rubriques à 4 ou 5 chiffres de la CITI. Il est utile de se demander comment on peut aboutir à de tels résultats.

17. Si :
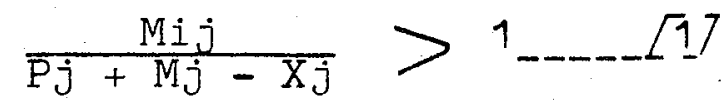

il s'ensuit que :

$X j>P j+\left(M_{j}-M_{i j}\right)$ 
La situation correspondant à [2], où les exportations de $j$ sont supérieures à la production intérieure de j augmentée des importations en provenance de toutes les sources autres que i, ne peut se présenter que si des exportations sont effectuées à partir de stocks constitués au cours d'une période antérieure. S'il peut occasionnellement en etre ainsi, ce ne peut pas etre le cas en longue période ; les résultats supérieurs à 100 pour cent qui figurent au Tableau $\mathrm{D}$. et dont certains se maintiennent durant plusieurs années successives correspondent presque certainement à des données de base erronées. L'explication la plus probable de ces erreurs est une sous-estimation de Pj résultant de l'omission des petites unités de production. Il peut également s'agir d'une surestimation de $\mathrm{Xj}$ ou d'une sous-estimation de $\mathrm{Mj}$, imputables à des erreurs de conversion de la CTCI en CITI.

18. $\mathrm{Si}$ :

$$
\frac{M i j}{P j+M j-X j}<0 \text {, }
$$

puisque Mij est toujours positif, il s'ensuit que :

$$
\begin{aligned}
& \mathrm{Pj}_{\mathrm{j}}+\mathrm{Mj}_{\mathrm{j}}-\mathrm{Xj}<0 \\
& \text { ou encore, que : } \\
& \mathrm{Xj}>\mathrm{Pj}+\mathrm{Mj}
\end{aligned}
$$

La situation correspondant à $[\overline{5}$, oì les exportations de j dépassent la production intérieure augmentée des importations de toutes provenances, y compris i, est encore moins plausible que celle évoquée plus haut. Comme dans le cas précédent, elle pourrait théoriquement se présenter du fait que les exportations s'effectuent en grande partie sur stocks, mais le résultat obtenu s'explique habituellement par une sous-estimation de la production ou des importations, une surestimation des exportations, ou encore une combinaison quelconque de ces erreurs.

19. Il est évident que les taux de pénétration du marché qui sortent des bornes admissibles n'ont pas de sens pour l'analyse économique. Ils permettent d'identifier les secteurs qui devraient donner lieu à une amélioration des tableaux de concordance ou des méthodes de collecte des données; des recherches sont actuellement en cours au Département des Affaires économiques et statistiques pour tenter d'éliminer ces difficultés. Toutefois, s'il convient de ne pas tenir compte des taux qui sortent des bornes admissibles, les utilisateurs seront peut-etre à même de se servir d'un ou de plusieurs des éléments du calcul -$P, M$ ou $X-s^{\prime} i l s$ parviennent à identifier la source d'erreur la plus probable.

20. Les Tableaux 1 à 4 résument quelques-unes des principales caractéristiques des ta'ux de pénétration du marché figurant au Tableau $D$ de $I$ 'annexe. Le Tableau 1 fait apparaftre les taux de pénétration du marché des produits manufacturés dans leur ensemble, avec une ventilation par pays ou zones partenaires. On voit en colonne la part des importations en provenance de chacun des partenaires -- qui figurent dans la colonne de gauche -- dans la 
consommation intérieure de produits manufacturés du pays déclarant. En d'autres termes, chaque colonne indique la pénétration des importations sur le marché des produits manufacturés de chaque pays déclarant, tandis que les lignes montrent dans quelle mesure les exportations des divers partenaires ont réussi à pénétrer le marché intérieur de l'ensemble de ces pays.

21. La dernière Iigne du Tableau 1 (pénétration du marché par I'ensemble des partenaires commerciaux) donne à penser que I'on peut subdiviser les onze pays déclarants en trois groupes : le premier, composé du Japon et des Etats-Unis, se caractérise par une faible pénétration étrangère, inférieure à 10 pour cent; ie second comprend sept pays ou cette pénétration est moyenne (entre 20 et 40 pour cent) ; le dernier, qui comprend la Belgique et les Pays-Bas, présente un taux de pénétration élevé, dépassant 60 pour cent. De manière générale, il semble exister une relation inverse entre l'importance d'un pays et le degré de pénétration de son marché. De grands pays, tels que le Japon et les Etats-Unis, se caractérisent par un faible taux de pénétration étrangère, alors que celui-ci est élevé dans de petits pays comme la Belgique et les Pays-Bas. Ces deux derniers pays ont traditionnellement une économie très ouverte et sont fortement liés entre eux dans le cadre du Bénélux, ainsi qu'avec leurs grands voisins, la France et l'Allemagne. Néanmoins, les taux de pénétration globa'x figurant au Tableau 1, qui s'élévent à 62 pour cent pour les Pays-Bas et à 33 pour cent pour la Belgique, sont presque certainement surestimés, du fait que la production y est minorée par l'omission des petits établissements.

22. Dans la colonne de droite du Tableau 1, on peut voir dans quelle mesure les divers partenaires commerciaux ont réussi à pénétrer l'ensemble du marché des produits manufacturés dans les onze pays déclarants. Le dénominateur de ce rapport est constitué par la consommation intérieure totale de l'ensemble de ces pays, agrégat qui convient sans aucun doute pour mesurer la pénétration du marché par les partenaires extérieurs à l'OCDE, mais qui est moins adéquat lorsqu'il s'agit des échanges qui ont lieu entre les pays déclarants eux-memes. Ainsi, le chiffre de 0.9 qui figure en tete de la colonne de droite signifie qu'en 1980 les importations de produits manufacturés effectuées par les dix autres pays déclarants en provenance du Canada représentaient 0.9 pour cent de la consommation totale de ces produits dans I'ensemble des onze pays déclarants, y compris le Canada luimême. Le Canada ne pouvant pas exporter vers son proṕre marché, le numérateur et le dénominateur de ce rapport ne correspondent donc pas à la même définition. Il existe au moins deux méthodes permettant de surmonter cette difficulté. On pourrait corriger le numérateur en y ajoutant la "pénétration" par le Canada de son propre marché (c'est-à-dire, la partie de sa consommation intérieure satisfaite par sa propre production) ou corriger le dénominateur en déduisant la consommation du Canada. C'est Ia seconde méthode que l'on a adoptée pour calculer les "taux ajustés" ci-après, qui rapportent les exportations de chaque pays vers les dix autres à la consommation totale de ces derniers. 
$\underline{\mathrm{Ca}} \underline{\mathrm{EU}} \quad \underline{\mathrm{Ja}} \underline{\mathrm{Au}}$ Be$\underline{\mathrm{Fr}} \underline{\mathrm{AI}} \underline{\mathrm{It}} \underline{\mathrm{Pa}} \underline{\mathrm{SU}} \underline{\mathrm{RU}}$

Taux

figurant

au

Tableau 1

0.9

2.2

1.3

0.11 .0

1.3

2.31 .0

1.0

$0.3 \quad 0.9$

Taux

ajusté

0.9

$3.7 \quad 1.6$

0.11 .0

1.5

2.5

1.1

1.0

0.31 .0

23. Il se trouve que la consommation intérieure du Canada est de si faible importance par rapport à celle du groupe de pays dans son ensemble qu'en l'éliminant du dénominateur, on ne modifie pas le taux calculé. Pour les Etats-Unis, en revanche, la correction augmente ce taux de plus des deux tiers. Si les exportations de produits manufacturés effectuées par les Etats-Unis à destination des pays déclarants sont plus faibles dans l'absolu que celles de l'Allemagne, le marché qui s'offre à elles est beaucoup plus réduit, car il exclut la consommation américaine, alors que le marché ouvert aux exportateurs allemands n'exclut que la consommation de l'Allemagne.

24. I'une des remarques les plus frappantes que permet de faire le Tableau 1 est que la pénétration du marché est essentiellement un phénomène qui caractérise les relations entre pays de l'OCDE. En 1980, les pays non Membres ne fournissaient que moins de 4 pour cent des produits manufacturés consommés par les onze pays déclarants. Si les sept "Pays nouvellement industrialisés" étaient parvenus à un taux de pénétration de 1.3 pour cent -- équivalent à celui que réalisaient conjointement les Pays-Bas et la Suède -- ce taux restait insignifiant dans le cas des autres zones non OCDE. Le continent africain (à I'exclusion de I'Afrique du Sud) fournissait moins de 0.3 pour cent des produits manufacturés consommés par les onze pays déclarants, tandis que les pays d'Asie en développement, qui comptent plus de la moitié de la population mondiale, s'assuraient un taux de pénétration inférieur à celui de la Belgique.

25. Le Tableau 2 fait apparaftre le taux de croissance annuel moyen, entre 1970 et 1980, des taux de pénétration figurant au Tableau 1 (5). Pour I'ensemble des pays déclarants, le taux de pénétration giobal a augmenté annuellement au rythme d'environ $4 \frac{1}{2}$ pour cent (chiffre figurant dans l'angle inférieur droit du Tableau 2). L'augmentation du taux de pénétration étrangère a été particulièrement prononcée pour I'Italie, le Royaume-Uni et les Etats-Unis et particulièrement faible pour le Canada et I'Australie.

26. On peut s'attendre, de manière générale, à voir la croissance du taux de pénétration varier en raison inverse de. son niveau, les taux initialement faibles ayant tendance à augmenter plus rapidement que ceux qui étaient déjà élevés en 1970. 
C'est bien ce que confirme dans l'ensemble une comparaison de nos deux tableaux, encore que le taux de pénétration rélativement bas des marchés australien et japonais n'ait connu depuis 1970 qu'une croissance modérée, alors que sur le marché belge, déjà fortement pénétré à l'origine par les importations, la part de ces dernières a continué à augmenter rapidement.

27. A l'exception du Canada, tous les partenaires commerciaux figurant au Tableau 2 ont accru leur pénétration du marché des pays déclarants. La contraction subie par le Canada s'explique par la forte baisse de sa part du marché britannique à la suite de l'intégration du Royaume-Uni à la CEE. La colonne de droite du tableau montre que, parmi les partenaires commerciaux appartenant à I'OCDE, c'est le Japon qui a le plus élargi sa part du marché, mais la France, I'Italie et les Pays-Bas ont eux aussi accru leur taux de pénétration des marchés étrangers à un rythme annuel égal ou supérieur. à 5 pour cent. Considérés globalement, les pays non Membres de 1'OCDE ont augmenté leur part du marché des onze pays déclarants beaucoup plus vite que ne l'ont fait les pays Membres; ce qui, bien sur, correspond dans une large mesure à la relative faiblesse du taux de pénétration qu'ils enregistraient en 1970."

28. Les Tableaux 3 et 4 font apparaitre le taux de pénétration du marché des onze pays déclarants, ventilé par classes de la CITI. Les taux de pénétration observés en 1980 figurent au Tableau 3 et leur croissance annuelle moyenne depuis 1970 au. Tableau 4. Globalement, les branches qui connaissaient les plus forts taux de pénétration en 1980 étaient celles des chaussures en cuir, de l'habillement, des autres articles en cuir, des métaux non ferreux et des appareils de mesure et de controle, les taux les plus bas étant observés dans les industries du tabac et des boissons, l'imprimerie et l'édition, ainsi que la fabrication d'ouvrages en matières plastiques. Parmi les branches où la croissance du taux de pénétration étrangère a été. particulièrement rapide, on relève I'industrie du tabac, I habillement, les chaussures de cuir et 1 'industrie du caoutchouc, tandis qu'elle était relativement lente pour les industries alimentaires, celle du papier et lá métallurgie de base. 
Tableau 1

Taux de pénétration des importations selon les pertenalres commerciaux : ensemble des produits manufacturés, 1980

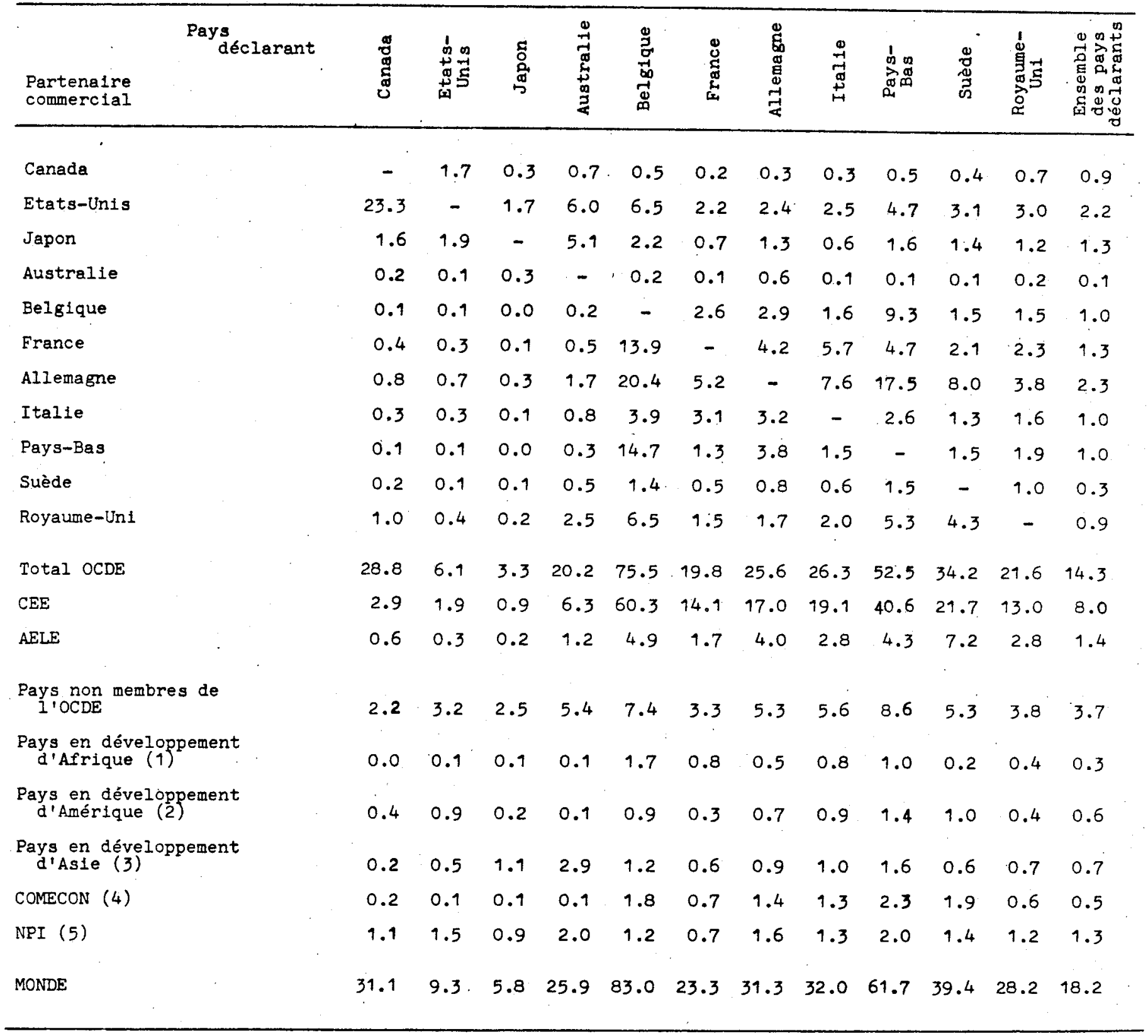

(1) Non compris I'Afrique du Sud.

(2) Non compris le Canada, les Etats-Unis, Cuba et le's NPI d'Amérique.

(3) Non compris Israel, les NPI d'Asie et les pays asiatiques nembres du COMECON.

(4) URSS; République démocratique allemande, Pologne, Tchécoslovaquie, Hongrie, Roumanie, Bulgarie, Cuba, Vietnam, Mongolie.

(5) NPI (Nouveaux Pays Industriels): Brés1l, Hong Kong, Mexique, Corée du Sud, Singapour, Ta1wan, Yougoslavie. 
Tableau 2

Croissance annuelle moyenne des taux de pénétration des importations selon les partenaires commerciaux: ensemble des prodults manufacturés, 1970-1980

\begin{tabular}{|c|c|c|c|c|c|c|c|c|c|c|c|c|}
\hline $\begin{array}{l}\text { Partenalre } \\
\text { commercial }\end{array}$ & 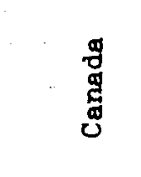 & 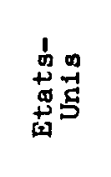 & 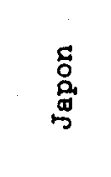 & 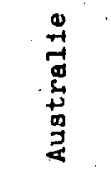 & 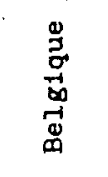 & 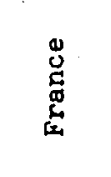 & 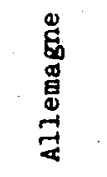 & 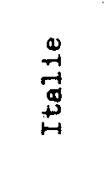 & 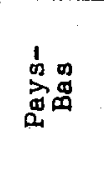 & 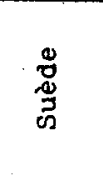 & 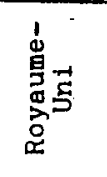 & 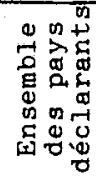 \\
\hline Canada & - & 1.7 & 1.8 & -1.9 & 1.6 & 3.1 & 1.2 & 4.3 & -2.2 & 4.6 & -6.2 & -0.2 \\
\hline Etats-Unis & 1.6 & - & -0.4 & 0.0 & 2.5 & 2.2 & 1.9 & 2.9 & 1.5 & 1.5 & 2.8 & 2.4 \\
\hline Japon & 2.0 & 6.8 & - & 4.9 & 11.5 & 12.3 & 10.8 & 7.0 & 9.2 & 8.3 & 14.4 & 6.5 \\
\hline Australie & 1.3 & 4.5 & 3.9 & - & 11.1 & -2.8 & 1.8 & 5.2 & 4.1 & 6.9 & -6.3 & 2.3 \\
\hline Belgique & 1.7 & -1.0 & 2.9 & 1.6 & - & 1.9 & 2.6 & 7.0 & -0.9 & 2.9 & 14.0 & 3.8 \\
\hline France & 2.1 & 7.9 & 4.5 & 1.6 & 3.0 & - & 3.9 & 8.0 & 1.4 & 3.9 & 12.1 & 5.7 \\
\hline Allemagne & -0.1 & 3.1 & -1.6 & 0.3 & 2.3 & 1.5 & - & 6.0 & 0.8 & 2.0 & 11.6 & 4.0 \\
\hline Italie & 0.6 & 1.7 & 4.6 & 4.1 & 3.8 & 5.0 & 3.5 & - & -0.4 & 3.2 & 10.7 & 5.2 \\
\hline Pays-Bas & -2.8 & 2.3 & -2.2 & -2.7 & 4.6 & 2.1 & 4.1 & 5.7 & - & 1.8. & 7.9 & 5.0 \\
\hline Suède & 0.0 & 5.2 & 2.3 & 2.5 & 3.0 & 1.6 & 3.4 & 6.3 & 0.7 & - & 8.7 & 3.1 \\
\hline Royaume-Uni & -4.4 & 2.4 & 0.0 & -6.8 & 6.6 & 5.2 & 7.0 & 9.3 & 4.8 & -0.8 & - & 3.6 \\
\hline Total OCDE & 1.2 & 3.7 & 0.4 & 0.0 & 3.8 & 3.4 & 4.5 & 6.7 & 1.3 & 2.2 & 5.5 & 4.0 \\
\hline CEE & -1.4 & 3.0 & 0.5 . & -3.0 & 3.5 & 2.9 & 4.3 & 7.1 & 1.0 & 1.6 & 9.3 & 4.6 \\
\hline AELE & $-1 \cdot 7$ & 4.1 & 1.1 & 0.8 & 5.5 & 3.5 & 5.5 & 7.5 & 2.6 & 3.0 & 1.2 & 4.2 \\
\hline $\begin{array}{l}\text { Pays non membres de } \\
\text { I OCDE }\end{array}$ & 4.6 & 9.6 & 4.7 & 10.1 & 9.4 & 5.5 & 6.7 & 8.5 & 7.3 & 3.6 & 2.3 & 6.9 \\
\hline $\begin{array}{l}\text { Pays en développement } \\
\text { d'Afrique (1) }\end{array}$ & -22.0 & 7.9 & -9.0 & -1.8 & -6.2 & 0.0 & 4.2 & 4.3 & 7.1 & -3.5 & -3.7 & 1.0 \\
\hline $\begin{array}{l}\text { Pays en développement } \\
\text { d'Amérique (2) }\end{array}$ & 1.0 & 6.3 & 2.7 & 4.8 & -1.9 & 1.3 & 0.3 & 7.9 & 1.5 & 2.8 & -2.8 & 3.5 \\
\hline $\begin{array}{l}\text { Pays en développement } \\
\text { d'Asie ( } 3 \text { ) }\end{array}$ & 2.4 & 10.9 & 7.0 & 11.2 & 10.7 & 12.2 & 10.9 & 12.9 & 9.4 & 8.4 & 6.2 & 10.2 \\
\hline COMECON (4) & 3.9 & 10.3 & -4.7 & -2.1 & 8.1 & 6.9 & 7.0 & 8.7 & 9.6 & 3.2 & 0.9 & 6.1 \\
\hline NPI (5) & 9.6 & 11.6 & 10.6 & 12.4 & 8.8 & 13.9 & 10.1 & 8.2 & 8.7 & 5.2 & 8.8 & 10.4 \\
\hline MONDE & 1.4 & 5.3 & 2.0 & 1.5 & 3.5 & 3.7 & 5.0 & 7.0 & 1.8 & 2.3 & 5.7 & 4.6 \\
\hline
\end{tabular}

(1) Non compris l'Afrique du Sud.

(2) Non compris le Canada, les Etats-Unis, Cuba et les NPI d'Amérique.

(3) Non compris Israel, les NPI d'Asle et les pays asiatiques membres du COMECON.

(4) URSS, République démocratique allemande, Pologne, Tchécoslovaquie, Hongrie, Roumante, Bulgarte, Cuba, Vietnam, Mongolie.

(5) NPI (Nouveaux Pays industriels) : Brésil, Hong Kong, Mexıque, Corée du Sud, Singapour, Taiwan, Yougosiavie. 
Tableau 3 : Taux de pénétration des 1mortations selon les classes de la CITI :

échanges avec l'ensemblo des partenalres commerclaux, 1980

\begin{tabular}{|c|c|c|c|c|c|c|c|c|c|c|c|c|c|}
\hline CIT & $\begin{array}{l}\text { Pays } \\
\text { déclarant }\end{array}$ & हु & 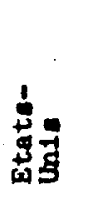 & $\stackrel{g}{g}$ & 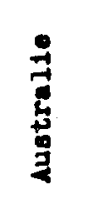 & 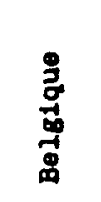 & $g$ & $\begin{array}{l}8 \\
5 \\
8 \\
8 \\
7 \\
7\end{array}$ & 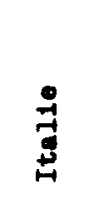 & $\underset{0}{\stackrel{0}{0}}$ & $\begin{array}{l}\stackrel{8}{8} \\
\stackrel{\varpi}{3}\end{array}$ & 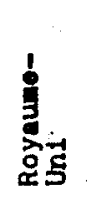 & 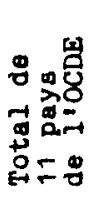 \\
\hline & Industries manufacturières & 31.9 & 9.3 & 5.8 & 25.9 & 83.0 & 23.3 & 31.3 & 32.0 & 61.7 & 39.4 & 28.2 & 18.2 \\
\hline $11 / 2$ & Industries alimentalres & 10.8 & 6.1 & 7.7 & 7.0 & 49.7 & 13.7 & 23.0 & 22.7 & 34.3 & 15.7 & 18.6 & 2.8 \\
\hline 13 & Fabrication de bolssons & 11.8 & 8.5 & 3.1 & 8.4 & 31.6 & 7.3 & 12.7 & 14.5 & 36.1 & 18.7 & 9.2 & 9.3 \\
\hline 14 & Industrle du tabac & 1.8 & 1.0 & 0.6 & 9.6 & 30.3 & 14.9 & 4.5 & 15.9 & 49.8 & 17.6 & 1.6 & 4.1 \\
\hline 21 & Industrie text1le & 6.3 & 4.9 & 7.6 & 5.3 & 87.5 & 27.7 & 34.4 & 26.8 & - & 65.6 & 3.4 & 0.4 \\
\hline 22 & Hablllement & 15.1 & 17.3 & 13.8 & 26.3 & 90.2 & 29.1 & 60.2 & - & - & 86.2 & 39.7 & 32.1 \\
\hline 23 & Articles en cuir, n.d.a. & 26.3 & 25.8 & 11.9 & 35.7 & - & 31.7 & 65.6 & 37.1 & 96.9 & 86.4 & 48.3 & 35.7 \\
\hline 324 & Chaussures & 3.8 & 31.4 & 10.1 & 34.6 & - & 31.1 & 58.2 & - & 83.7 & 77.1 & 31.1 & \\
\hline 1 & n.d. & 9.7 & 11.2 & 9.0 & 16.8 & 50.7 & 22.6 & 25.8 & 52.7 & 58.7 & 9.9 & 1.3 & 9 \\
\hline 32 & Meubles & 9.4 & 6.8 & .8 & 9.4 & 52.3 & 18.9 & 15.3 & 10.7 & 63.1 & 36.8 & 1.2 & 7.8 \\
\hline 1 & Papier, n.d.a. & 1.0 & 7.6 & 5.6 & 29.1 & 67.5 & 23.6 & 38.0 & 33.5 & 55.1 & 10.3 & 29.5 & 7 \\
\hline 2 & Imprimerie & 3.3 & 1.1 & 0.8 & 11.0 & 35.9 & 9.5 & 5.9 & 3.8 & 9.2 & 7.7 & 6.5 & .9 \\
\hline 1 & Industrie chimique & 4.2 & 10.0 & 9.3 & 54.2 & - & 53.1 & 39.8 & 46.4 & 80.1 & 77.0 & 4.7 & 5 \\
\hline 2 & Produits & 19.2 & 3.3 & 6.6 & 18.7 & 52.3 & 13.3 & 15.3 & 19.3 & 65.5 & 30.8 & 17.7 & 1.1 \\
\hline 53 & Raffineries de pétrole & 4.4 & 6.3 & 10.3 & 61.8 & - & 10.9 & 51.6 & 30.9 & 64.9 & 50.9 & 15.9 & 4.3 \\
\hline 5 & chouc & .3 & 10.2 & 2.6 & 0.4 & - & .0 & 9 & 23.3 & 83.6 & 51.6 & 20.7 & 18.1 \\
\hline 356 & Matlères plast & 1.1 & 5.8 & 0.8 & 11.6 & 33.2 & 12.7 & 25.7 & 11.0 & 45.8 & 37.2 & 12.6 & 8.9 \\
\hline 1 & Grès, & 3 & & 9 & .0 & 5.8 & 9 & & 2 & - & 56.9 & 6 & 1 \\
\hline 52 & Verre & 32.8 & 5.9 & 2.8 & 29.8 & 57.5 & 20.6 & 23.2 & 33.6 & 77.9 & 37.2 & 20.3 & 5.7 \\
\hline 369 & Autres & 8.9 & 3.0 & 0.7 & 7.0 & 33.8 & 11.3 & 16.3 & 10.9 & 25.5 & 13.8 & 5.5 & 5.6 \\
\hline & & & & & 0.4 & 5.0 & & & & & 4 & & 4 \\
\hline 2 & Métaux & 7.3 & 1 & 2 & 4.6 & - & 5 & 56.5 & 59.1 & 77.5 & 49.3 & .5 & 77 \\
\hline 381 & $\begin{array}{l}\text { Ouvre } \\
\text { I'exc }\end{array}$ & 6.7 & 3.6 & 0.9 & 2.2 & 70.9 & 22.7 & 12.9 & 23.5 & 48.2 & 24.7 & 15.7 & 3.8 \\
\hline 382 & $\begin{array}{l}\text { Iusion des } \\
\text { ques, n.d.a. }\end{array}$ & 5.4 & 9.3 & 5.1 & 1.4 & 78.2 & 32.3 & 36.1 & 54.1 & 92.7 & 68.0 & +2.9 & 3.7 \\
\hline 93 & Mach & 8 & & 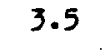 & 0 & 6 & 3 & 37.7 & 25.1 & 52.5 & 53.4 & 26.3 & .2 \\
\hline 384 & Matériel de $t$ & • 0 & 17.9 & 3.6 & 24.0 & - & 6.4 & 30.8 & 37.2 & 91.1 & 39.5 & 4.2 & 5.9 \\
\hline & de controle & .07 & 14 & 9.3 & 75.2 & - & 78.3 & 51.2 & 100.0 & - & 96.8 & 60.5 & \\
\hline
\end{tabular}

n.d.a.: non détermind allieurs. 
Tabieau 4

Crolssance des taux de pénétration des importations selon les classes de la CITI:

échanges avec l'ensemble des partena1res commerciaux, 1970-1980

\begin{tabular}{|c|c|c|c|c|c|c|c|c|c|c|c|c|c|}
\hline CITI & $\begin{array}{l}\text { Pays } \\
\text { déclarant }\end{array}$ & : & 䓪 & : & 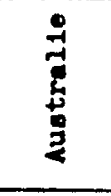 & 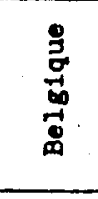 & $\underset{:}{\stackrel{8}{E}}$ & 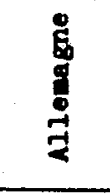 & 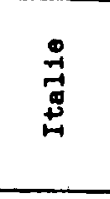 & 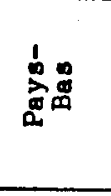 & 密 & $\stackrel{\infty}{0}_{0}^{1}$ & 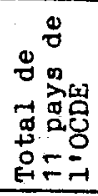 \\
\hline 3 & $\begin{array}{l}\text { Industries } \\
\text { manufacturières }\end{array}$ & 1.4 & 5.3 & 2.0 & 1.5 & 3.5 & 3.7 & 5.0 & 7.0 & 1.8 & 2.3 & 5.7 & 4.6 \\
\hline $311 / 2$ & $\begin{array}{l}\text { Industries } \\
\text { alimentalres }\end{array}$ & 2.2 & 2.4 & 1.3 & 3.0 & 3.8 & 3.0 & 0.8 & 1.4 & 3.7 & 1.1 & -1.0 & 2.5 \\
\hline 313 & $\begin{array}{l}\text { Fabrication } \\
\text { de bolssons } \\
\text { Industrie }\end{array}$ & 6.0 & 2.5 & 12.8 & 0.9 & 7.7 & -1.2 & 5.4 & 15.2 & 5.6 & -2.2 & 3.9 & 4.0 \\
\hline 314 & $\begin{array}{l}\text { Industrie } \\
\text { du tabac }\end{array}$ & 5.8 & 10.9 & 4.6 & 5.1 & 6.8 & 21.3 & 13.7 & 29.0 & 10.6 & -0.3 & 13.2 & 13.7 \\
\hline 321 & $\begin{array}{l}\text { Industrie } \\
\text { textile }\end{array}$ & 1.0 & 0.8 & 6.3 & 2.7 & 4.0 & 8.1 & 5.4 & 8.1 & - & 3.1 & 8.8 & 5.5 \\
\hline 322 & Habiliement & 4.0 & 10.4 & 12.1 & 9.8 & 2.8 & 10.9 & 8.4 & - & - & 6.6 & 11.4 & 10.5 \\
\hline 323 & $\begin{array}{l}\text { Articles en cuir, } \\
\text { n.d.a. }\end{array}$ & 0.1 & $7: 8$ & 7.0 & 7.2 & - & 6.9 & 7.6 & 10.1 & 5.1 & 5.3 & 9.3 & 7.0 \\
\hline 324 & Chaussures en culr & 3.3 & 9.0 & 15.6 & 9.8 & - & 12.0 & 9.4 & - & 4.7 & 3.2 & 10.6 & 10.4 \\
\hline 331 & Bo1s, n.d.a. & 1.3 & 2.7 & 6.7 & 2.6 & 4.1 & 6.6 & 2.5 & 7.7 & 1.5 & 3.2 & 0.4 & 3.4 \\
\hline 332 & Meubles en bois & 7.9 & 7.2 & 19.6 & 11.4 & 6.0 & 3.9 & 6.9 & 20.7 & 0.4 & 9.9 & 15.4 & 8.5 \\
\hline 341 & Papier, n.d.a. & 5.6 & 1.8 & $4 \cdot 3$ & -0.3 & 2.6 & 2.3 & 3.2 & 7.1 & 0.6 & 2.7 & 0.9 & 2.7 \\
\hline 342 & $\begin{array}{l}\text { Imprimerie } \\
\text { et édition }\end{array}$ & 0.9 & 3.9 & -5.6 & 0.3 & 4.6 & 1.1 & 5.1 & 5.0 & 1.7 & 2.8 & 7.5 & 3.7 \\
\hline 351 & $\begin{array}{l}\text { Industrie } \\
\text { chimique }\end{array}$ & 1.0 & 6.2 & 2.8 & 2.6 & - & 4.9 & 4.8 & 5.5 & 0.7 & 2.6 & 4.8 & 4.7 \\
\hline 352 & $\begin{array}{l}\text { Produtts chimiques, } \\
\text { n.d.a. }\end{array}$ & 3.8 & 9.1 & -0.2 & -0.4 & 2.8 & 2.4 & 4.9 & 6.3 & 3.1 & 0.4 & 6.2 & 5.1 \\
\hline 353 & $\begin{array}{l}\text { Rafinertes } \\
\text { de pétrole. }\end{array}$ & -7.6 & 0.0 & -3.7 & 5.4 & - & 13.4 & 11.8 & 14.2 & 1.9 & -2.8 & -2.6 & 3.1 \\
\hline 355 & Caoutchouc & 3.7 & 11.3 & 13.6 & 4.1 & - & 5.9 & 8.3 & 10.0 & 4.2 & 5.2 & 11.4 & 8.1 \\
\hline 356 & $\begin{array}{l}\text { Metières } \\
\text { plastiques }\end{array}$ & 2.5 & 1.0 & 4.5 & 4.8 & 2.1 & 2.4 & 5.7 & 11.4 & 1.0 & 1.8 & 9.8 & 3.3 \\
\hline 361 & $\begin{array}{l}\text { Grès, porcelaines } \\
\text { et fárences }\end{array}$ & 4.4 & 5.7 & 9.5 & 1.4 & 6.1 & 4.5 & 8.0 & 3.7 & - & 5.8 & 9.1 & 5.3 \\
\hline 362 & Verre & 0.9 & 2.4 & 5.2 & -0.9 & 1.4 & 2.9 & 4.8 & 6.8 & -0.2 & 2.5 & 3.7 & 3.6 \\
\hline 369 & $\begin{array}{l}\text { Autres produits } \\
\text { non minéraux }\end{array}$ & 2.1 & 7.8 & 0.7 & 3.7 & 5.8 & 0.2 & 7.1 & 13.6 & 0.5 & 2.8 & 5.6 & 4.8 \\
\hline 371 & Sidérurgie & -1.1 & 4.6 & -1.6 & -0.4 & 2.2 & 3.1 & 3.5 & 5.2 & 6.0 & 1.8 & 4.9 & 2.9 \\
\hline 372 & Métaux non ferreux & -6.7 & 4.3 & 1.9 & -6.9 & - & 1.7 & 3.9 & 1.8 & 0.3 & 0.7 & 3.4 & 2.2 \\
\hline 381 & $\begin{array}{l}\text { Ouvrages en métaux, } \\
\text { a liexclusion des } \\
\text { machines }\end{array}$ & 0.9 & 5.1 & 0.8 & 0.5 & 5.0 & 4.3 & 7.3 & 11.1 & 2.1 & 4.5 & 15.2 & 5.6 \\
\hline 382 & $\begin{array}{l}\text { Machines, I'exclusion } \\
\text { des machines électriques }\end{array}$ & 1.4 & 7.1 & -1.8 & 1.1 & 2.1 & 9.6 & 4.8 & 9.8 & -0.1 & 4.4 & 5.4 & 4.5 \\
\hline 383 & $\begin{array}{l}\text { Machines électriques, } \\
\text { n.d.a. }\end{array}$ & 3.8 & 8.1 & 3.3 & 3.6 & 3.4 & 4.7 & 7.8 & 4.5 & 0.6 & 1.8 & 9.3 & 6.0 \\
\hline 384 & Matérlel de transport & -1.6 & 7.6 & 1.6 & 0.4 & 2.1 & 2.2 & 3.5 & 5.5 & 0.4 & 0.9 & 15.1 & 5.5 \\
\hline 385 & $\begin{array}{l}\text { Appare1ls de mesure } \\
\text { et de controle }\end{array}$ & 1.4 & 7.7 & 2.3 & 0.1 & 4.4 & 4.3 & 5.9 & 6.7 & - & 1.6 & 6.1 & 4.9 \\
\hline
\end{tabular}

n.d.a.: non dénommé aillzeurs. 
NOTES

1. La CITI fait l'objet d'un document des Nations Unies, Série M, n० 4, Révision 2, Nations Unies, New York, 1969.

2. Les données concernant la Belgique comprennent également la production et le commerce extérieur du Luxembourg. Par souci de concision, on utilise dans la présente note le terme "Belgique" pour désigner à la fois ce pays et le Luxembourg.

3. Classification type pour le commerce international, Série M, $n^{\circ}$ 34, Révision 2, Nations Unies, New York, 1975.

4. Les statistiques du commerce extérieur des pays de la CEE sont publiées sur la base de la nomenclature NIMEXE. Celle-ci étant compatible avec la CTCI, mais beaucoup plus détaillée, les produits qu'elle définit peuvent presque toujours etre attribués à une branche unique de la CITI.

5. Ce taux de croissance est calculé selon la formule

$\left[\frac{\text { MPR }}{\text { MPR }}\right]$

MPR étant le taux de pénétration du marché. 

Statistical Annex -- Annexe Statistique

Page

Table A

Tableau A

Table B

Tableau B

Table C

Tableau C

Table D

Tableau D
Production of manufactured goods

Production des produits manufacturés

Imports of manufactured goods

Importations des produits manufacturés

Exports of manufactured goods

Exportations des produits manufacturés

Penetration ratios

Taux de pénétration Canada - Canada

United States - Etats Unis

Japan - Japon

Australia - Australie

Belgium - Belgique

France - France

Germany - Allemagne

Italy - Italie

Netherlands - Pays bas

Sweden - Suède

United Kingdom - Royaume Unis

Total of 11 countries - Total des 11 pays 69-72
$22-24$

$16-18$

$19-21$

$25-28$

$29-32$

$37-40$

$41-44$

$45-48$

49-52

$53-56$

57-60

61-64

65-68 

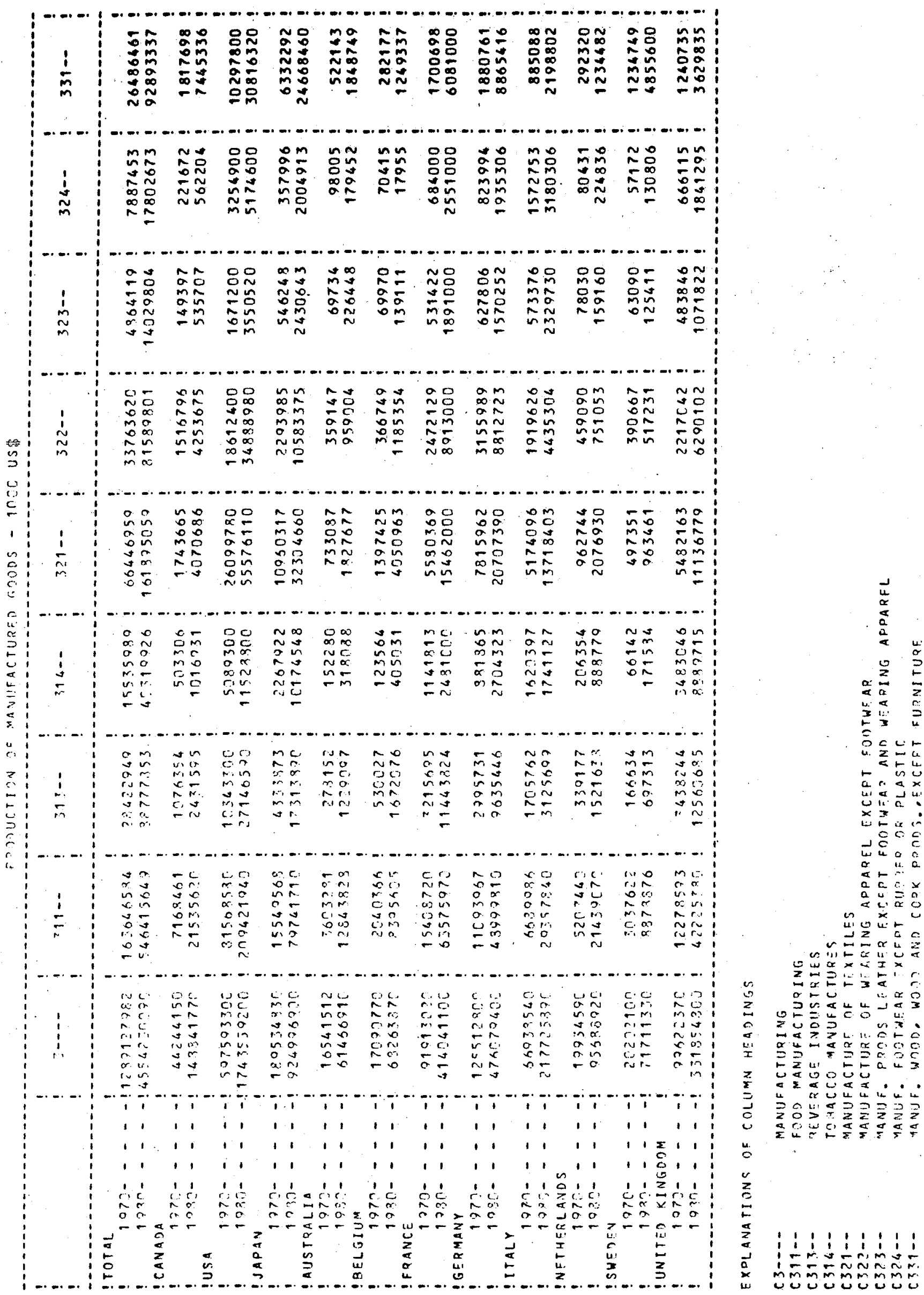


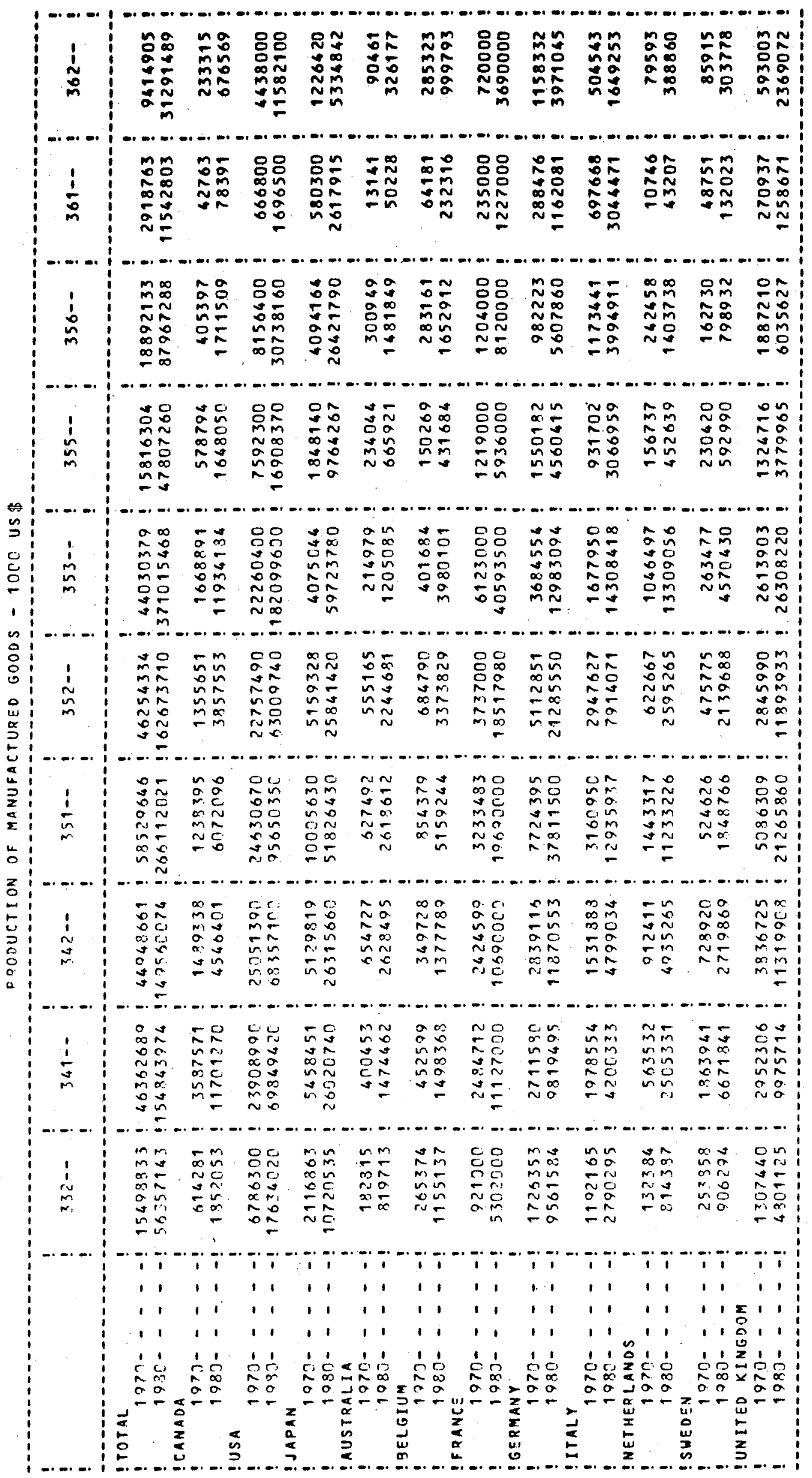

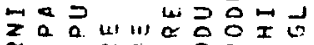

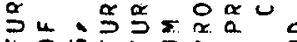

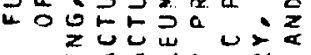

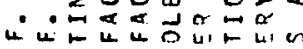

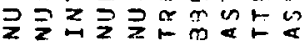

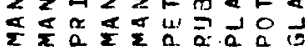

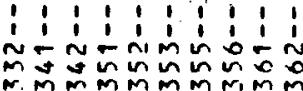



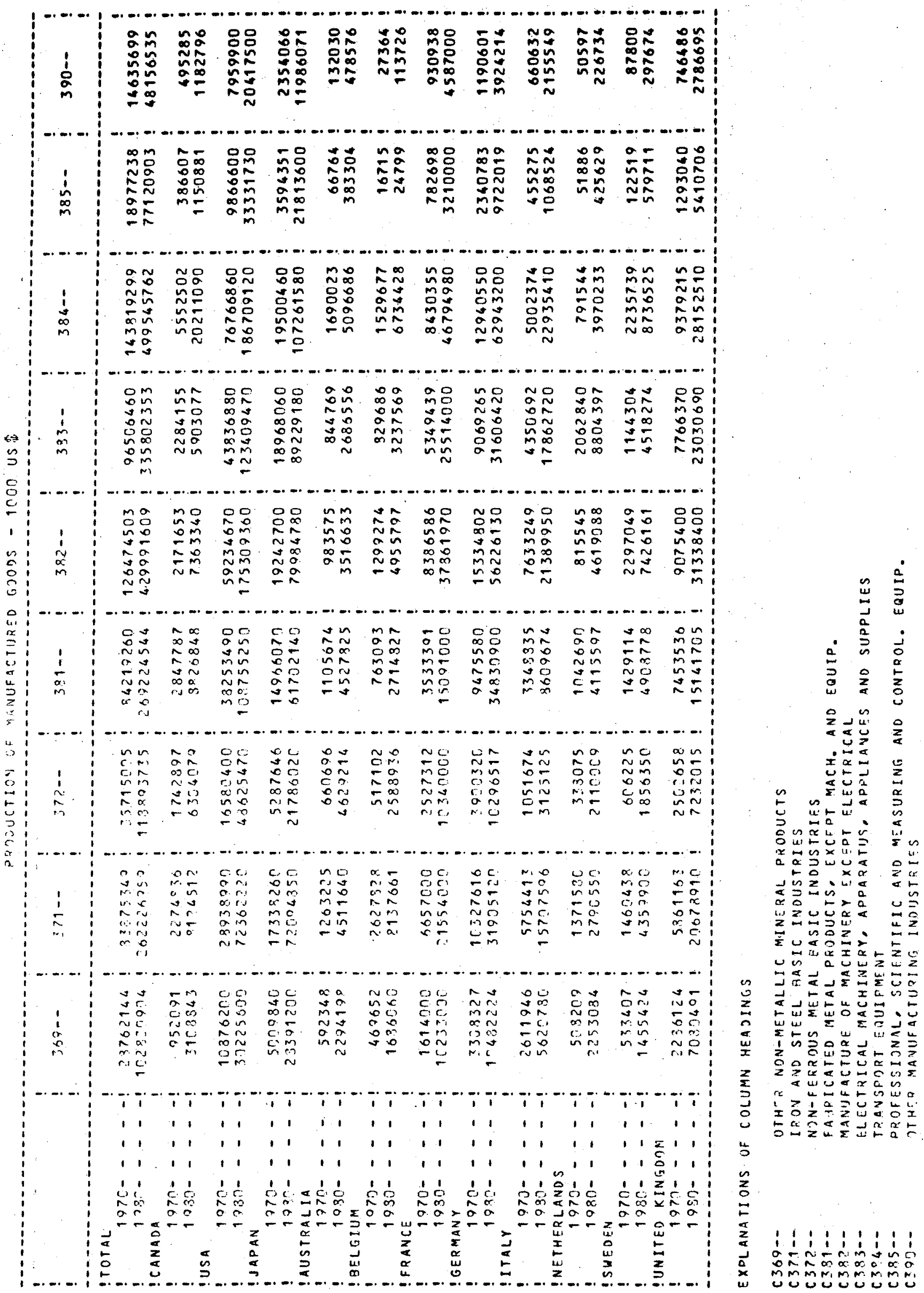


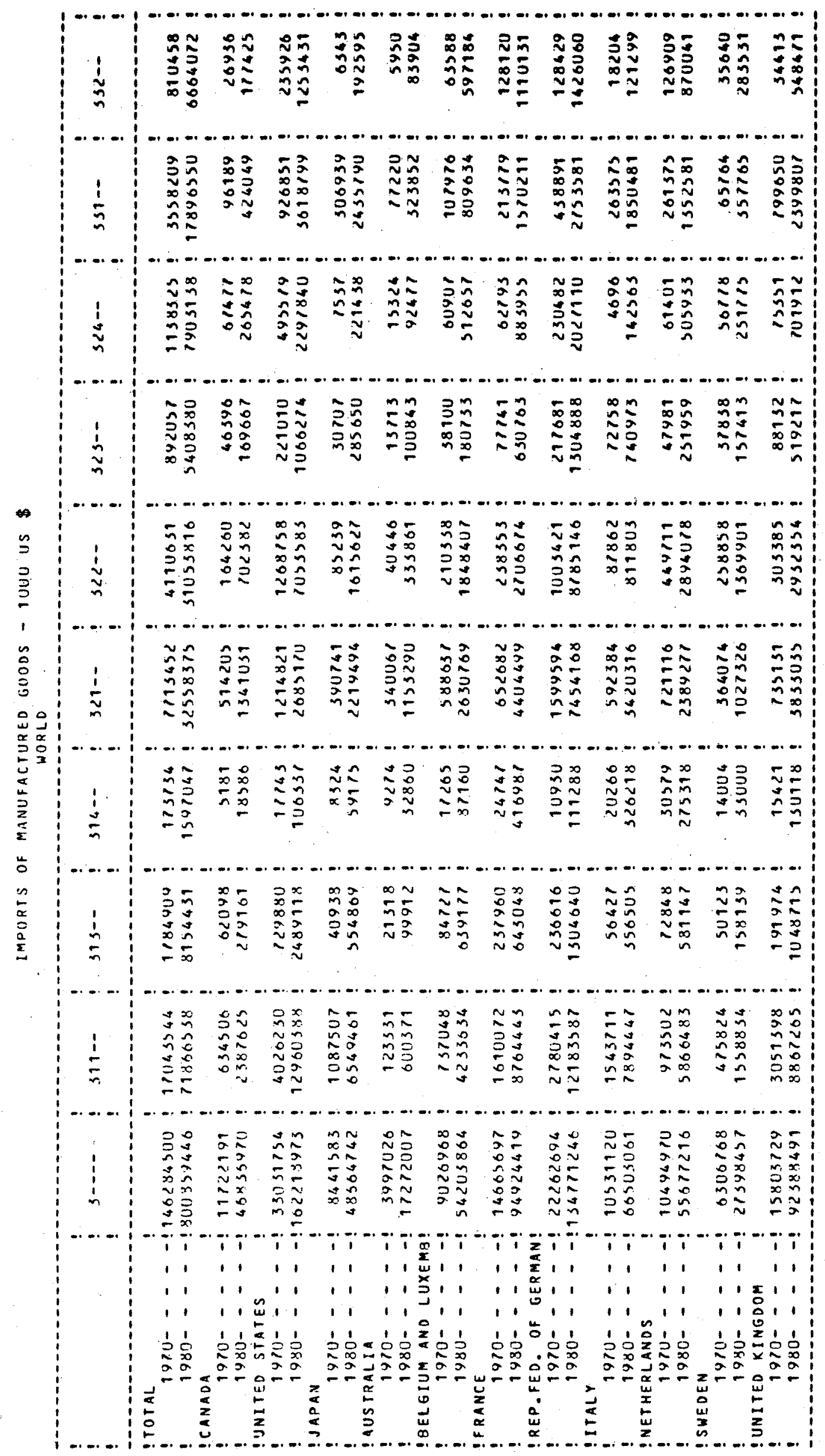

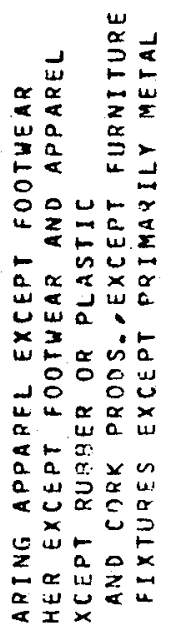

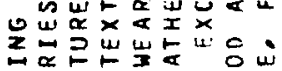

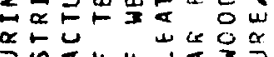

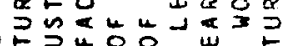

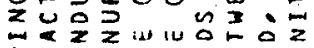

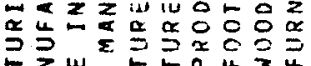

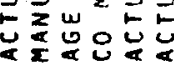

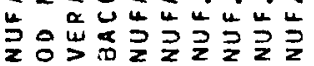

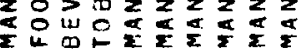
o

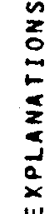



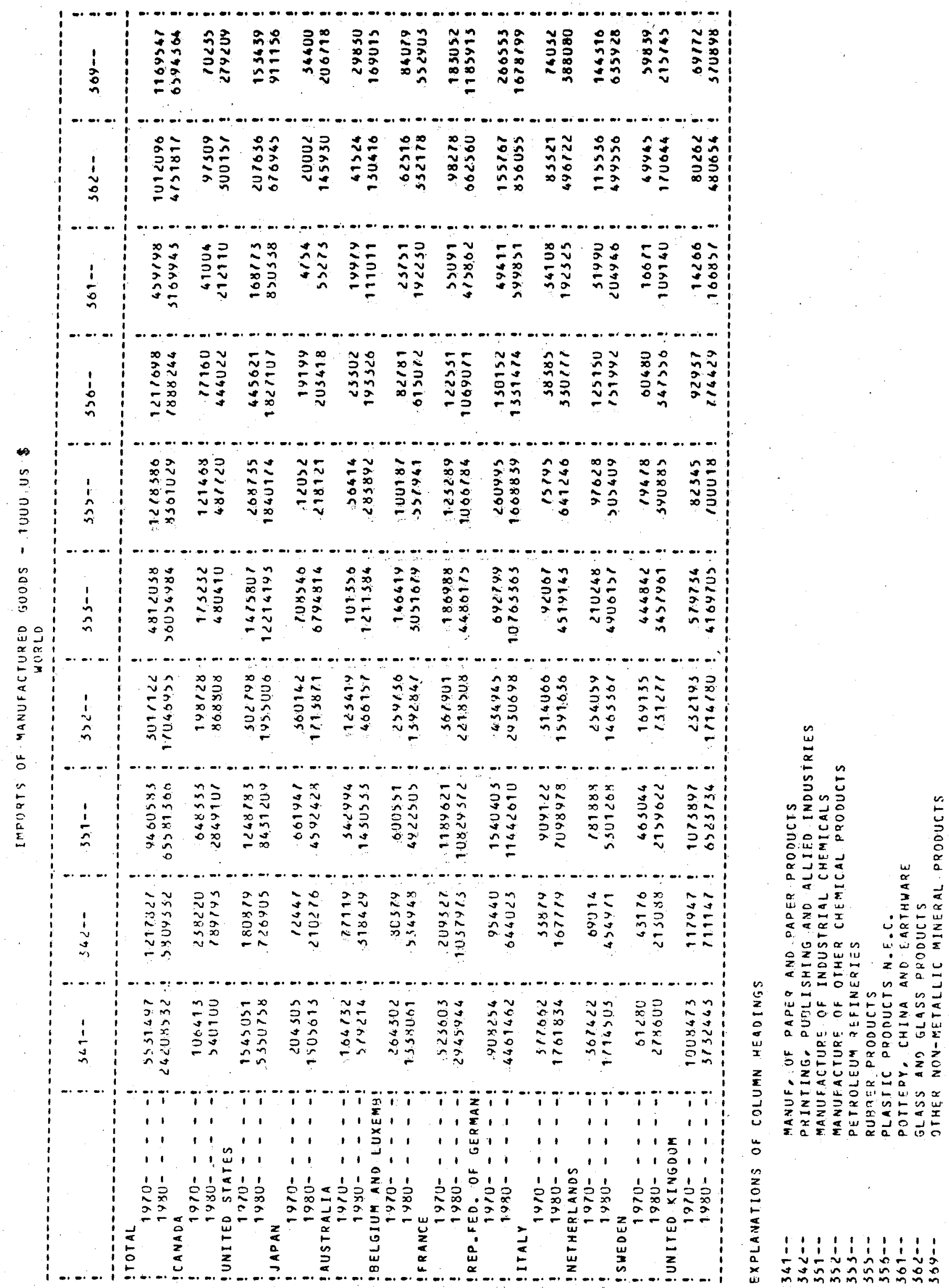


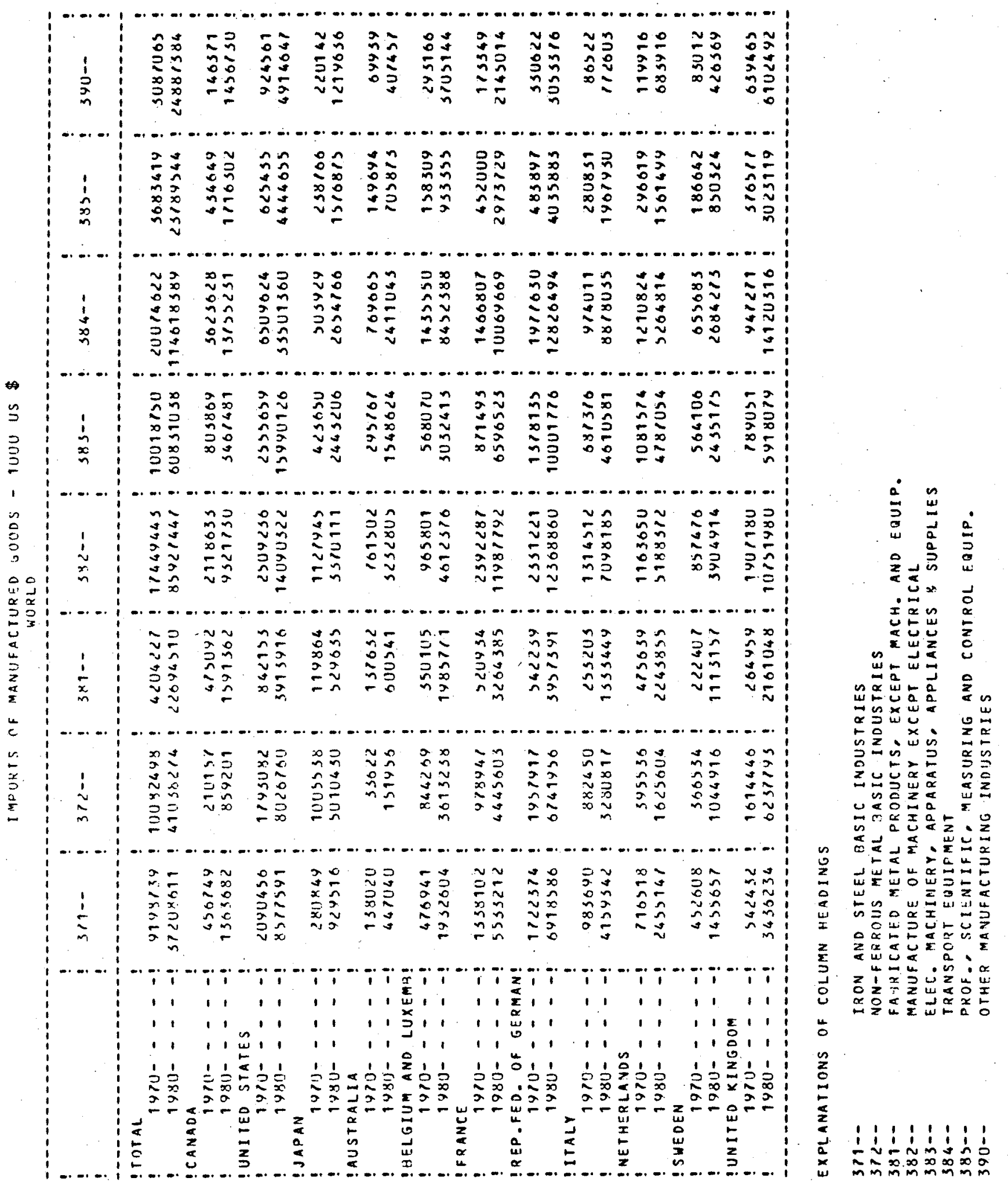




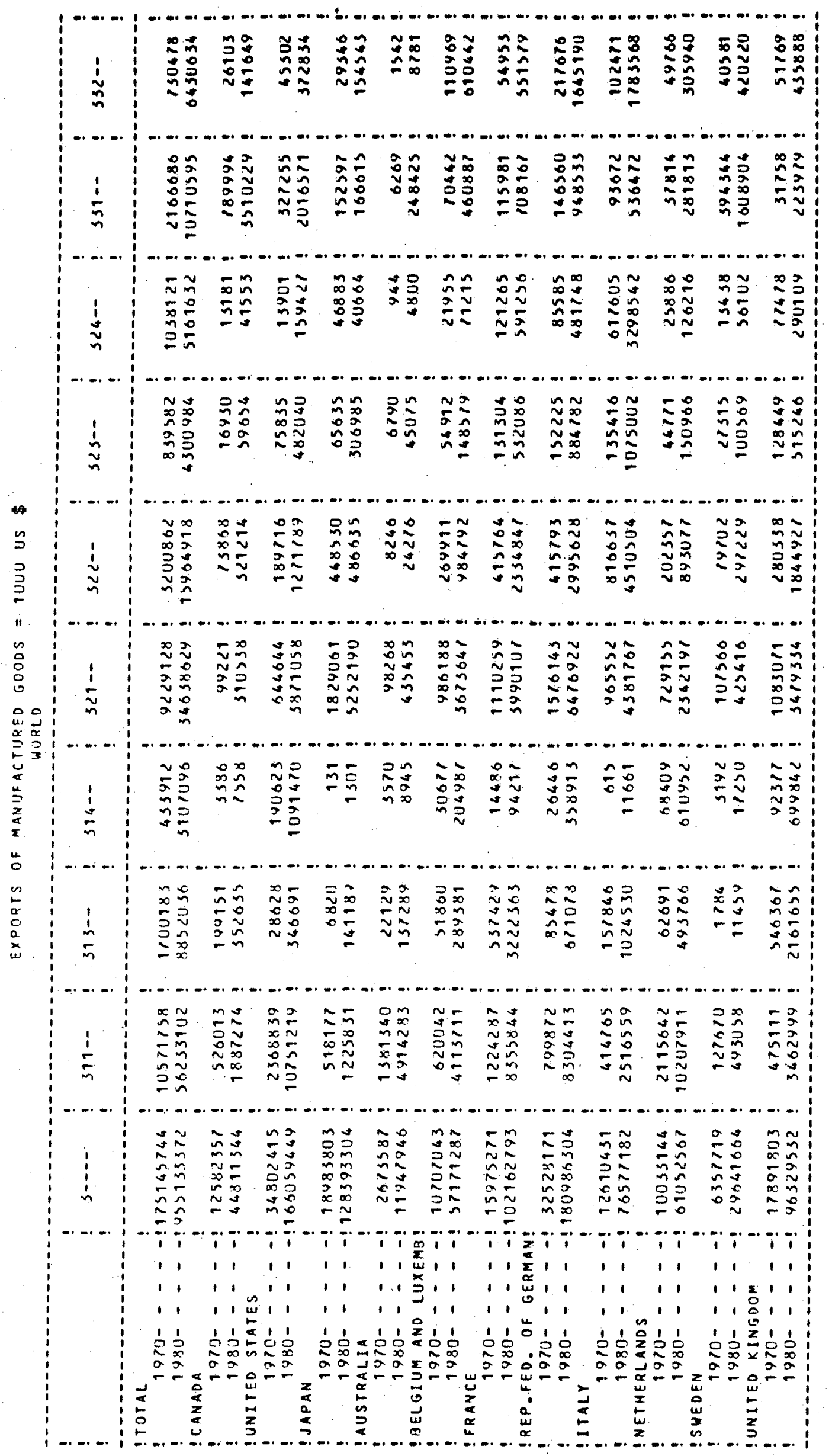

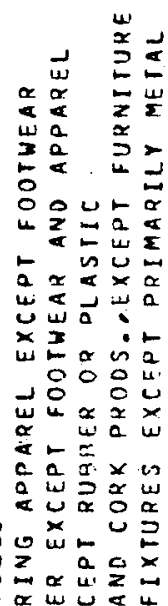

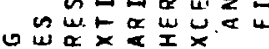

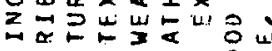

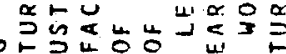

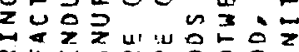

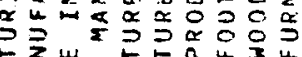

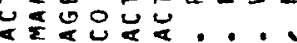

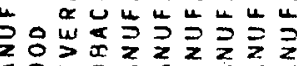

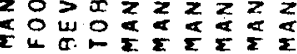
19

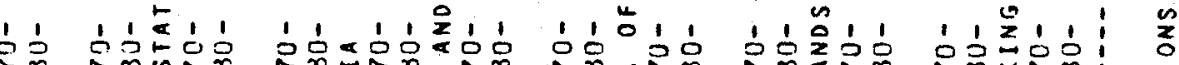
$\underset{2}{2}$

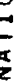

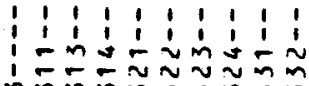



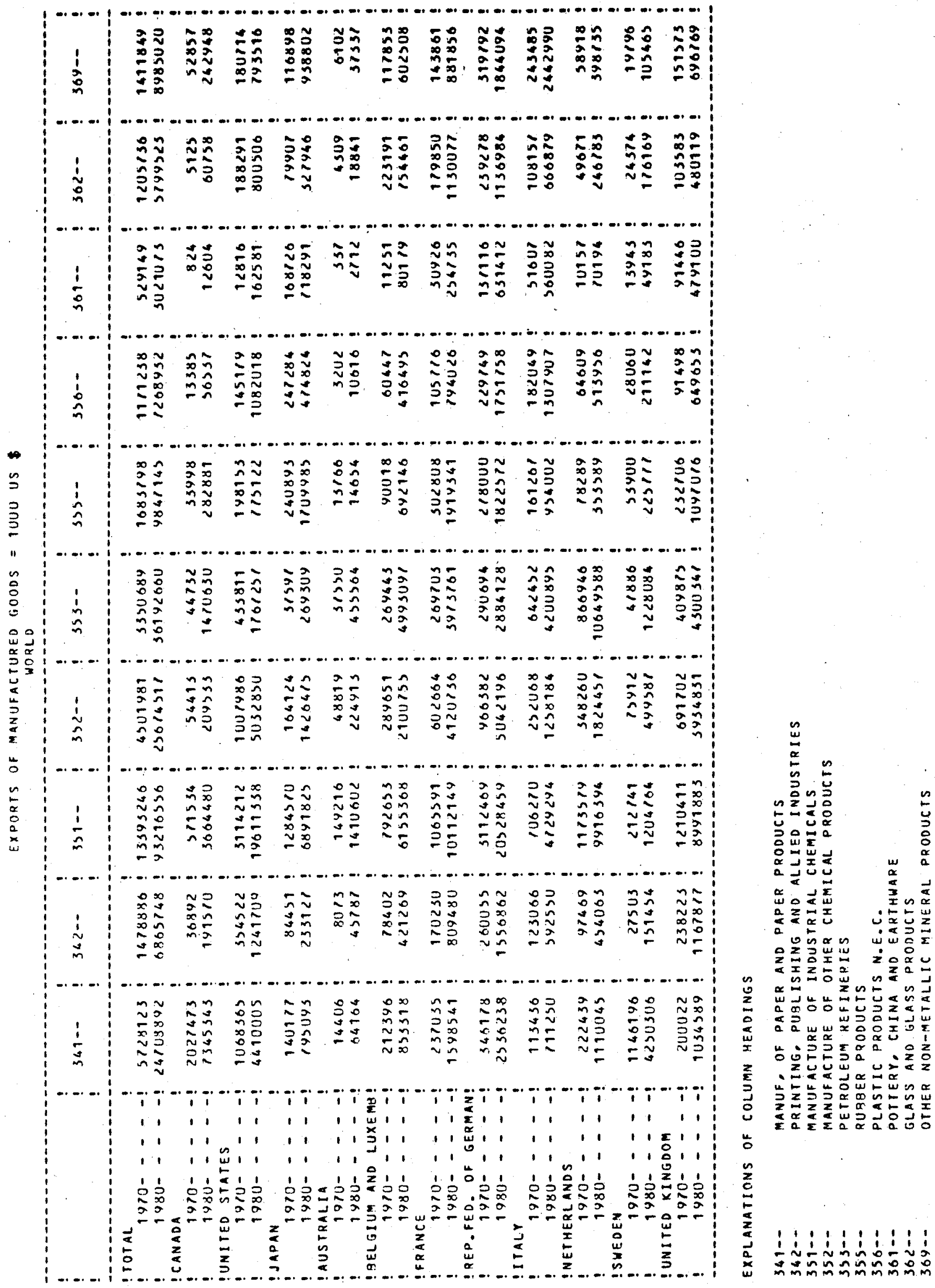


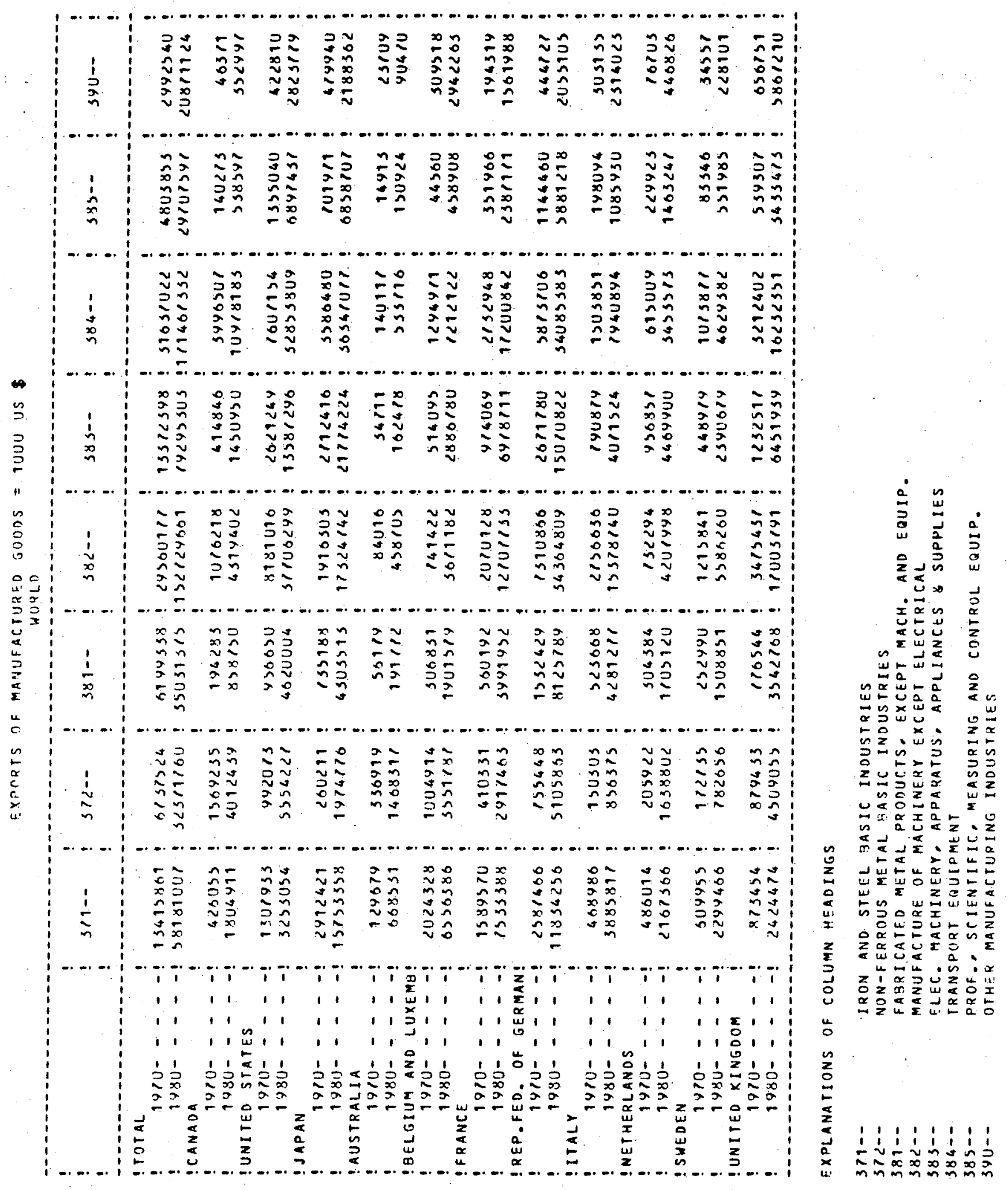




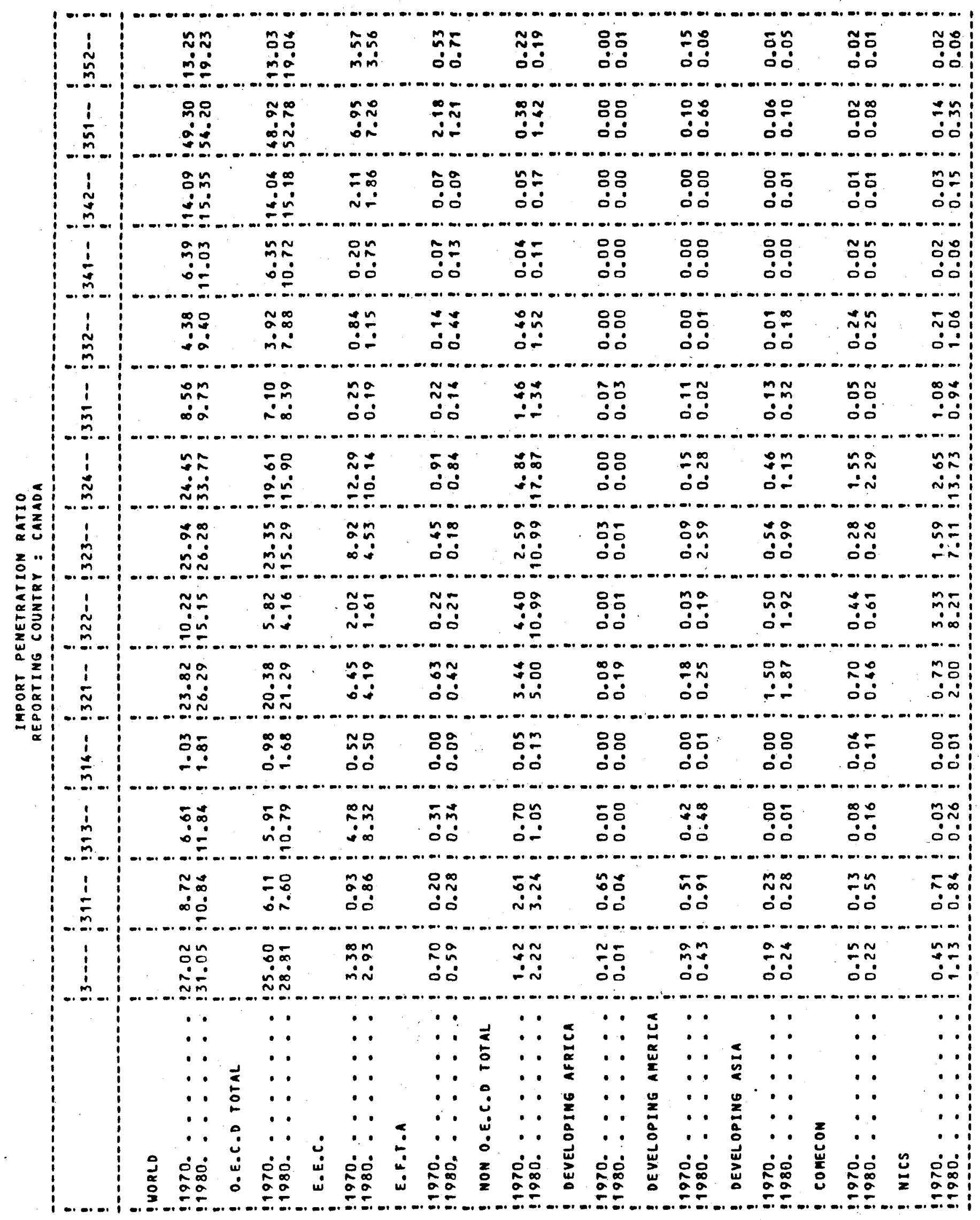




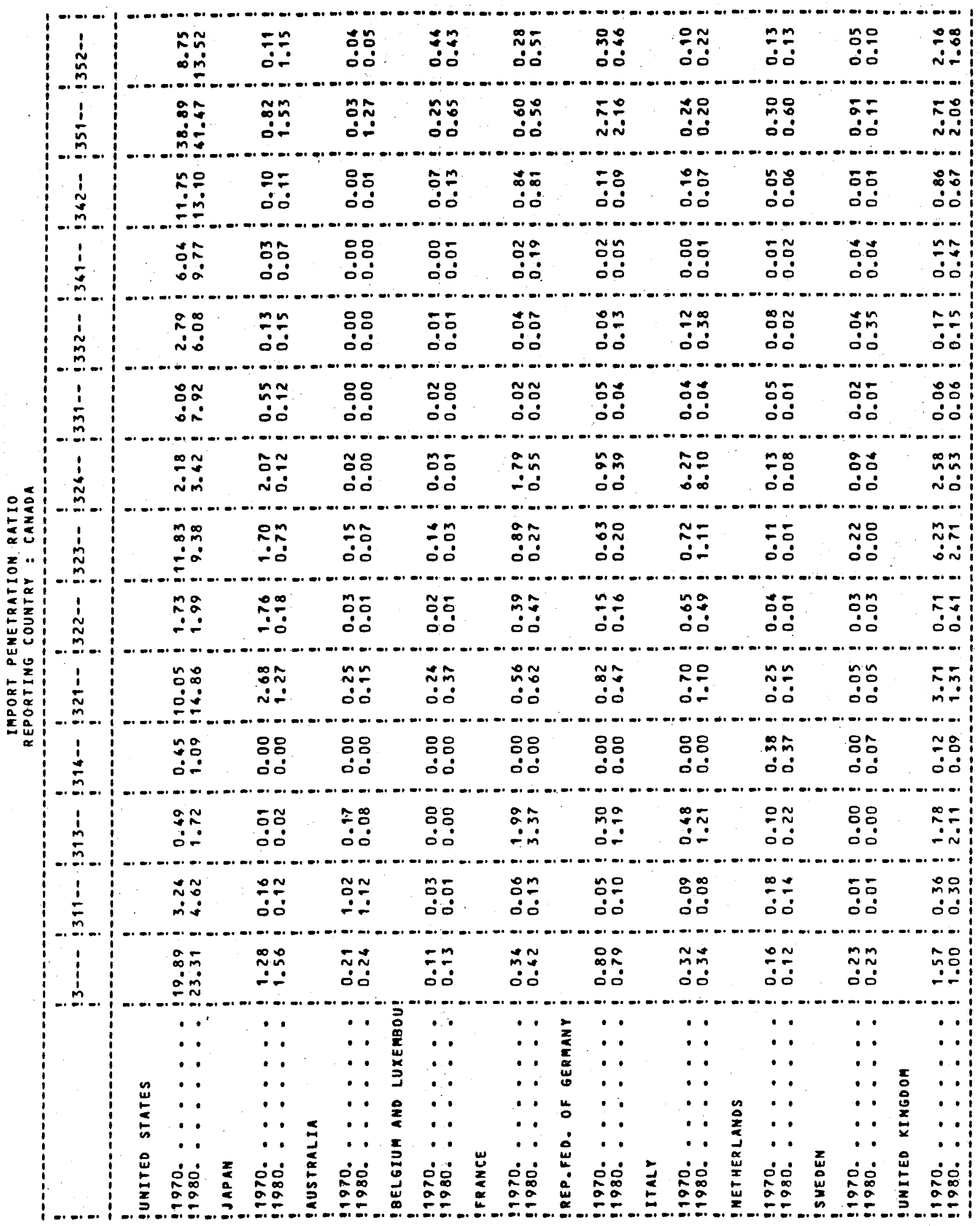




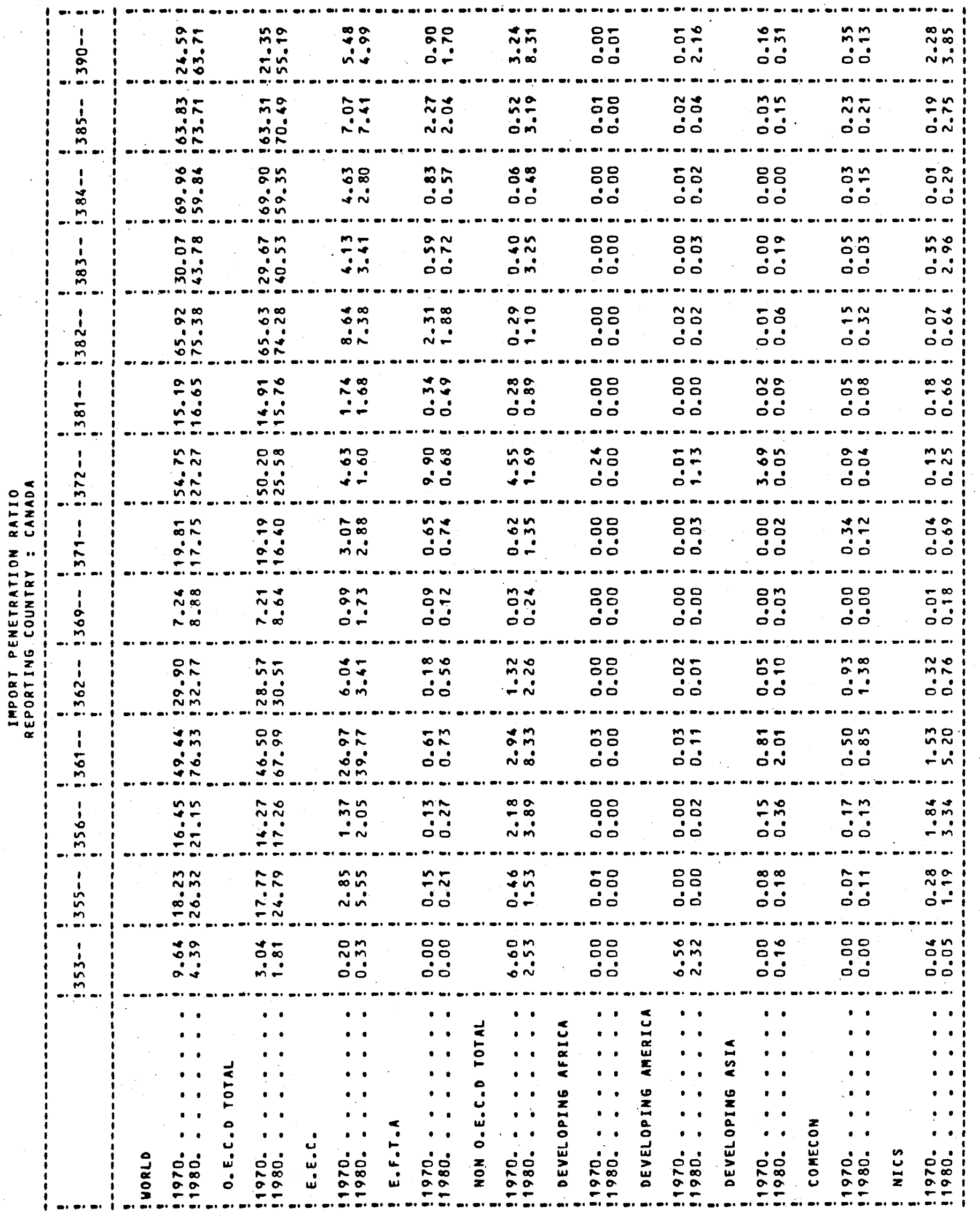




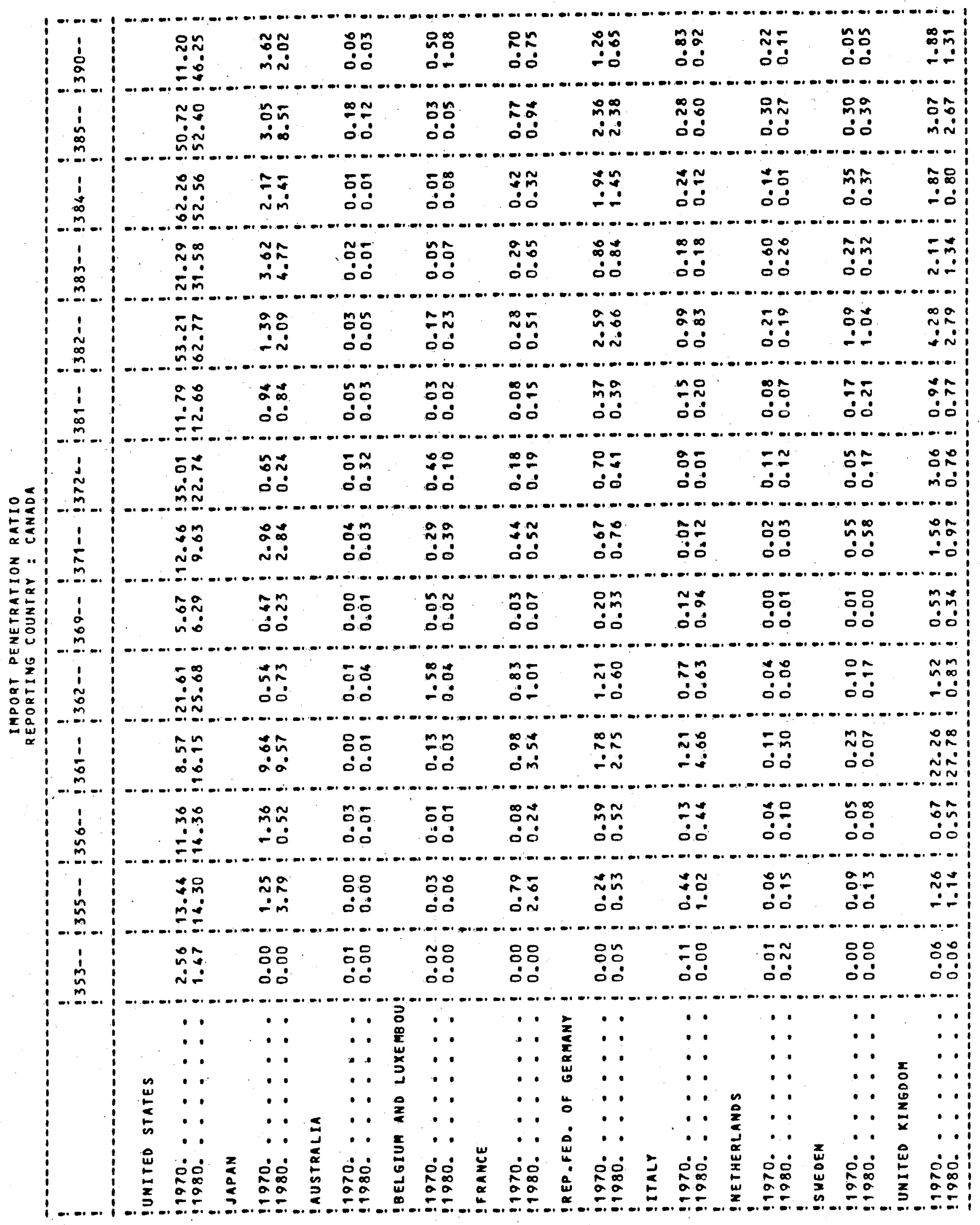




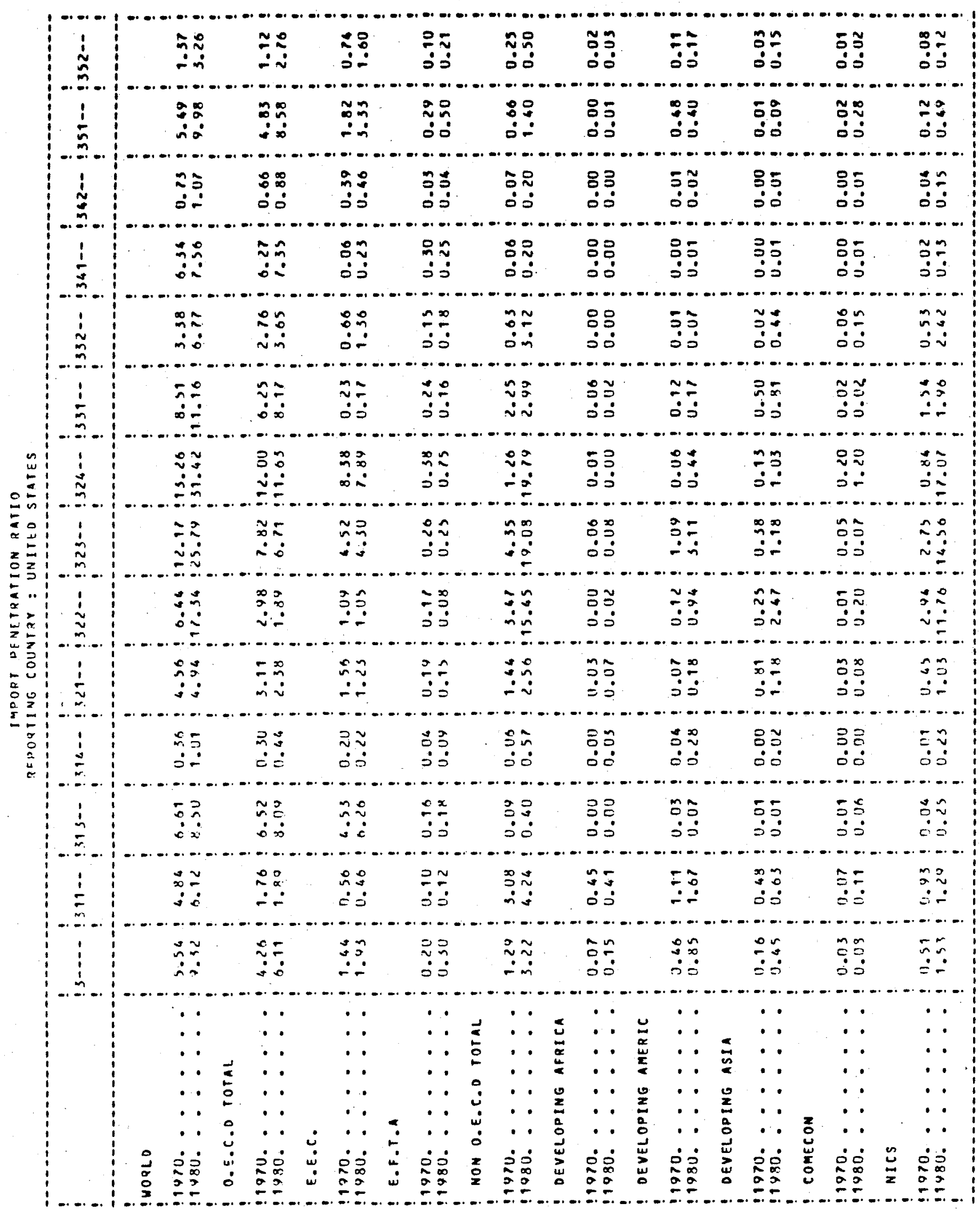




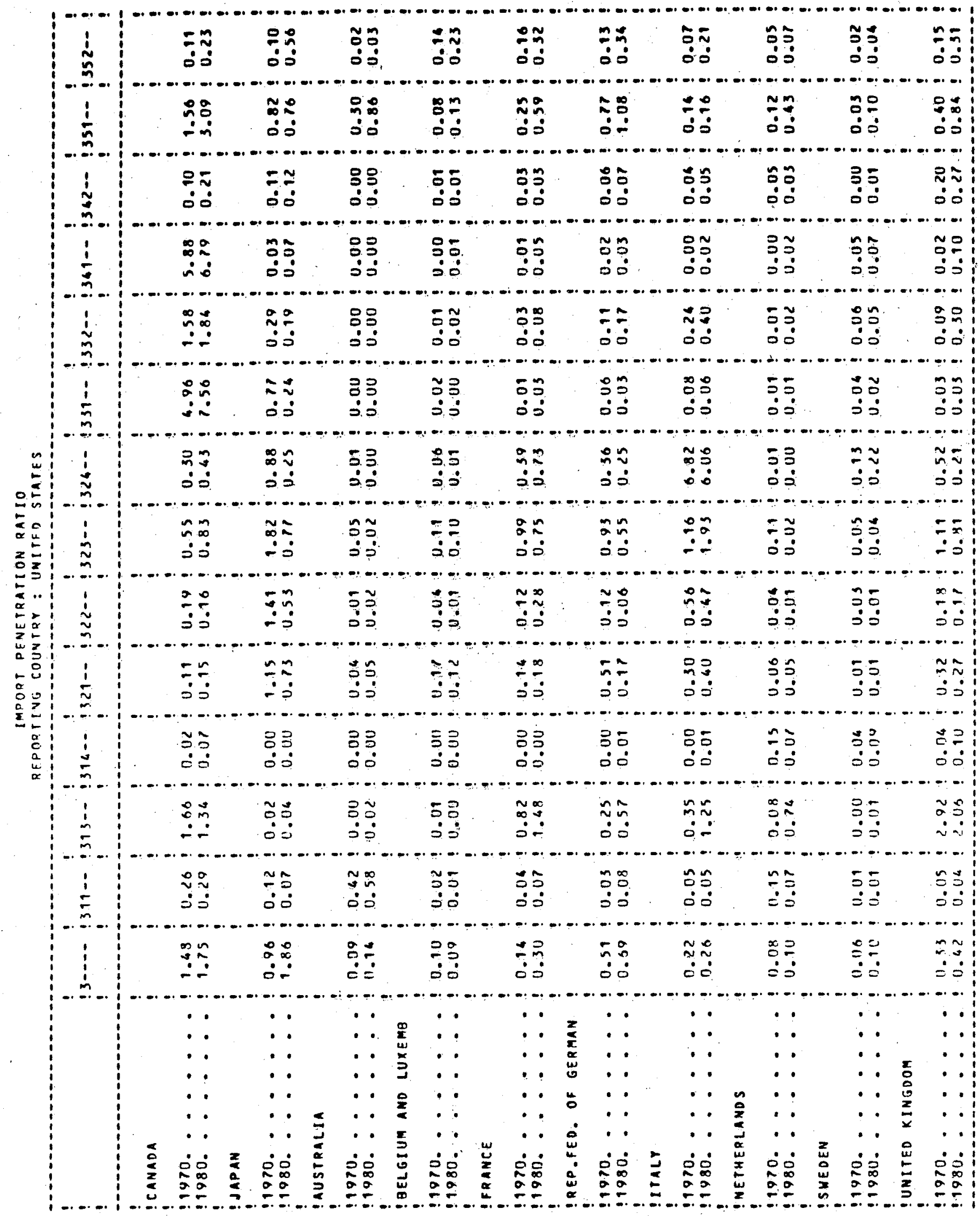




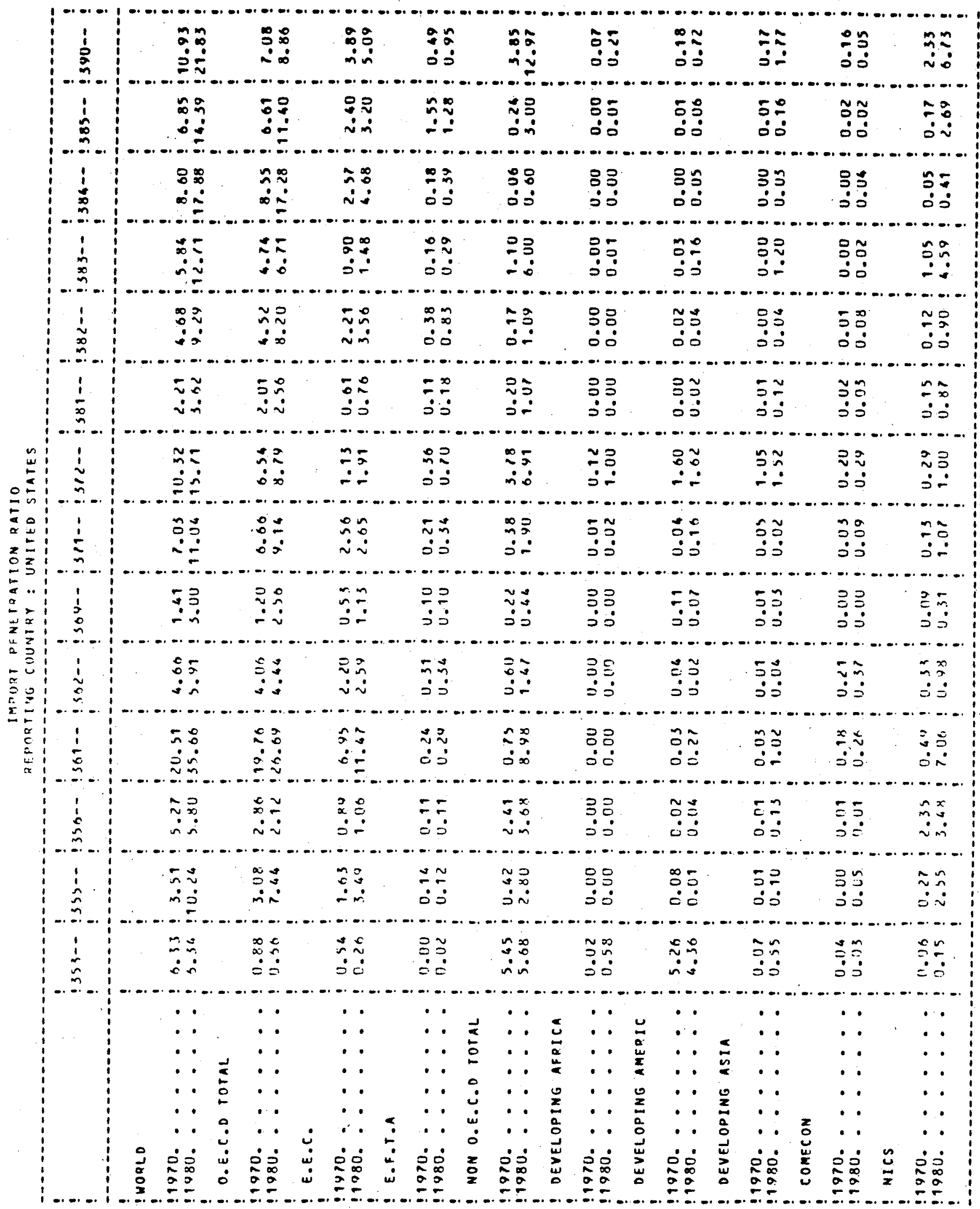




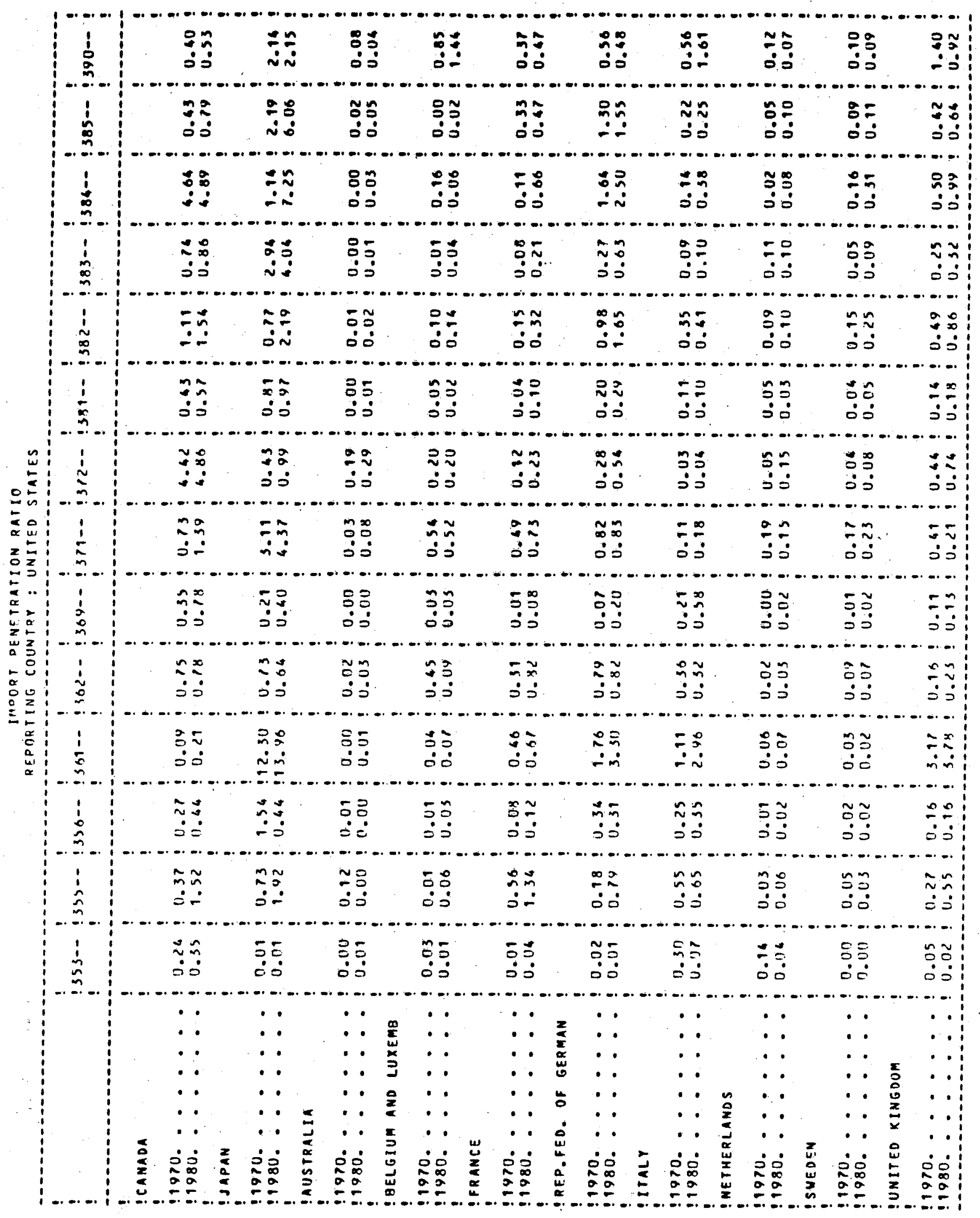




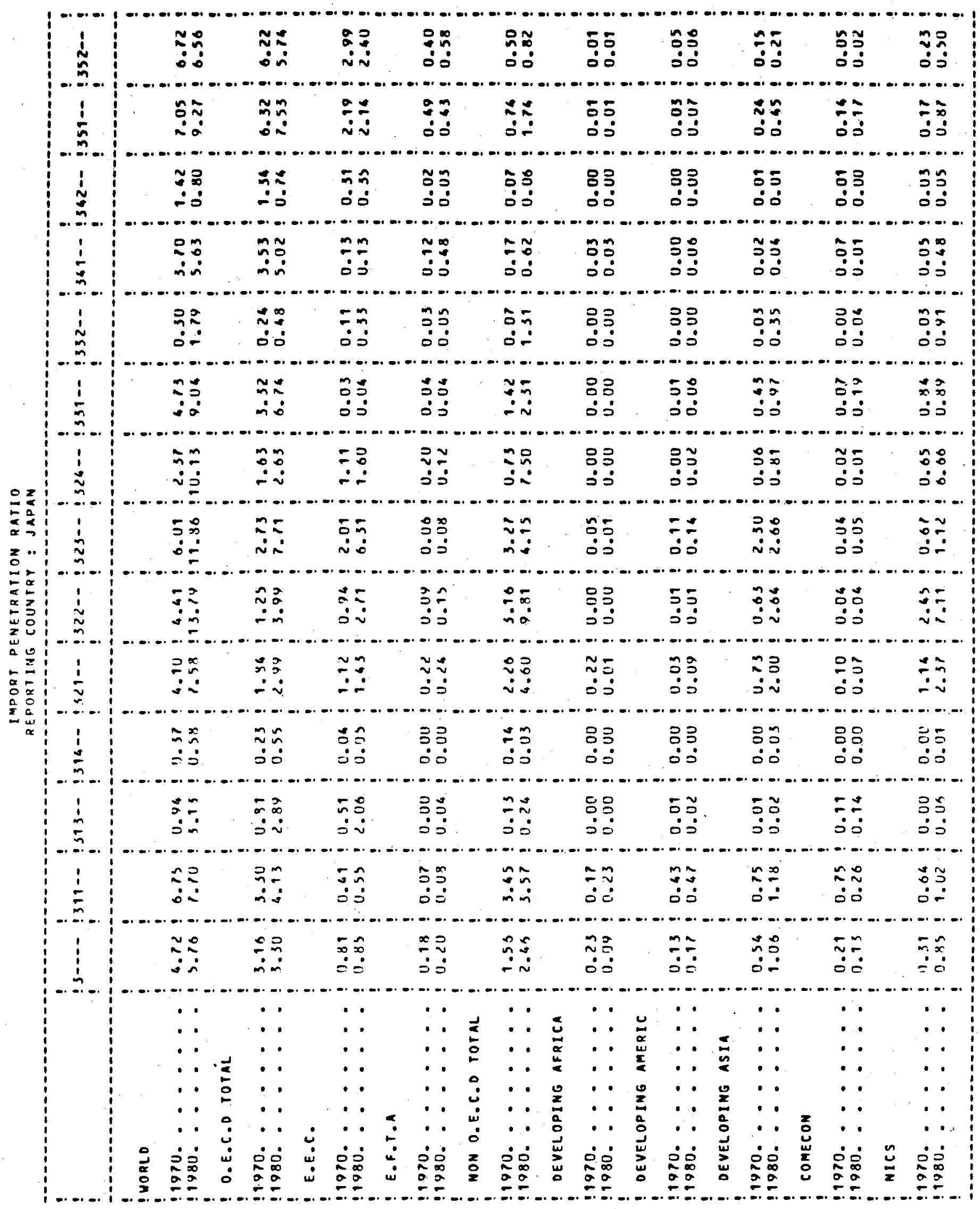




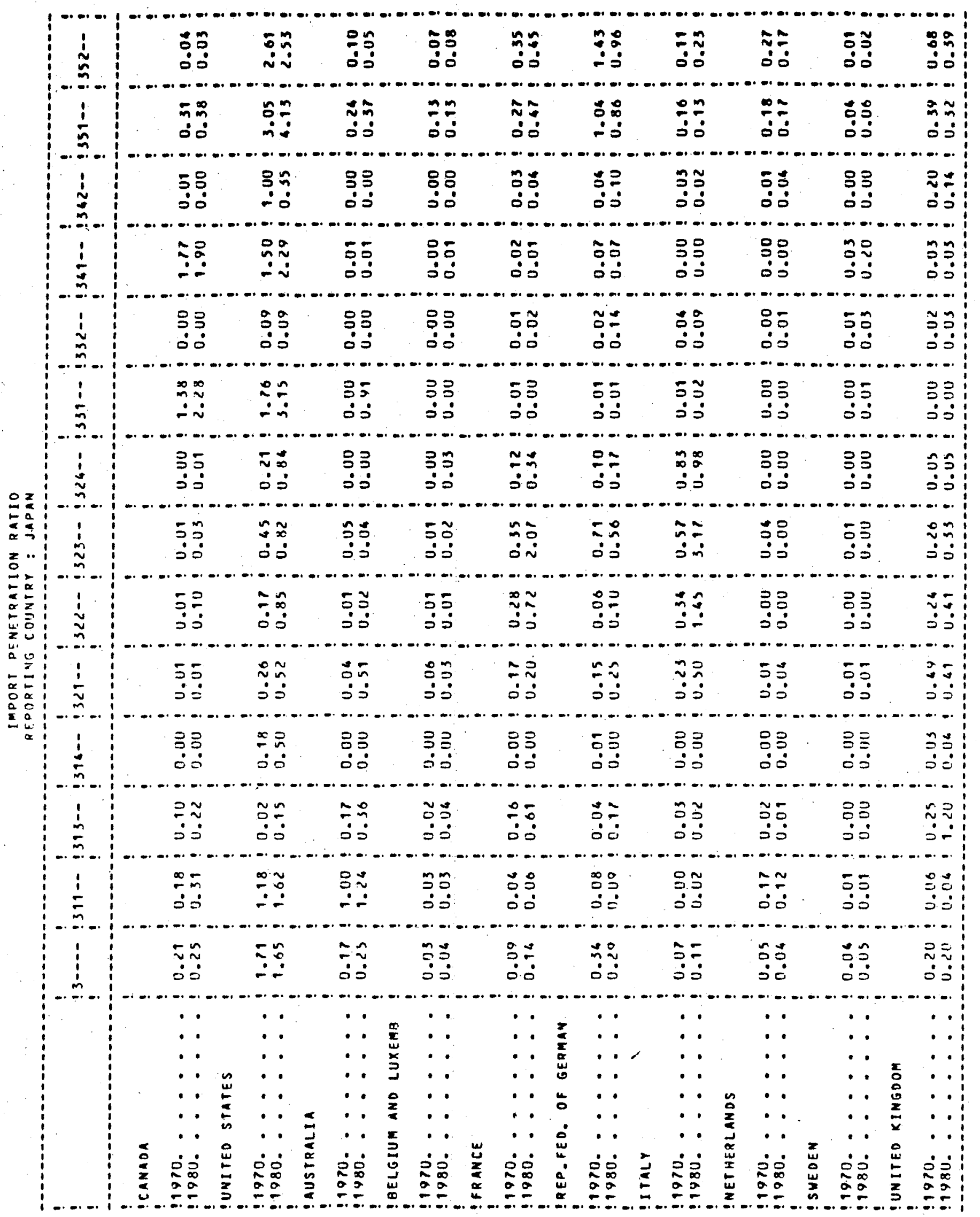




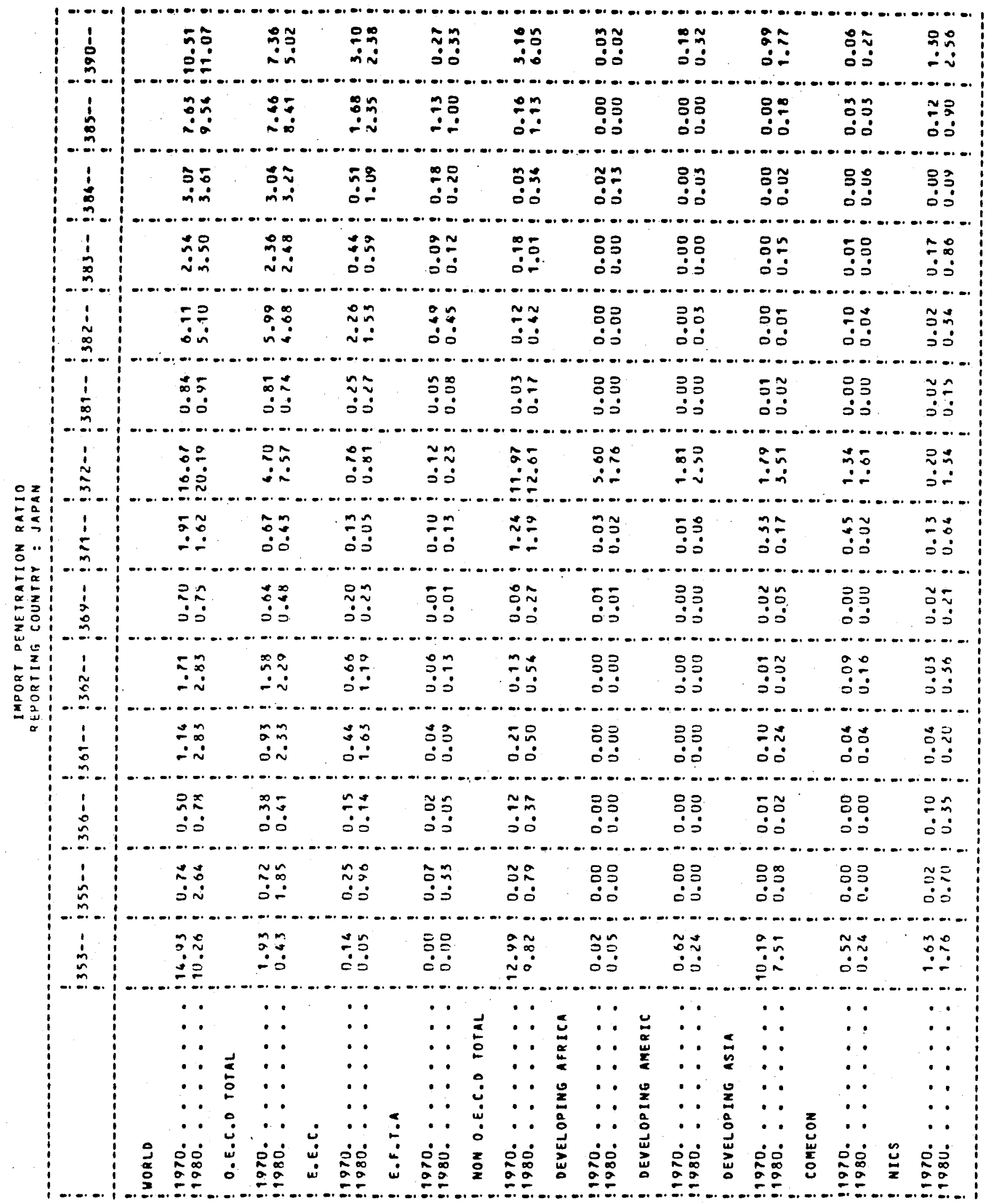




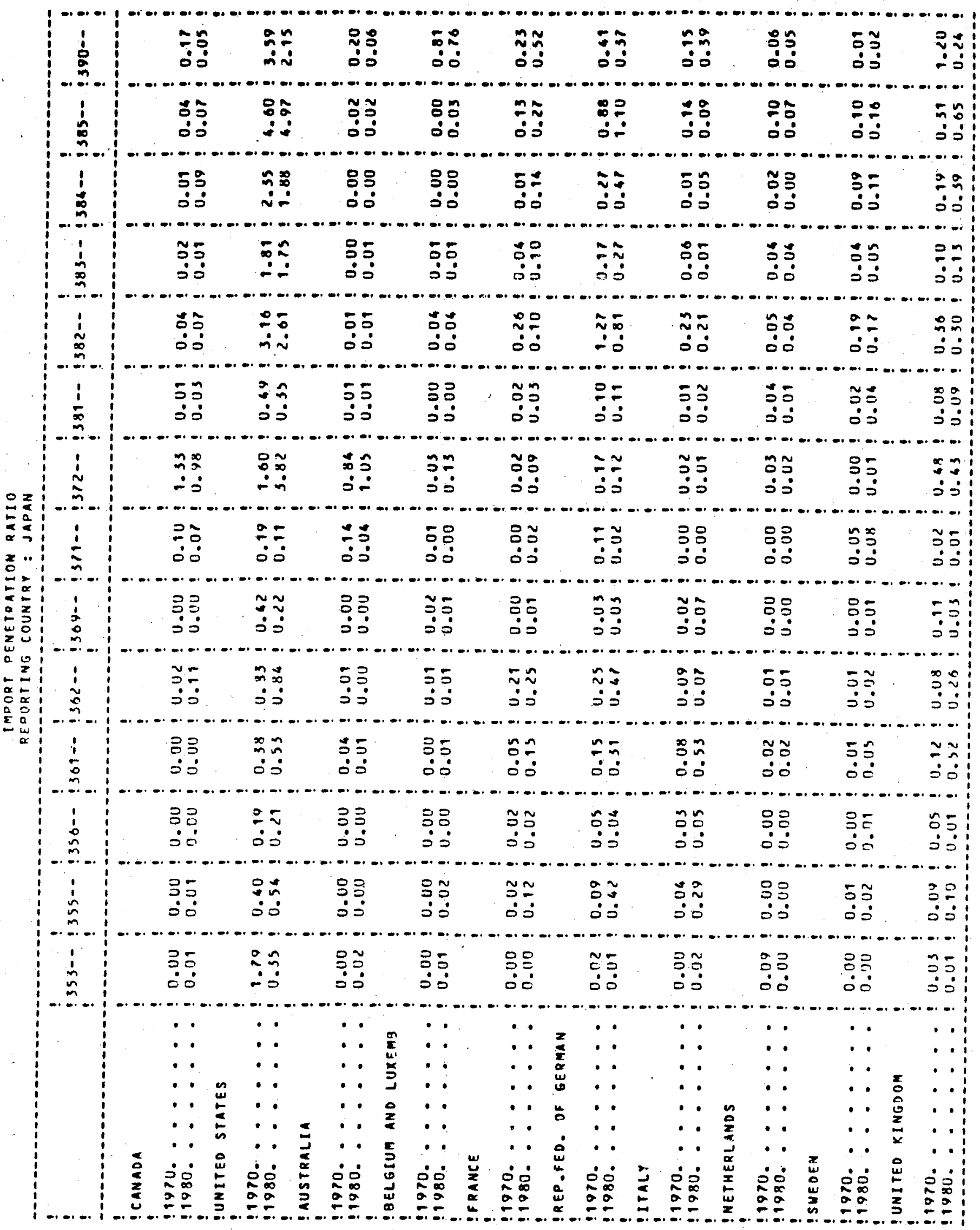




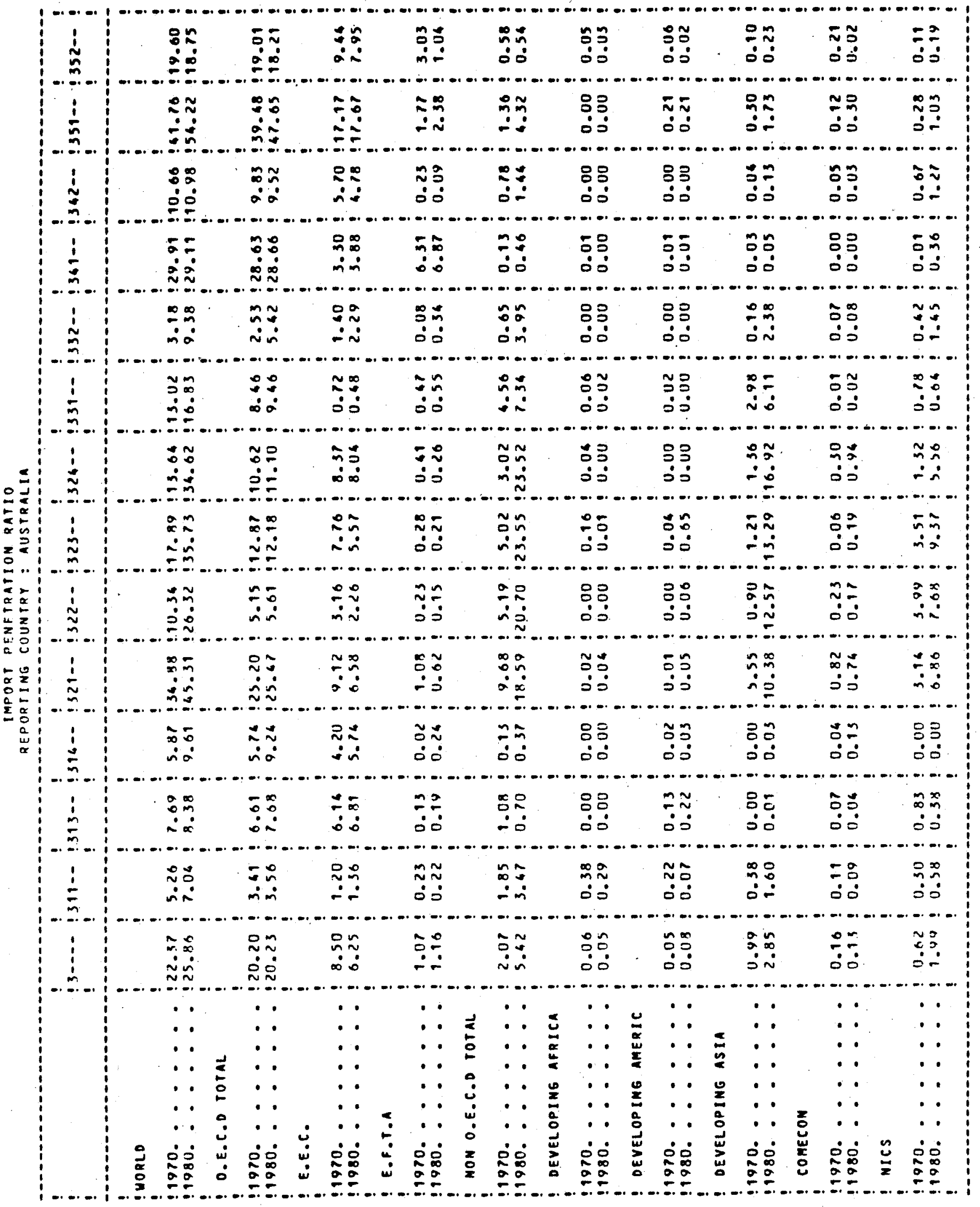




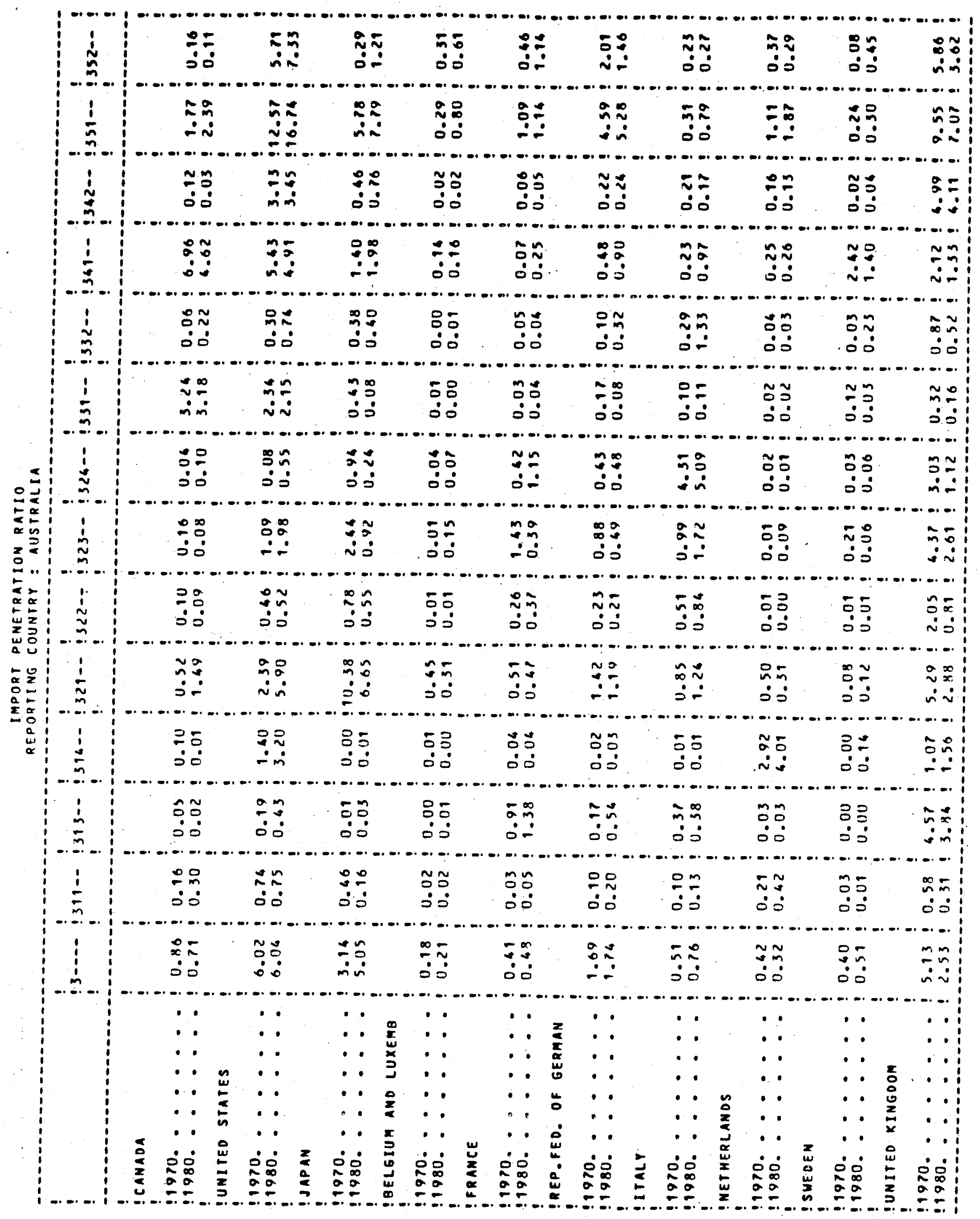




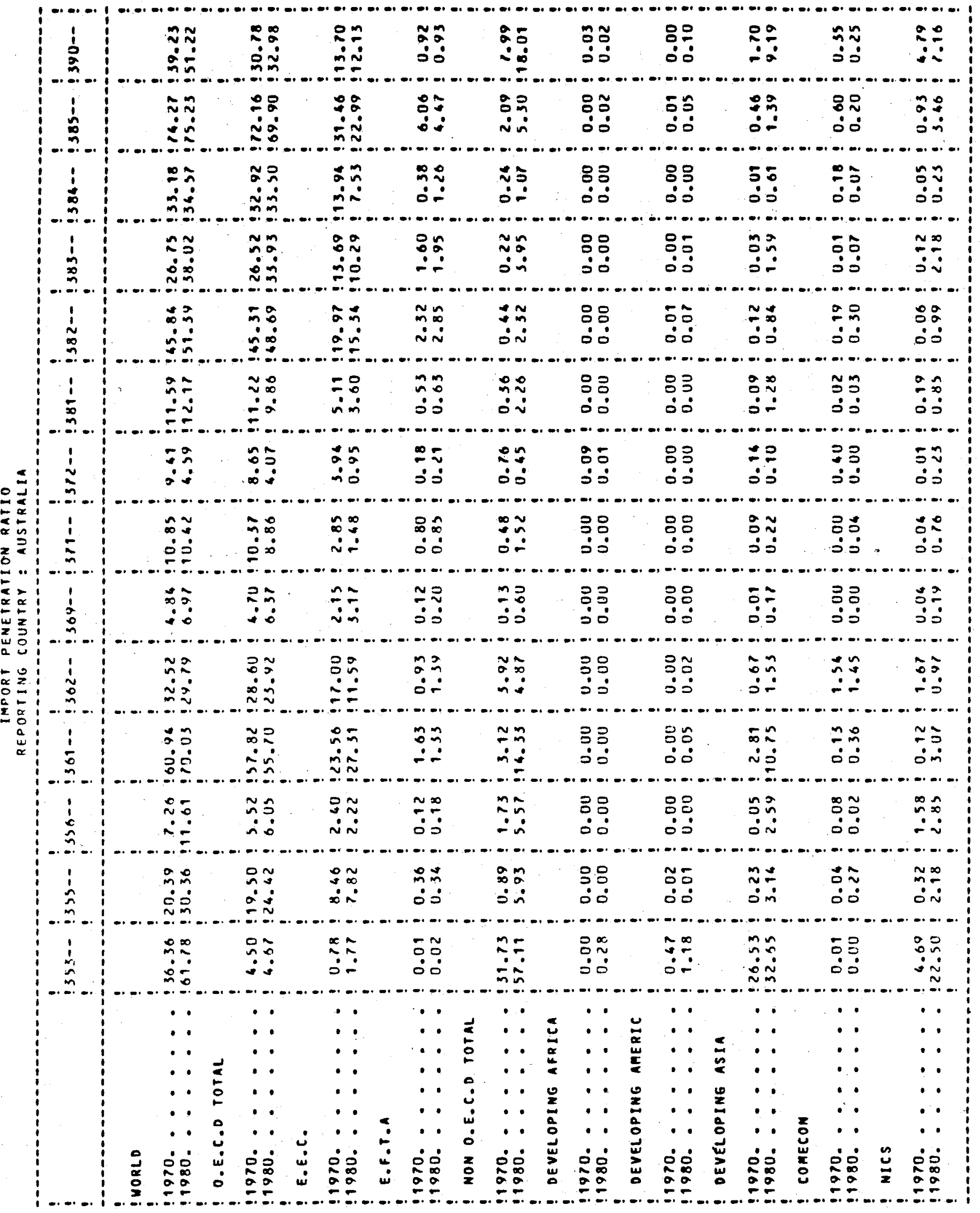




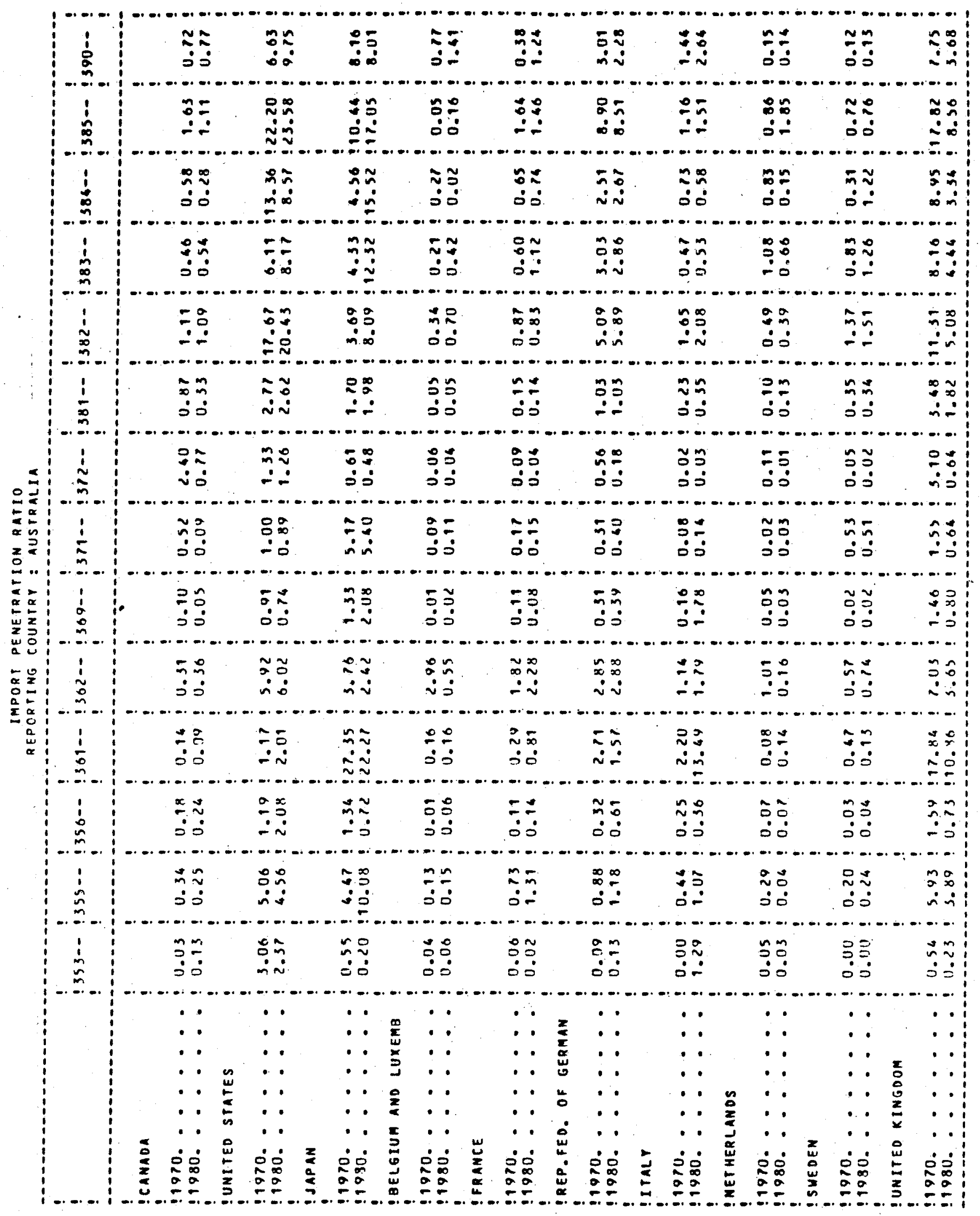




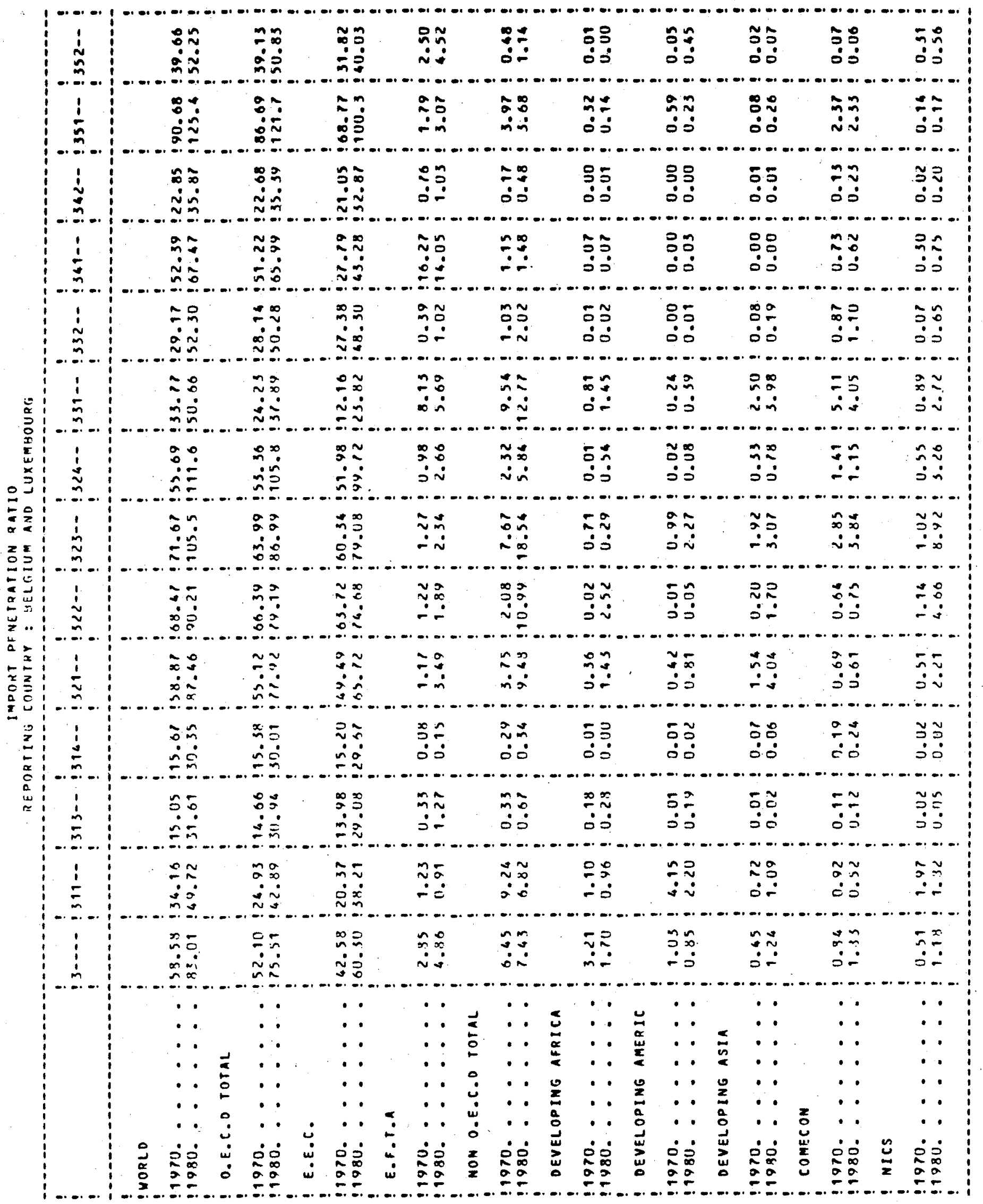




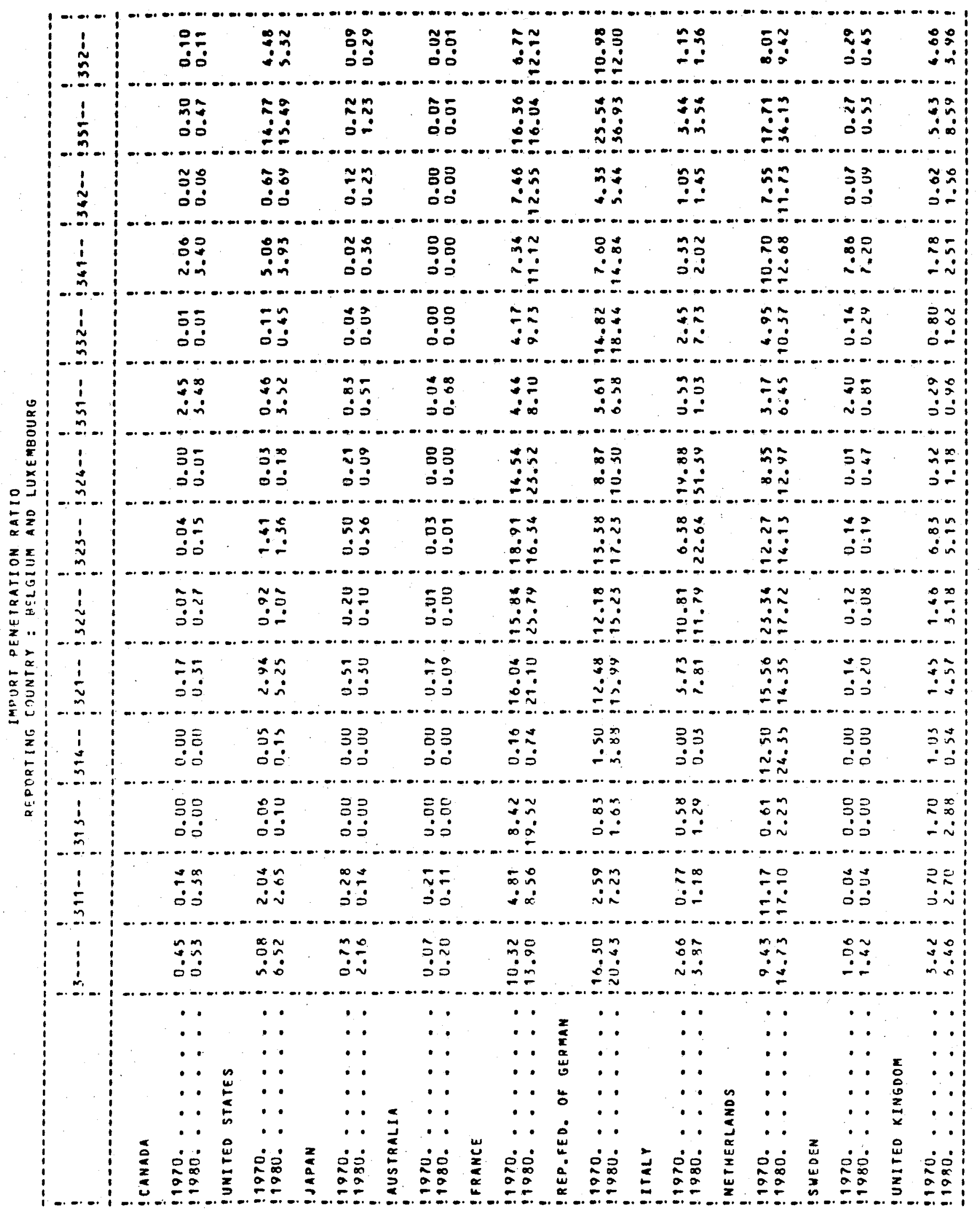




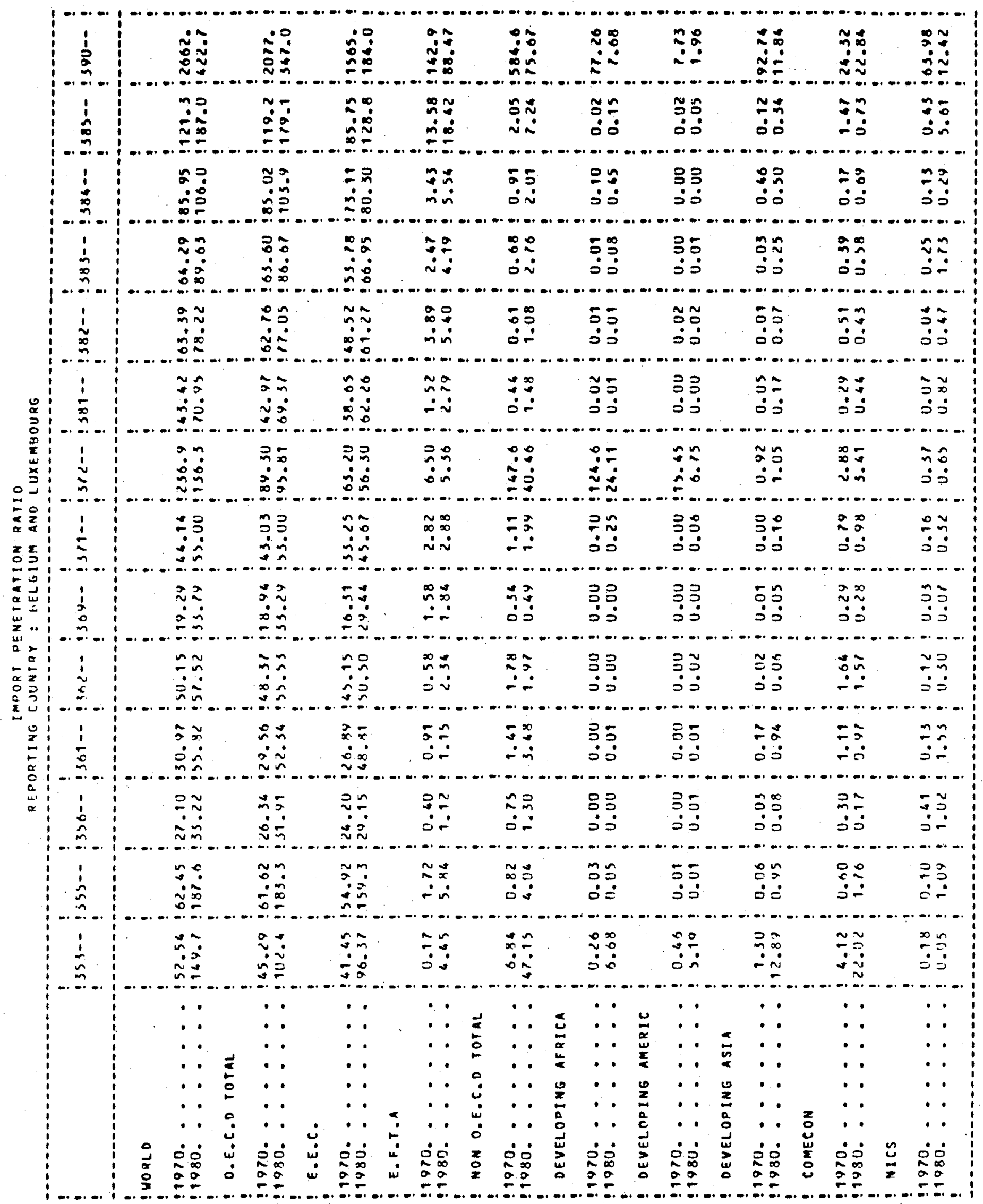




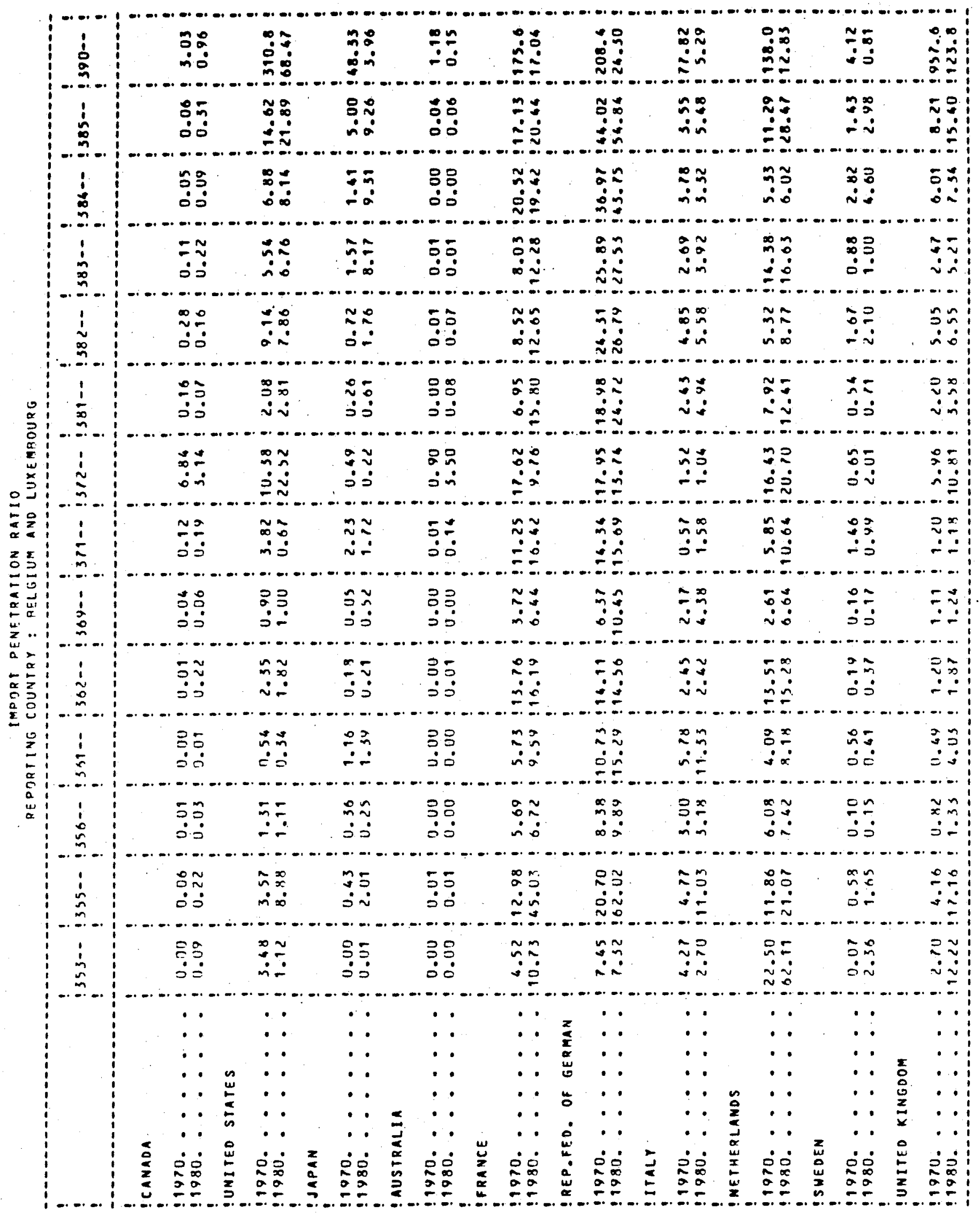




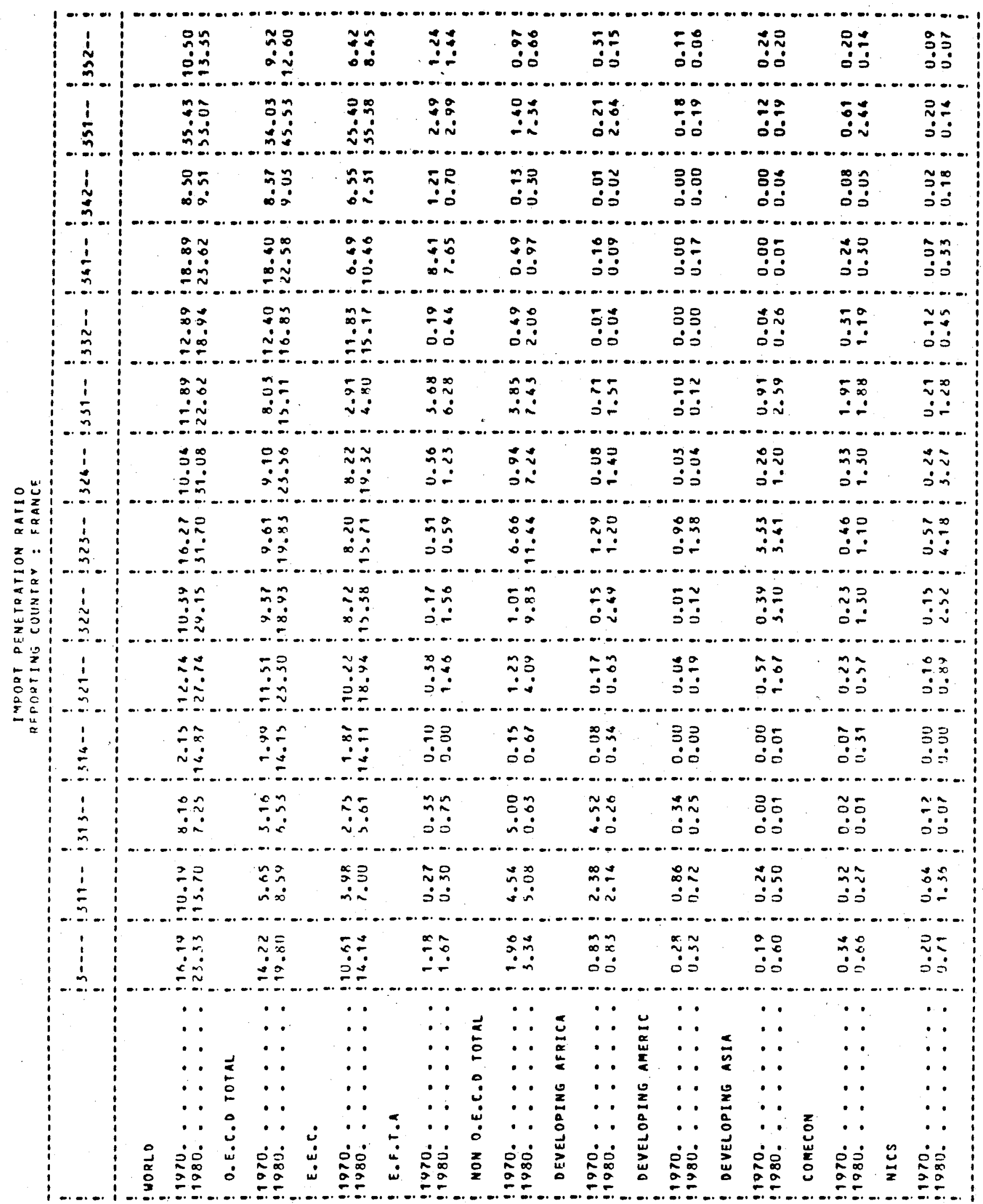




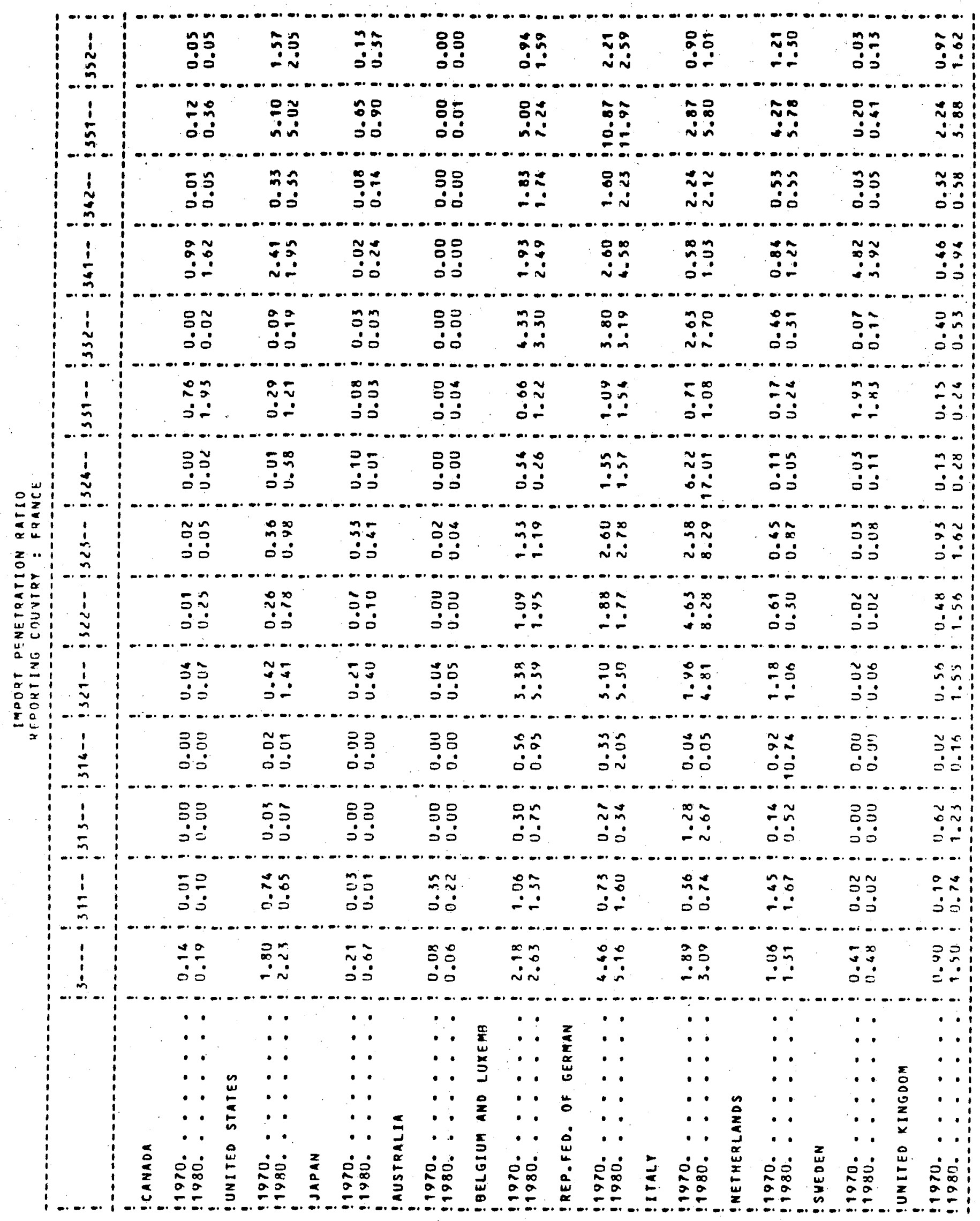




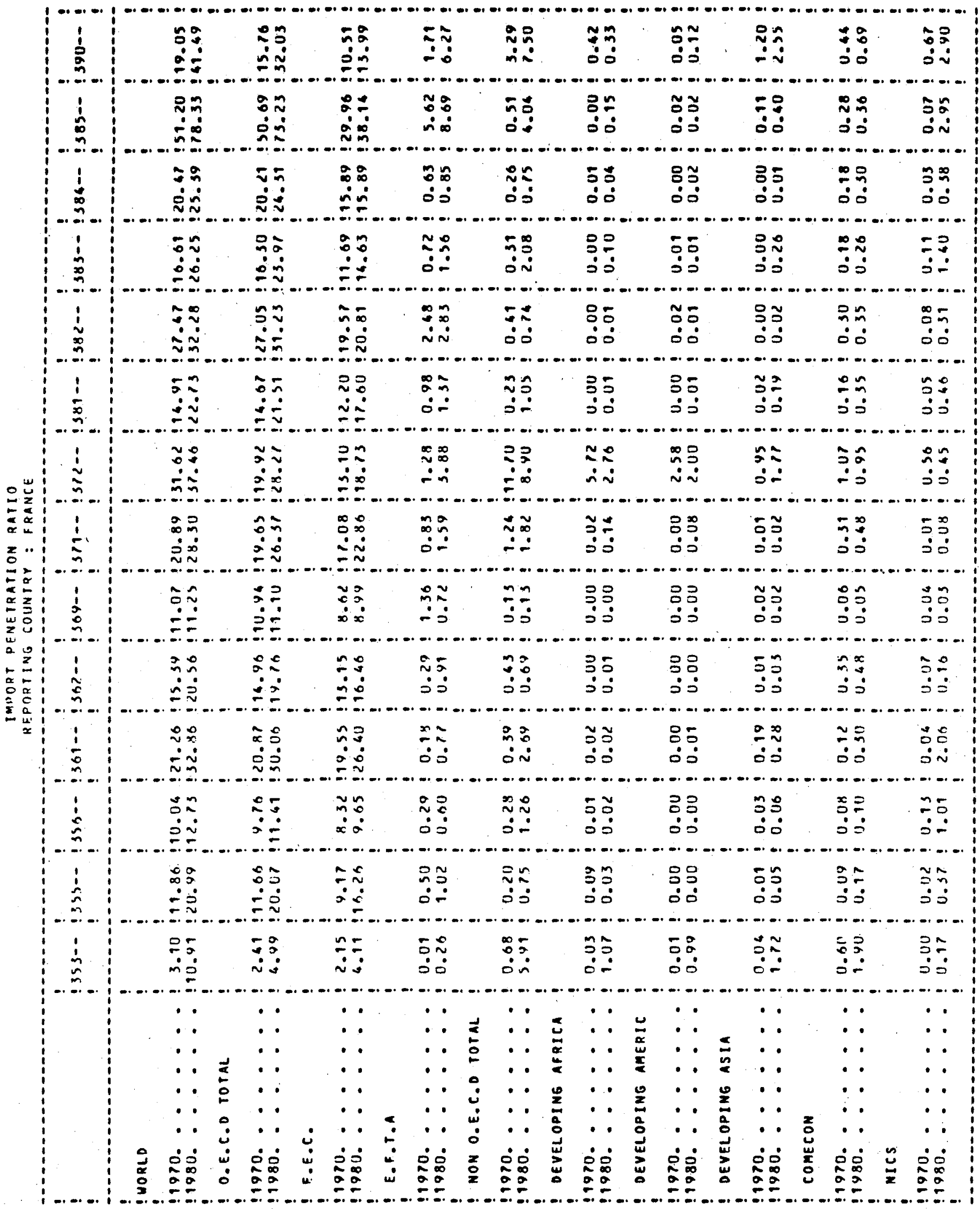




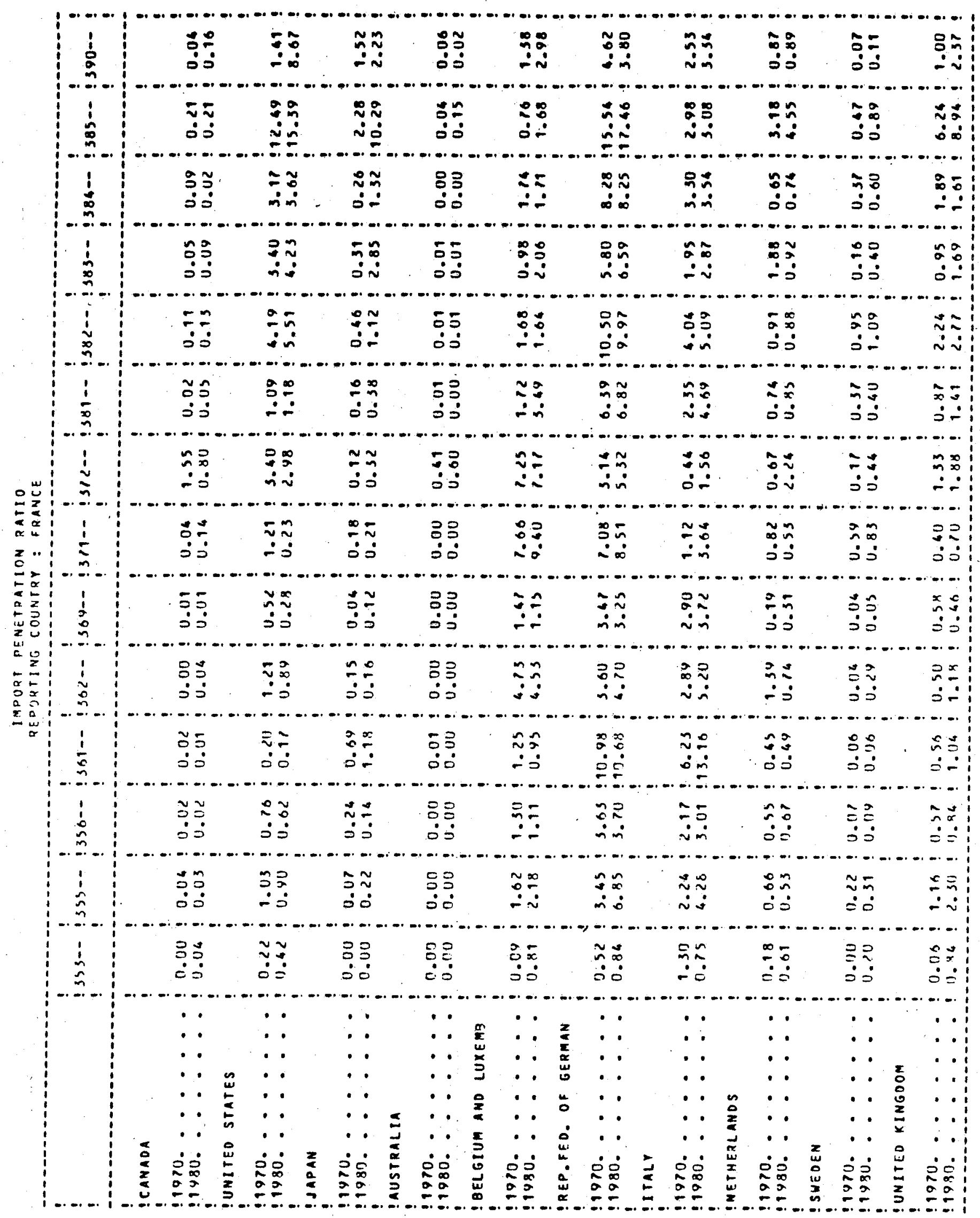




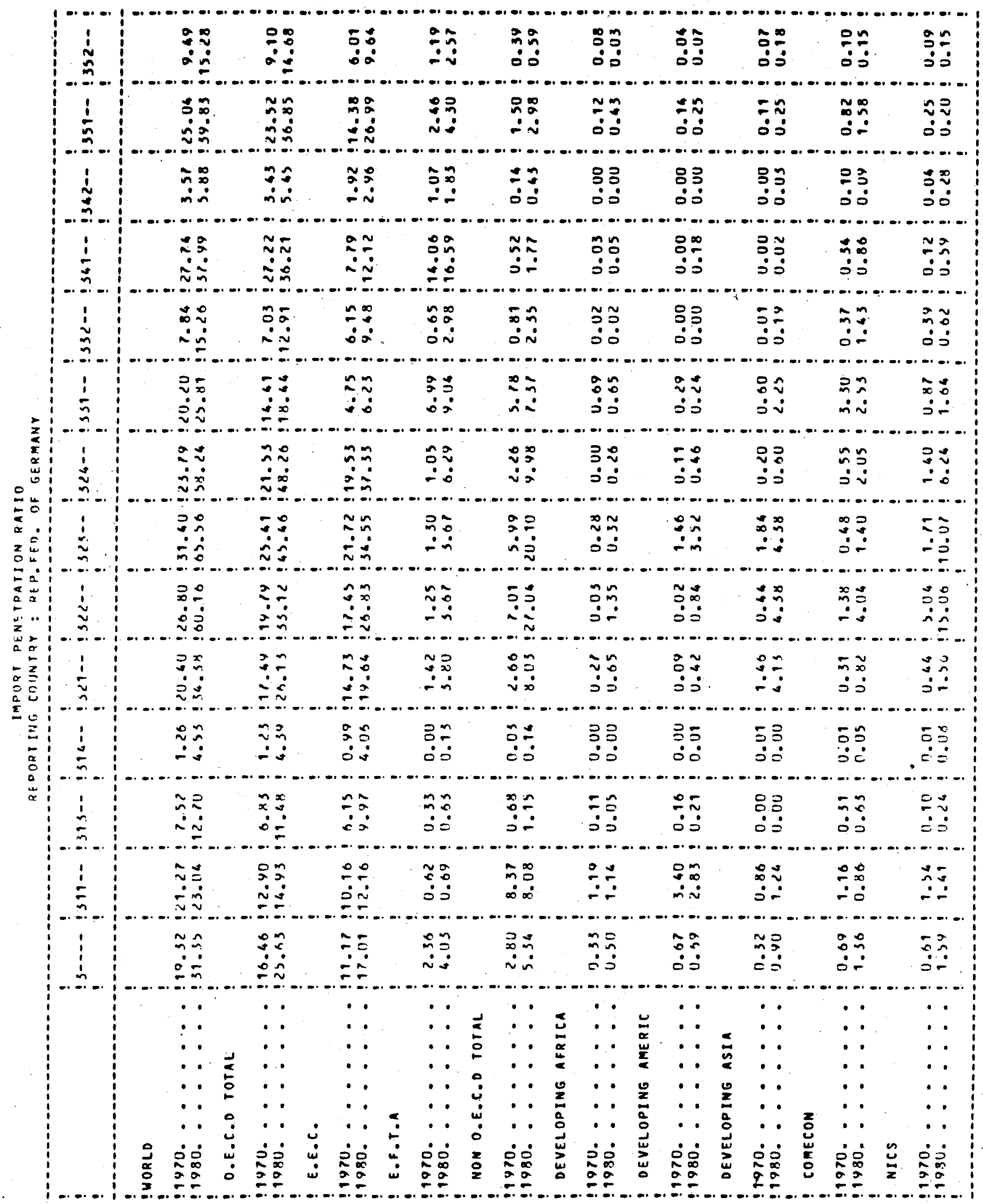




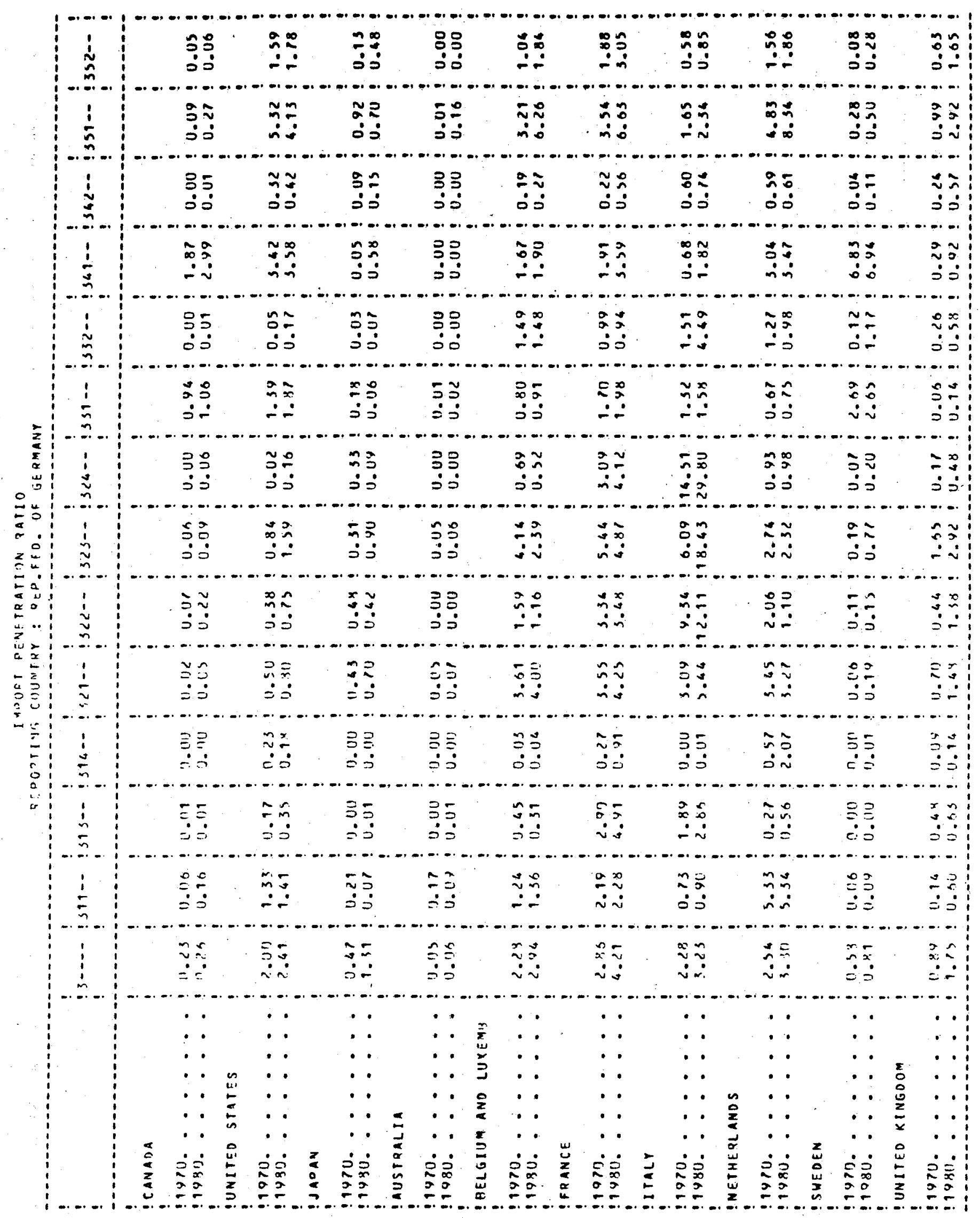




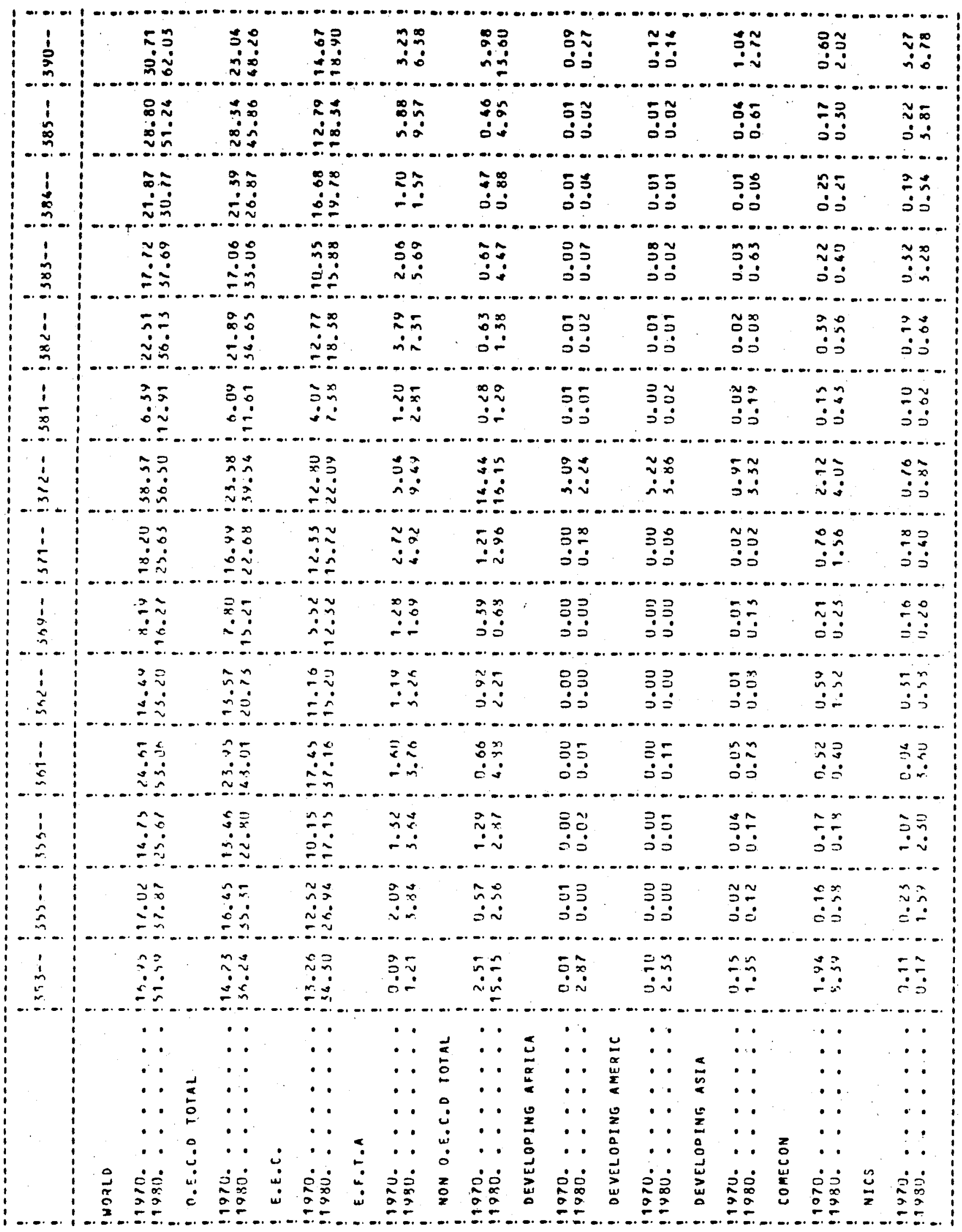




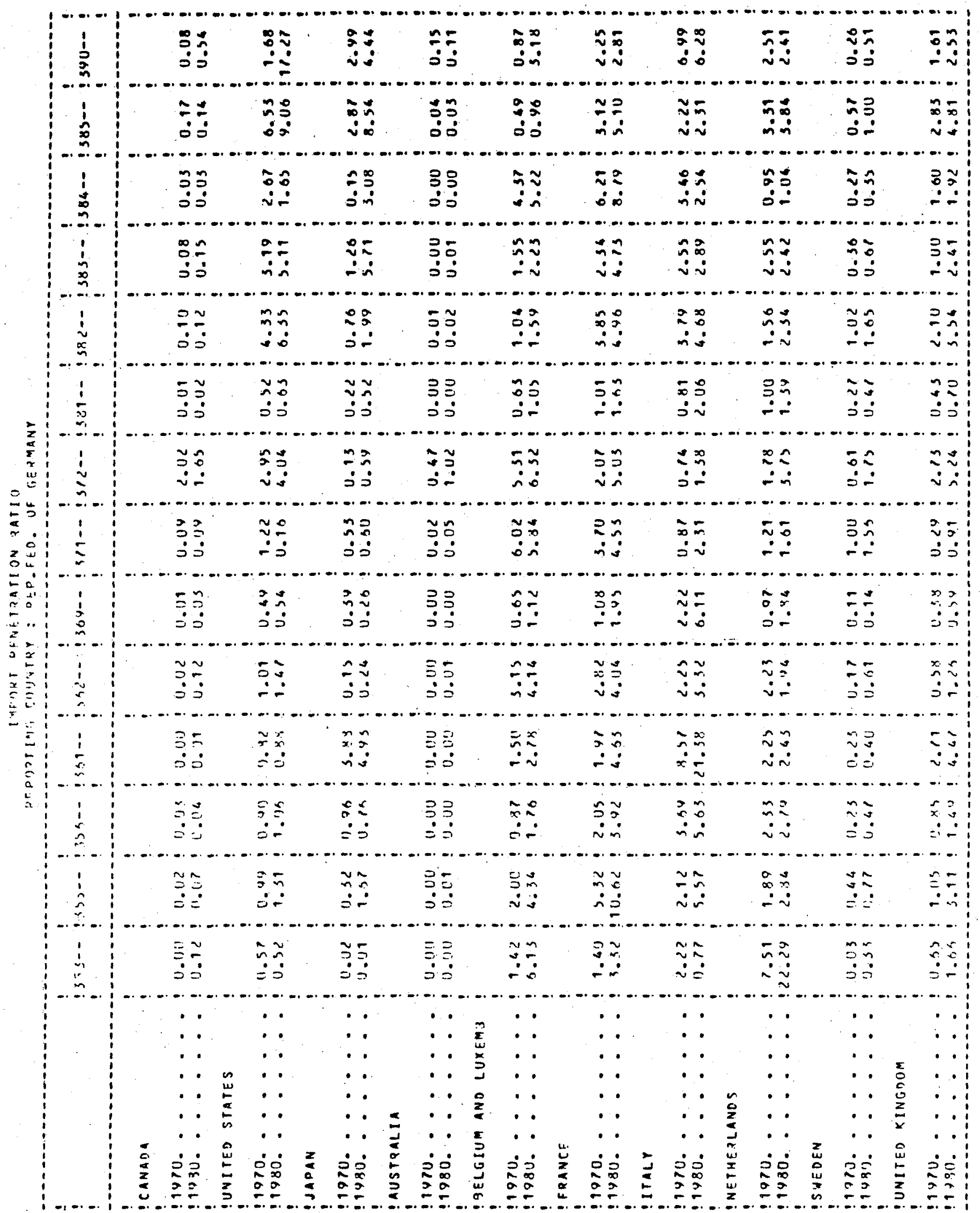




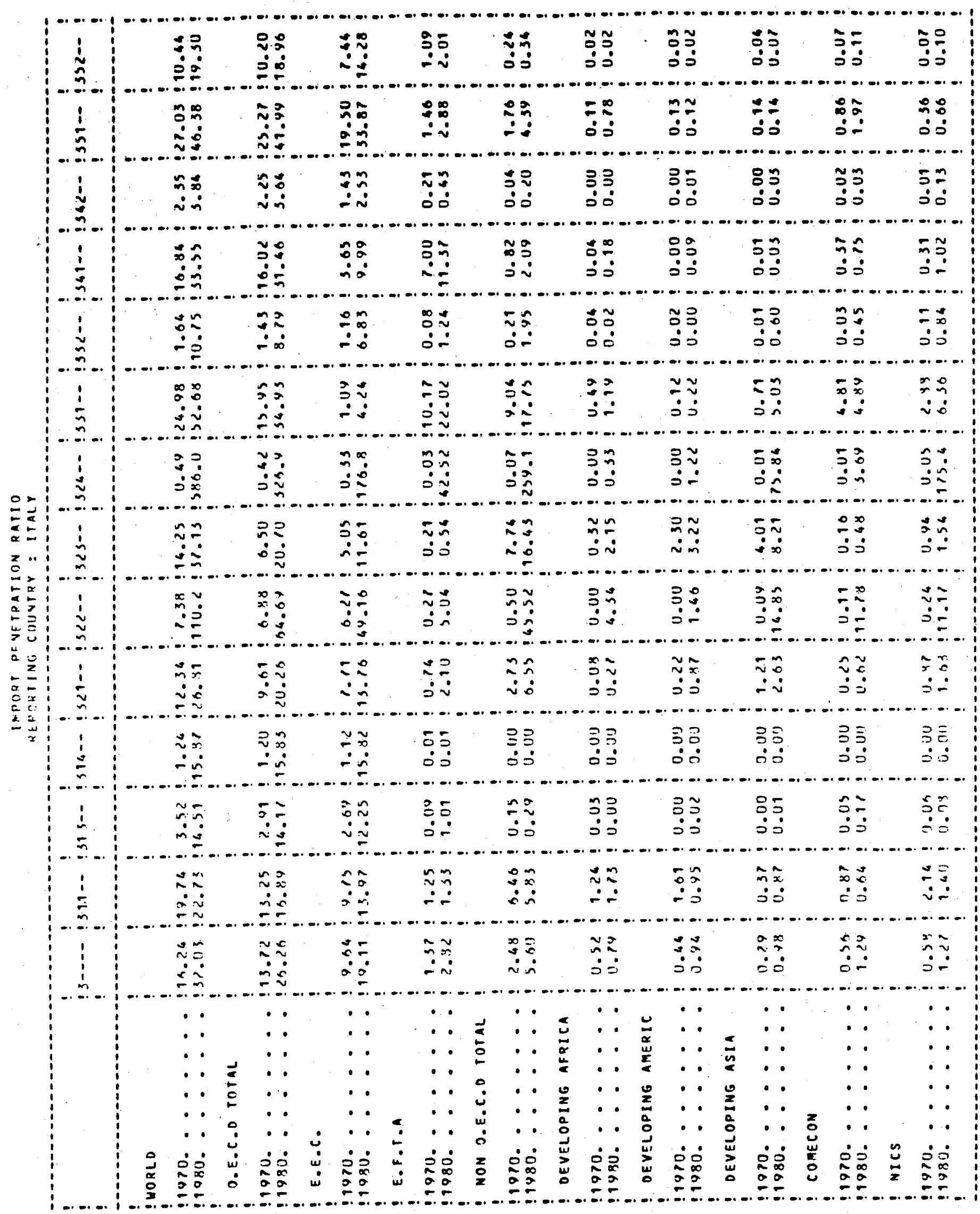




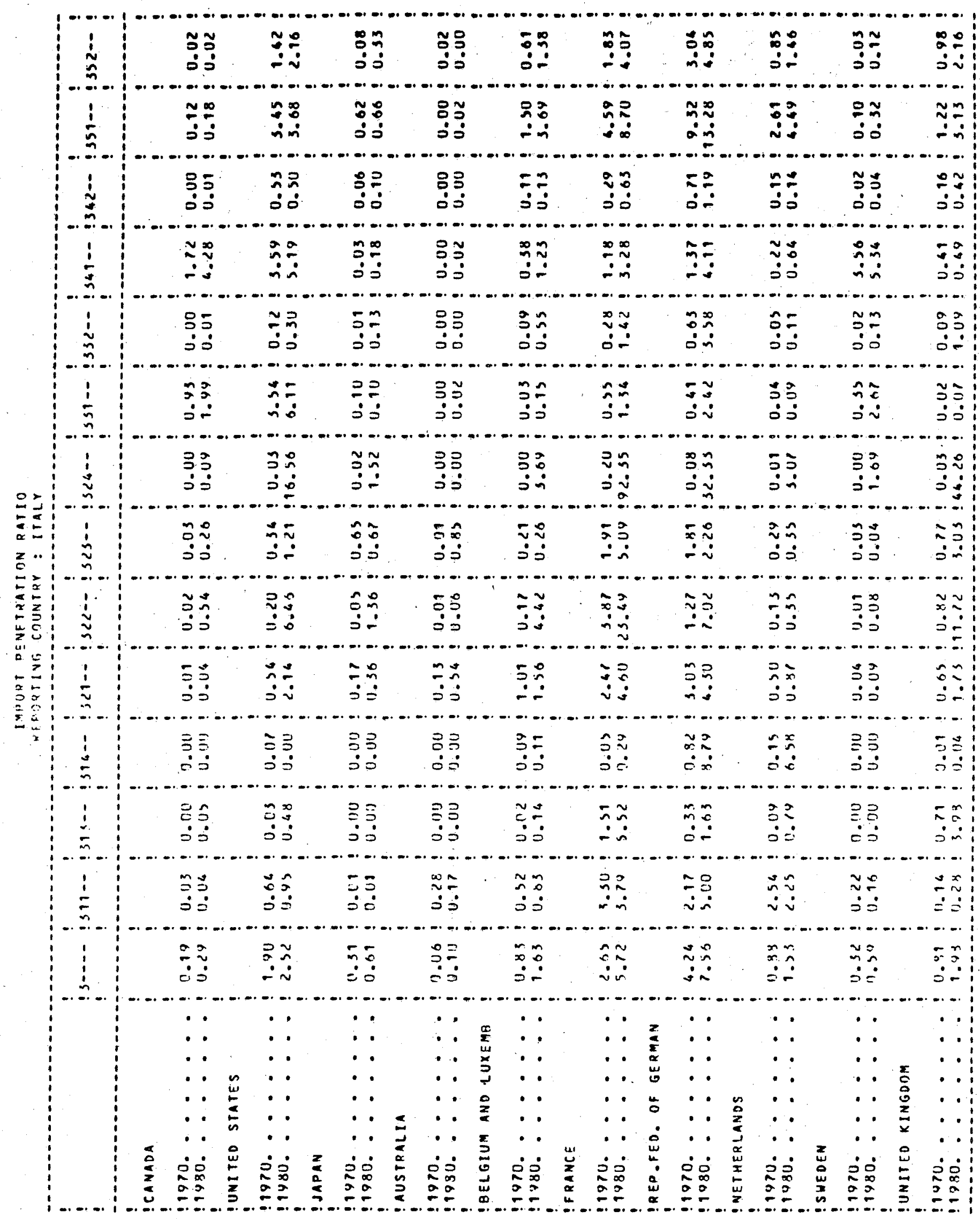




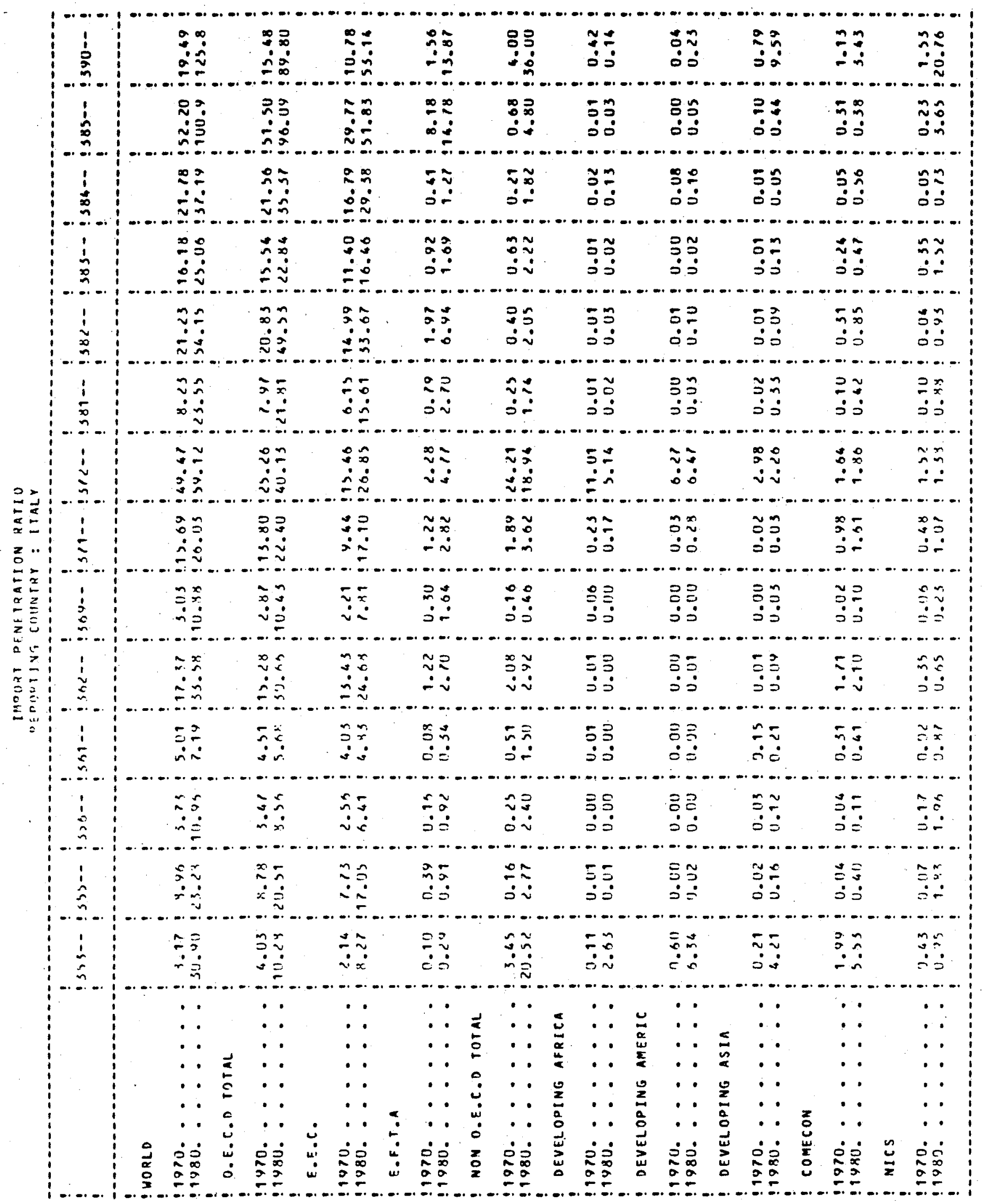




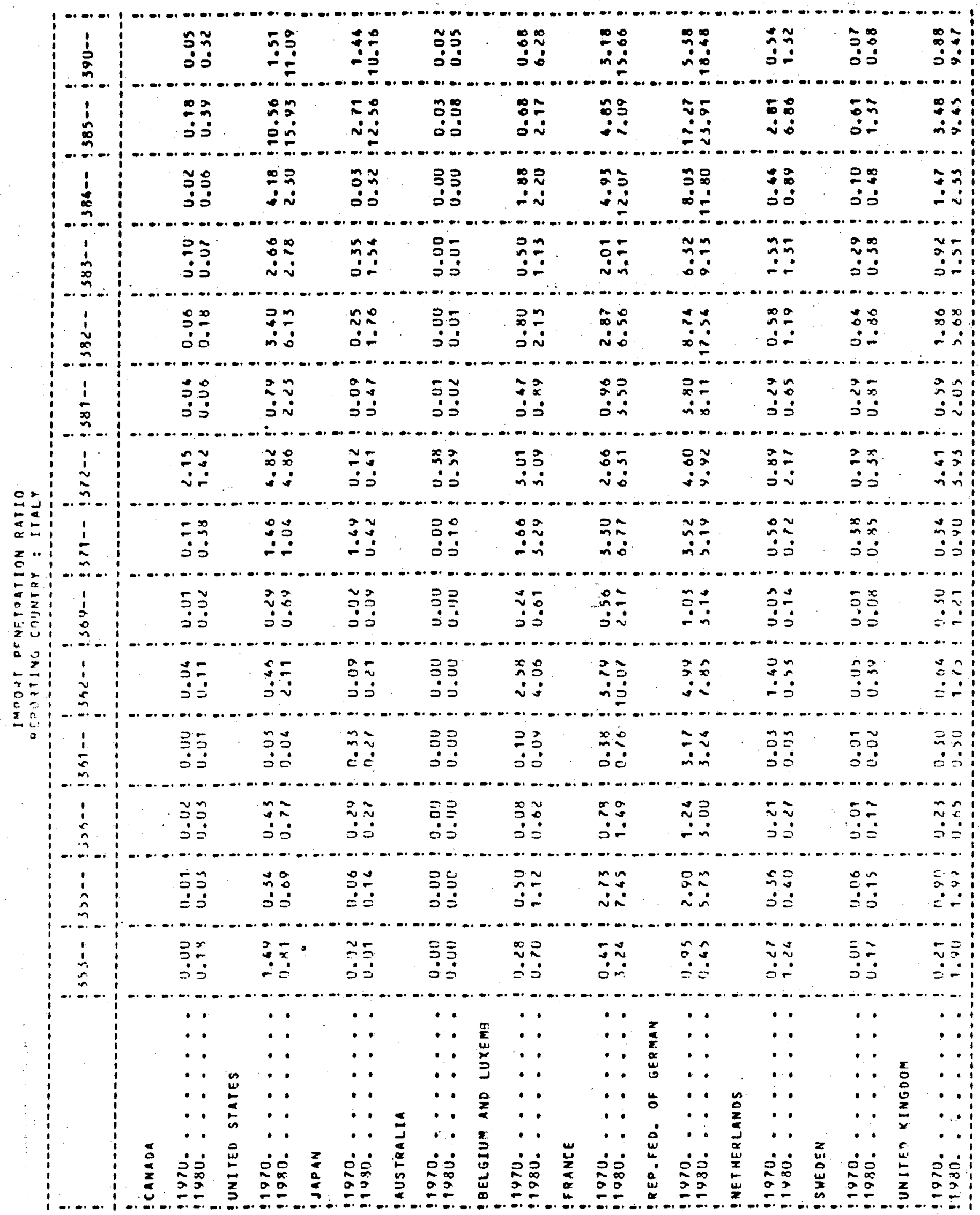




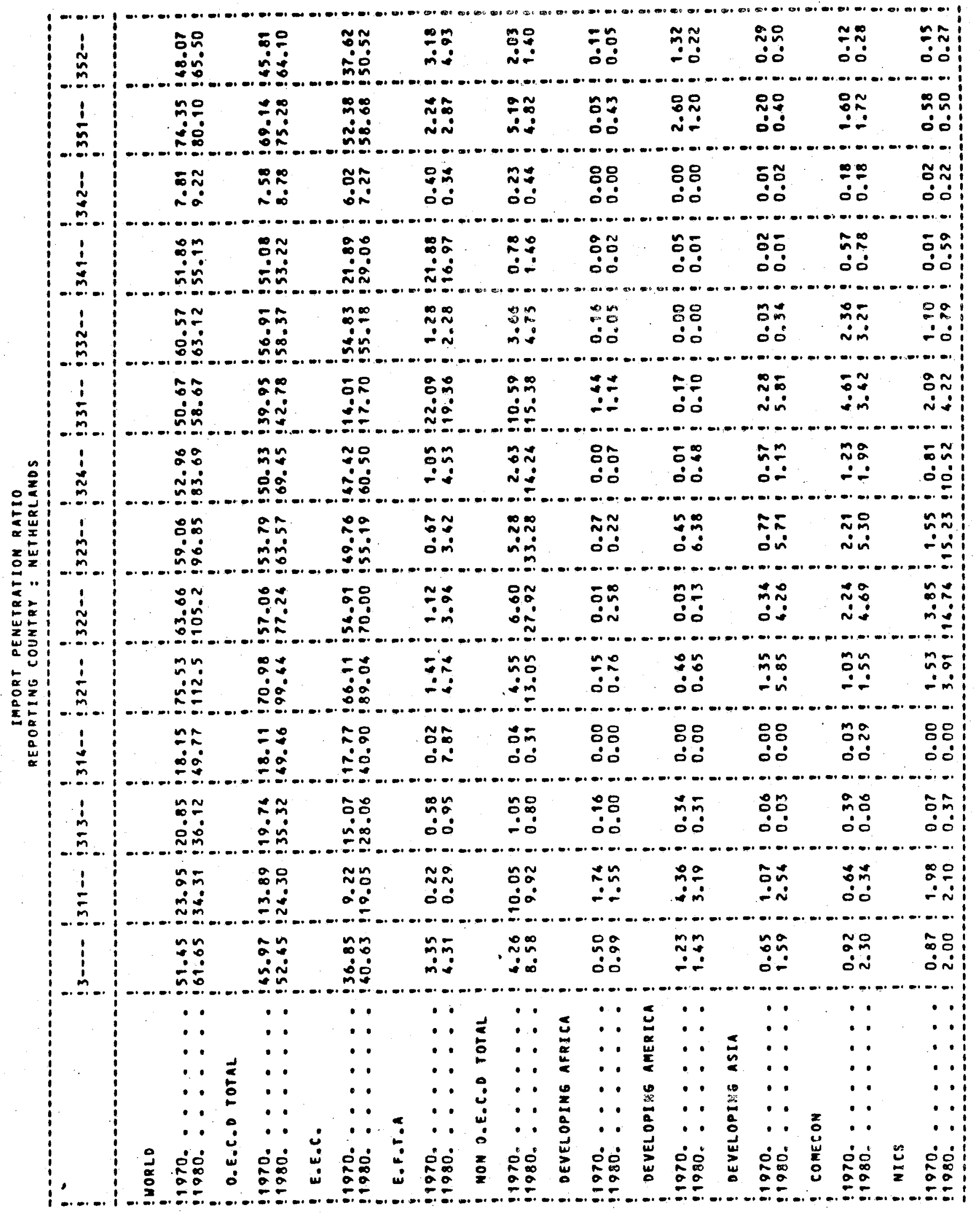




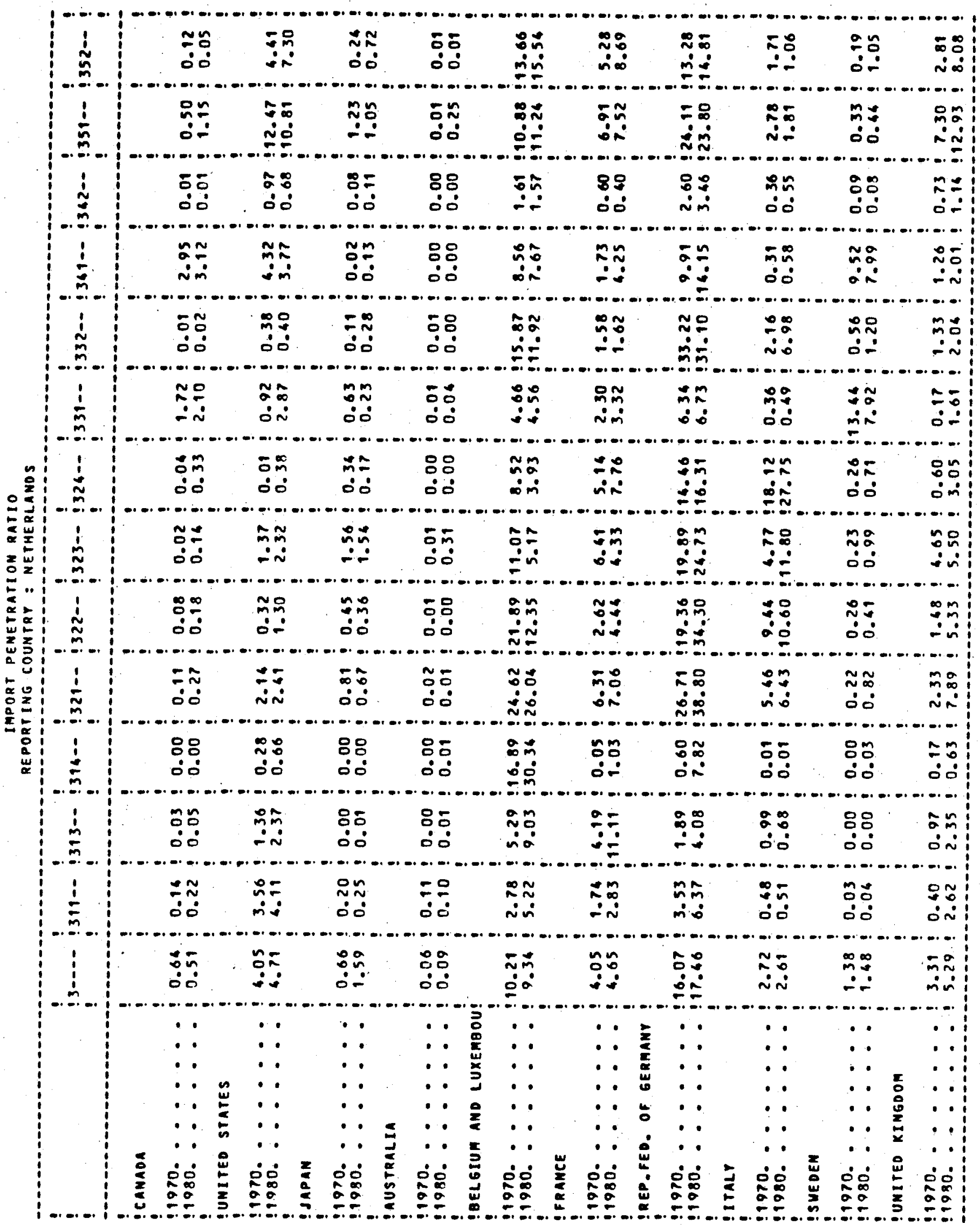




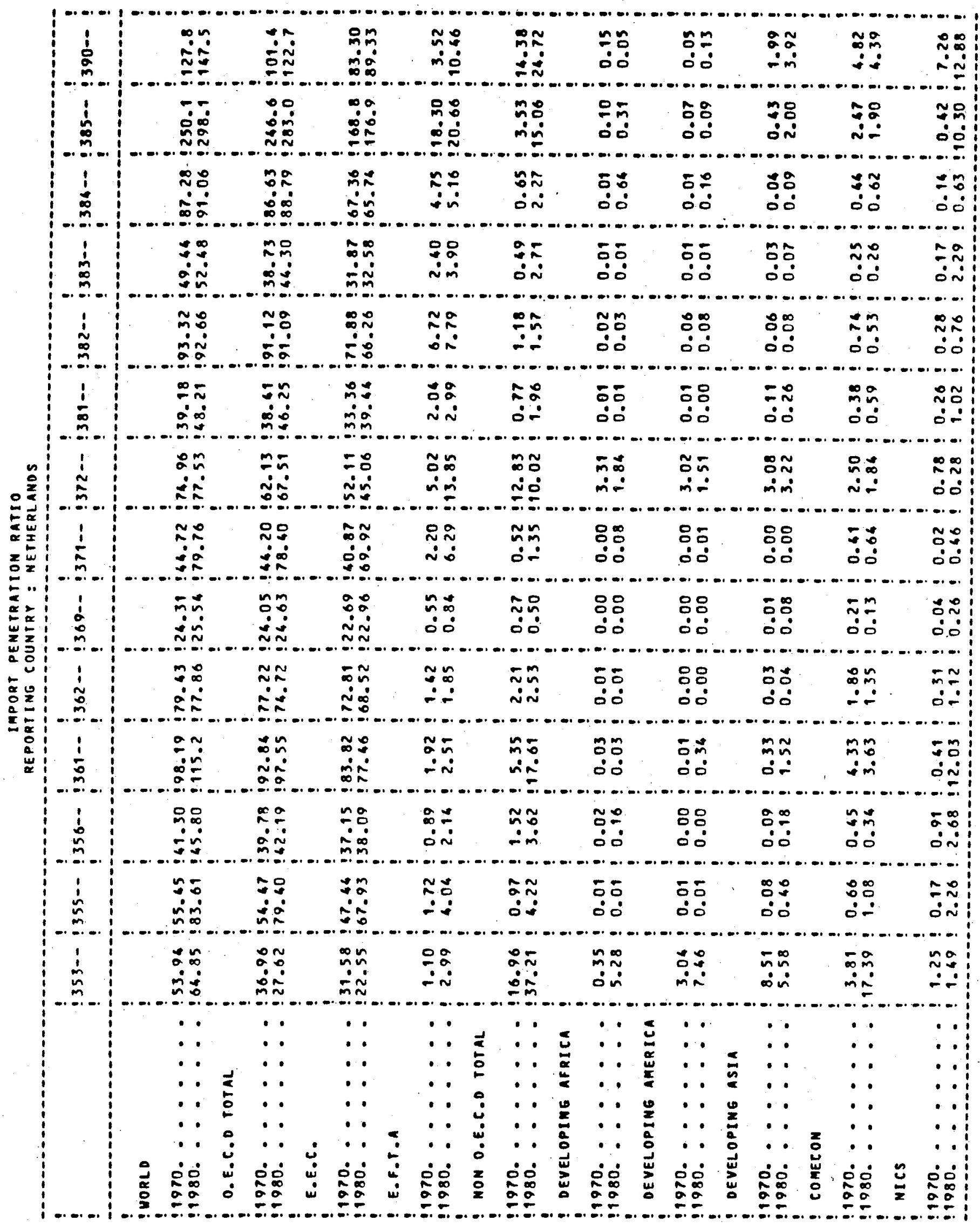




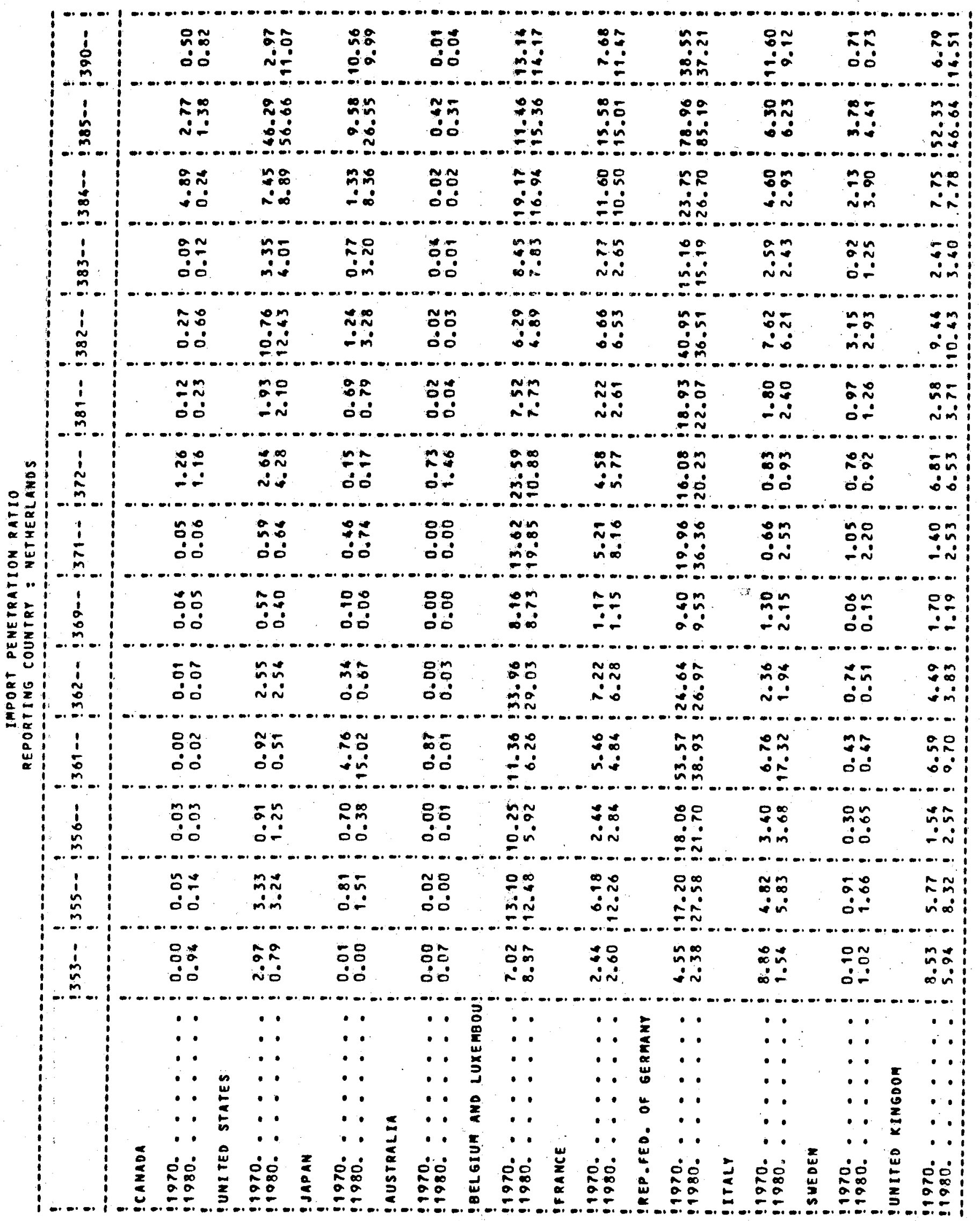




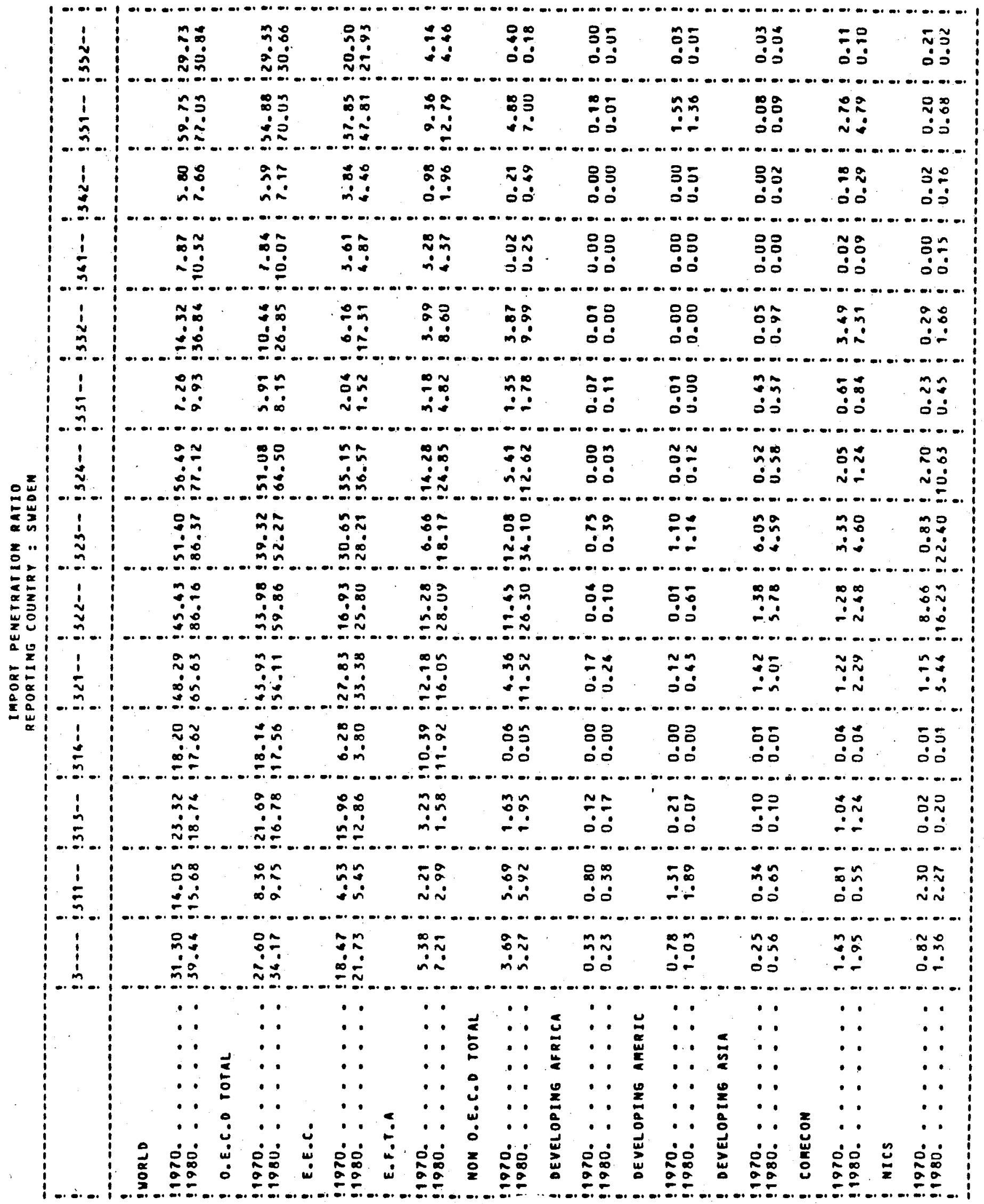




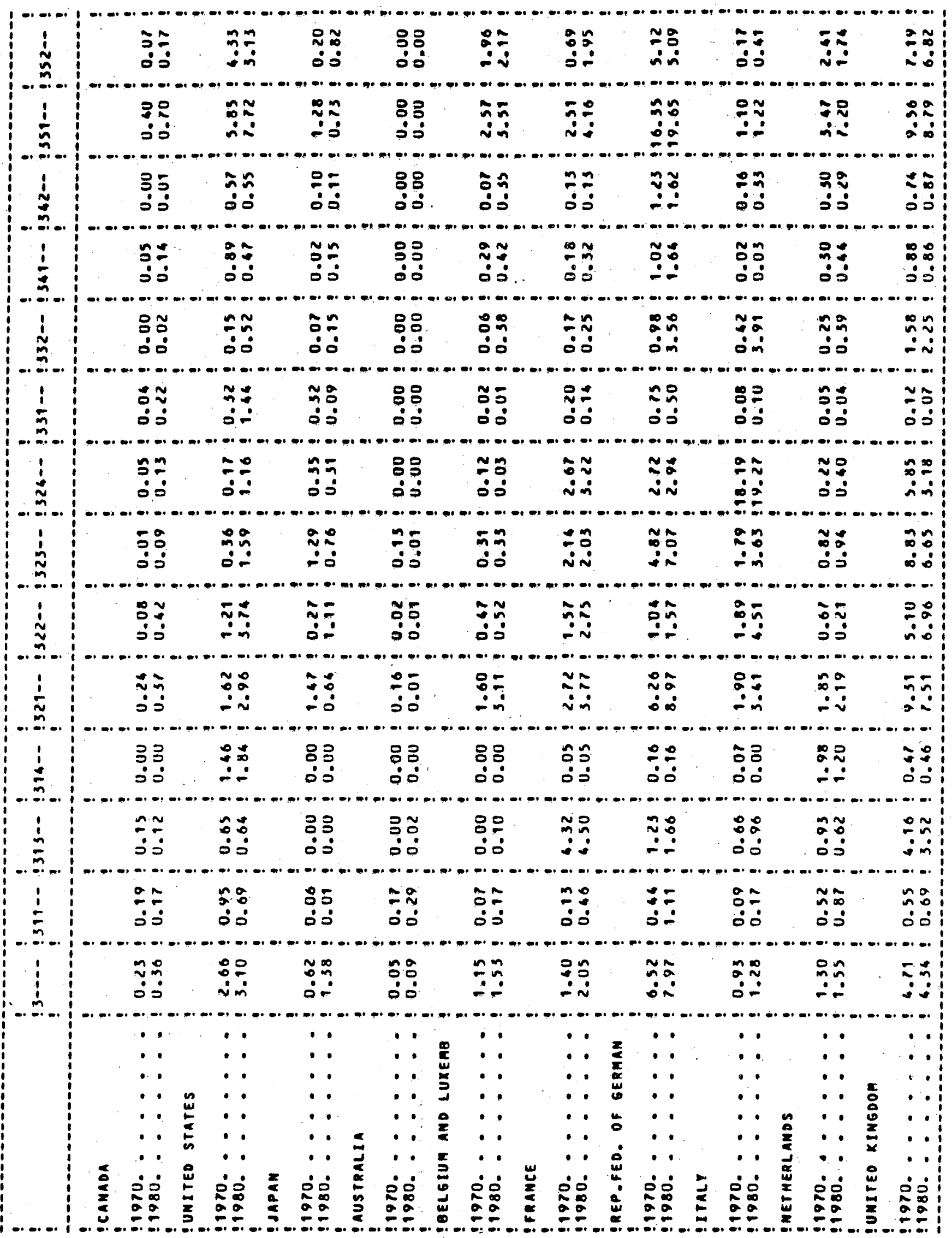




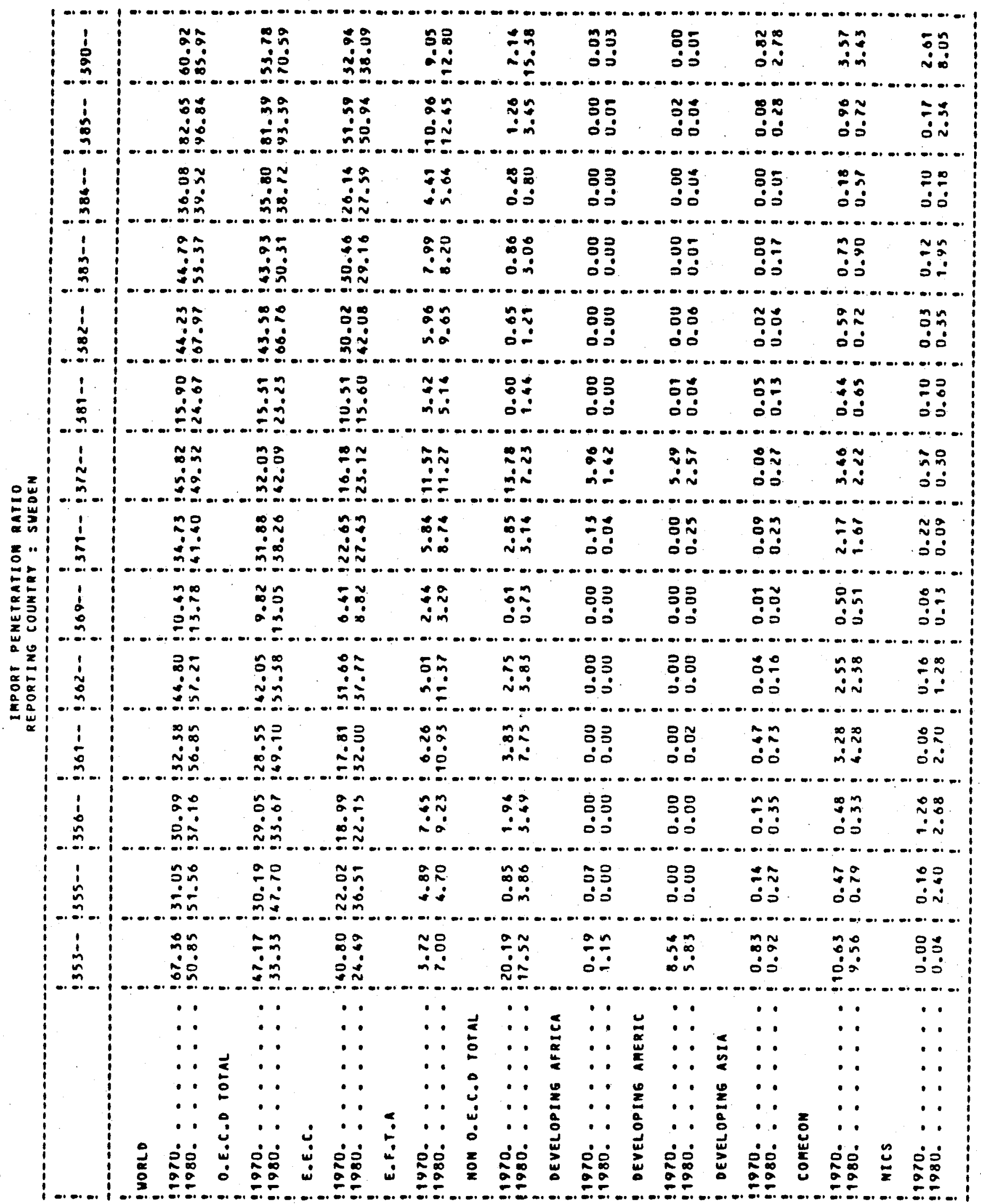




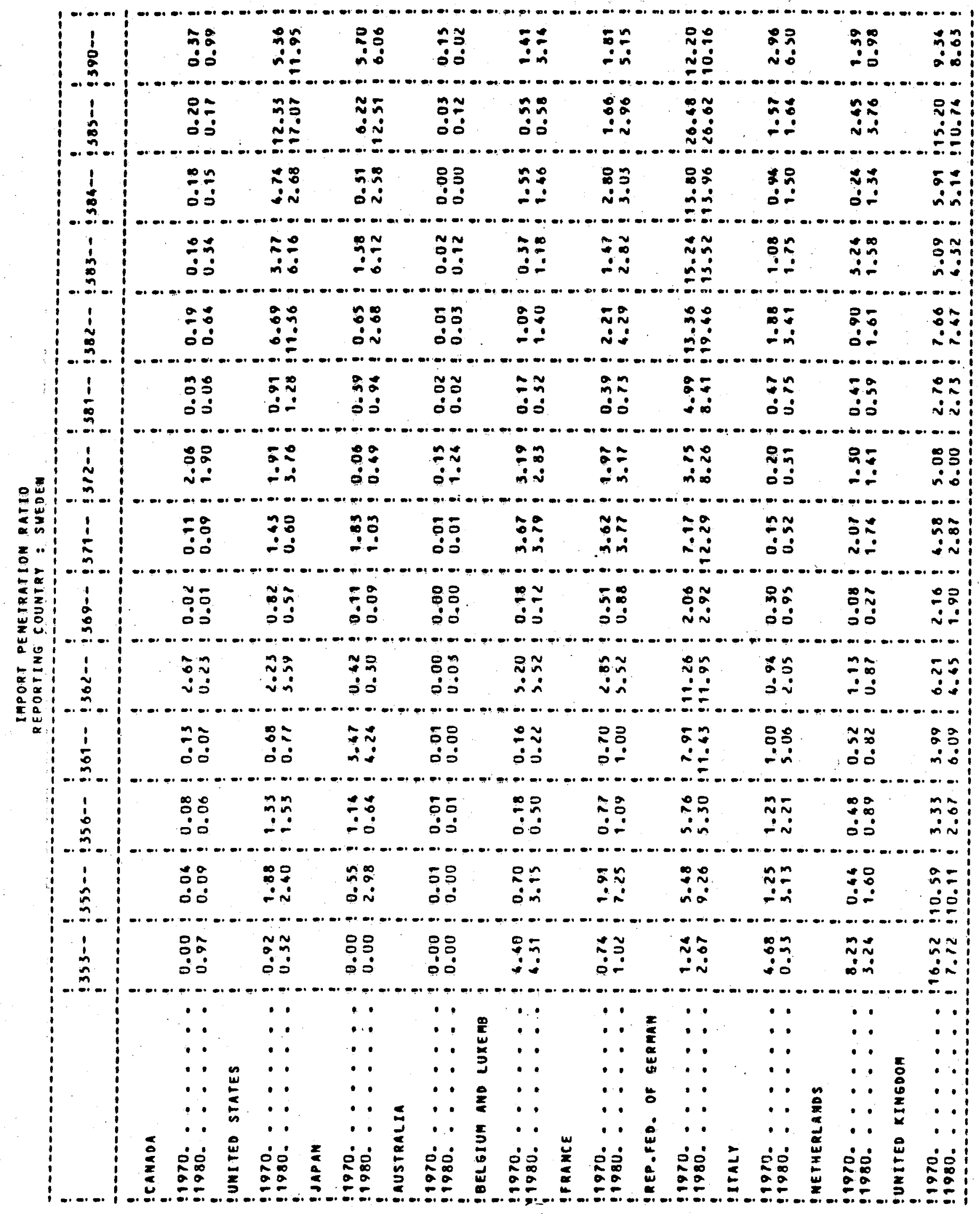









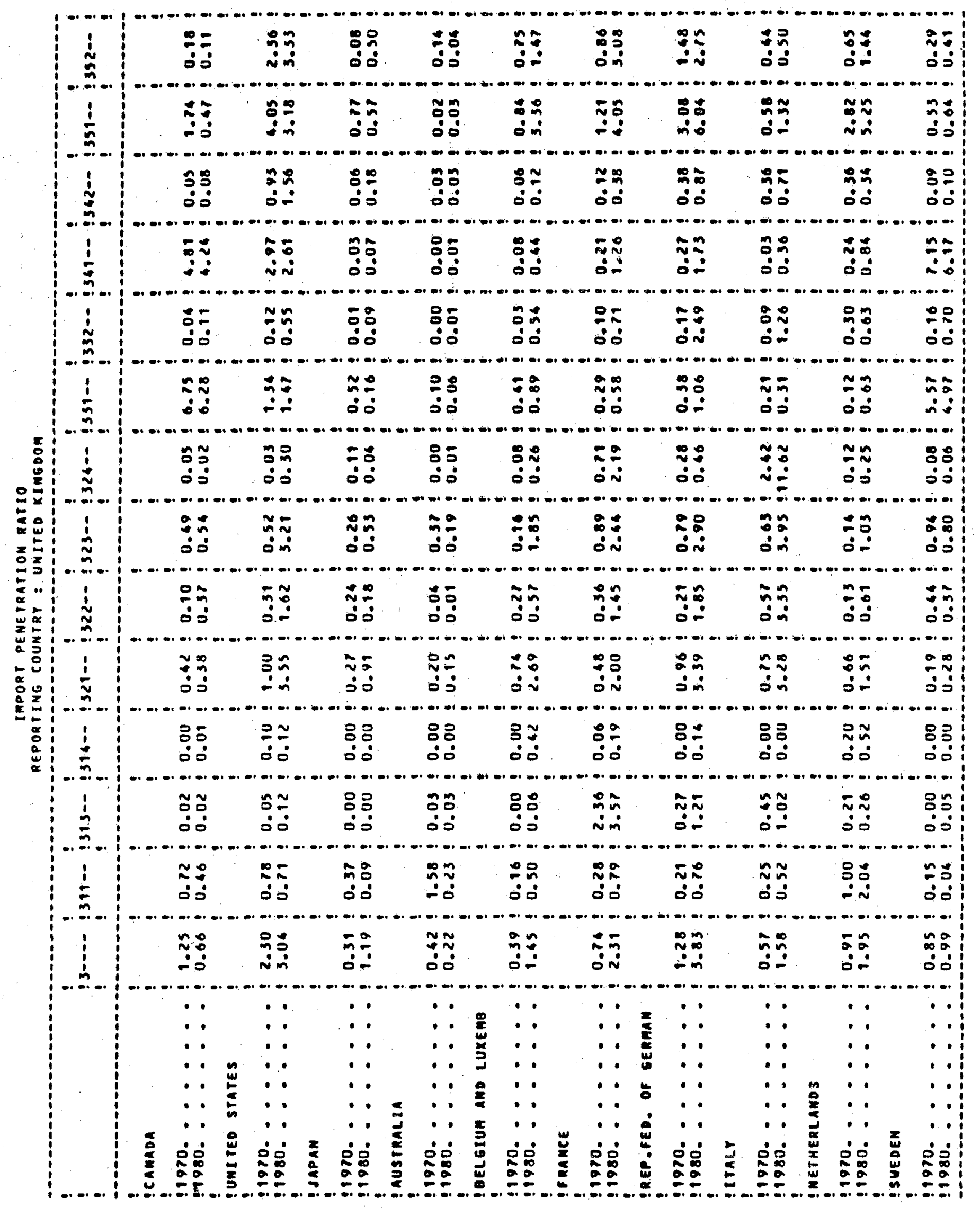




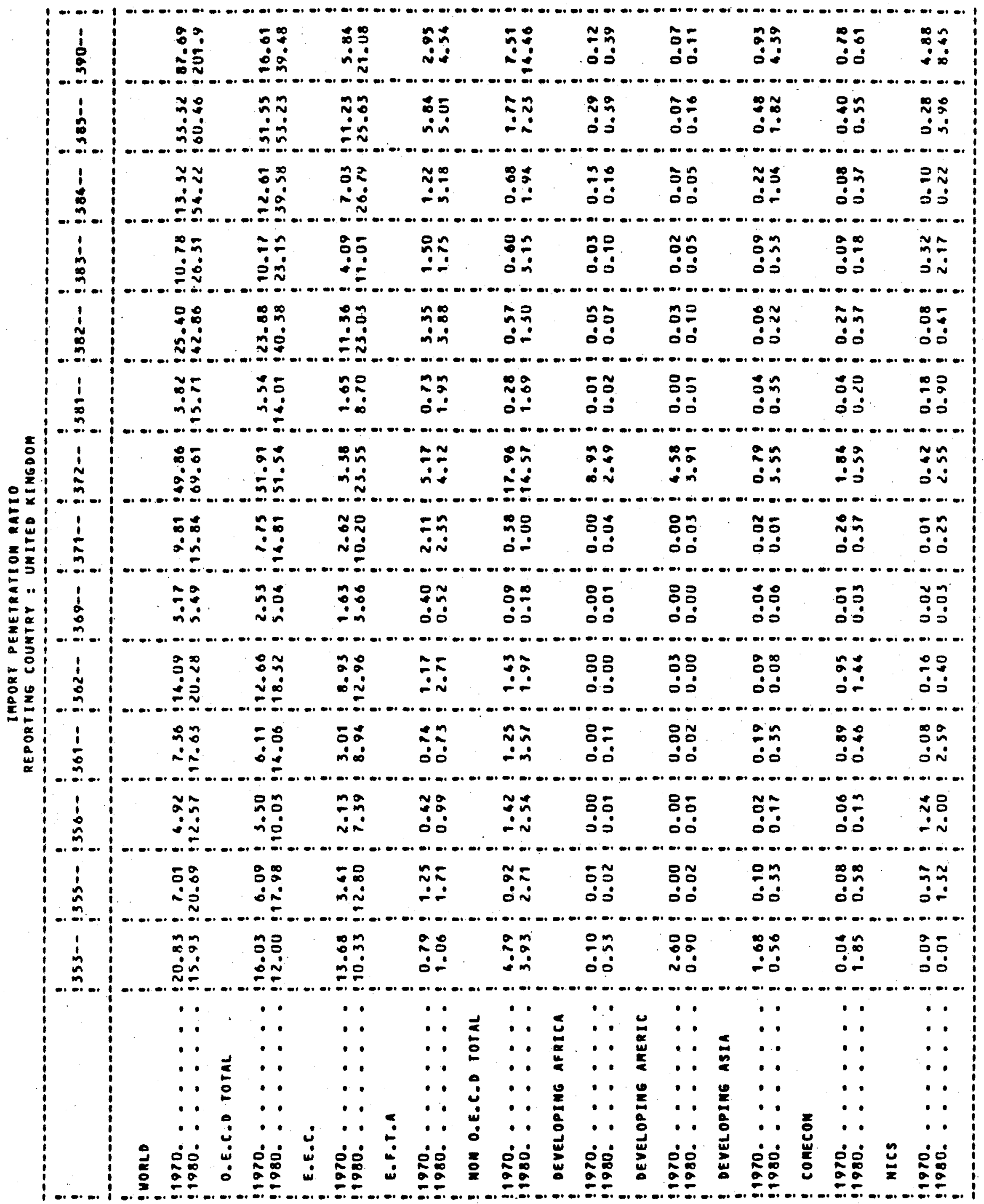




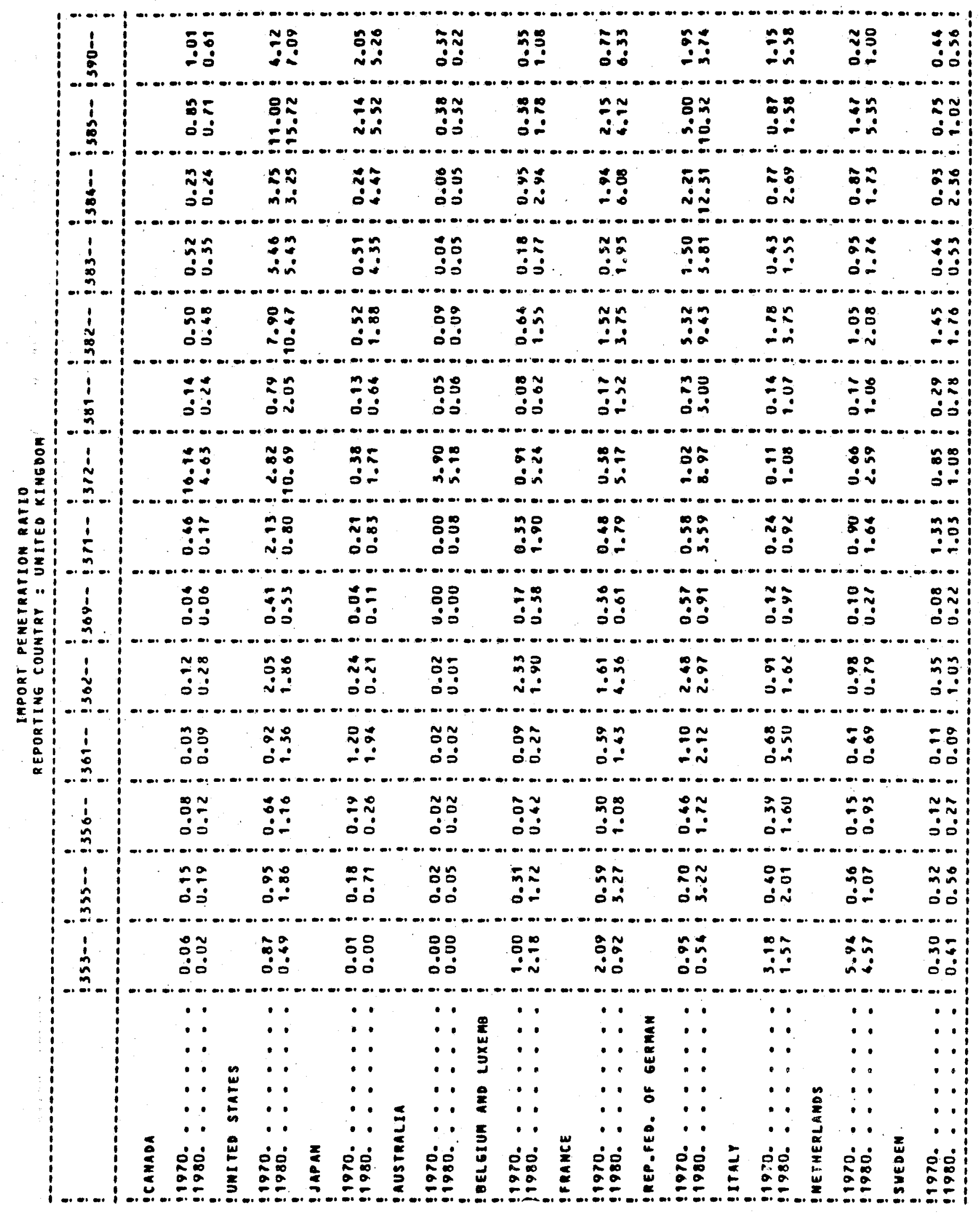




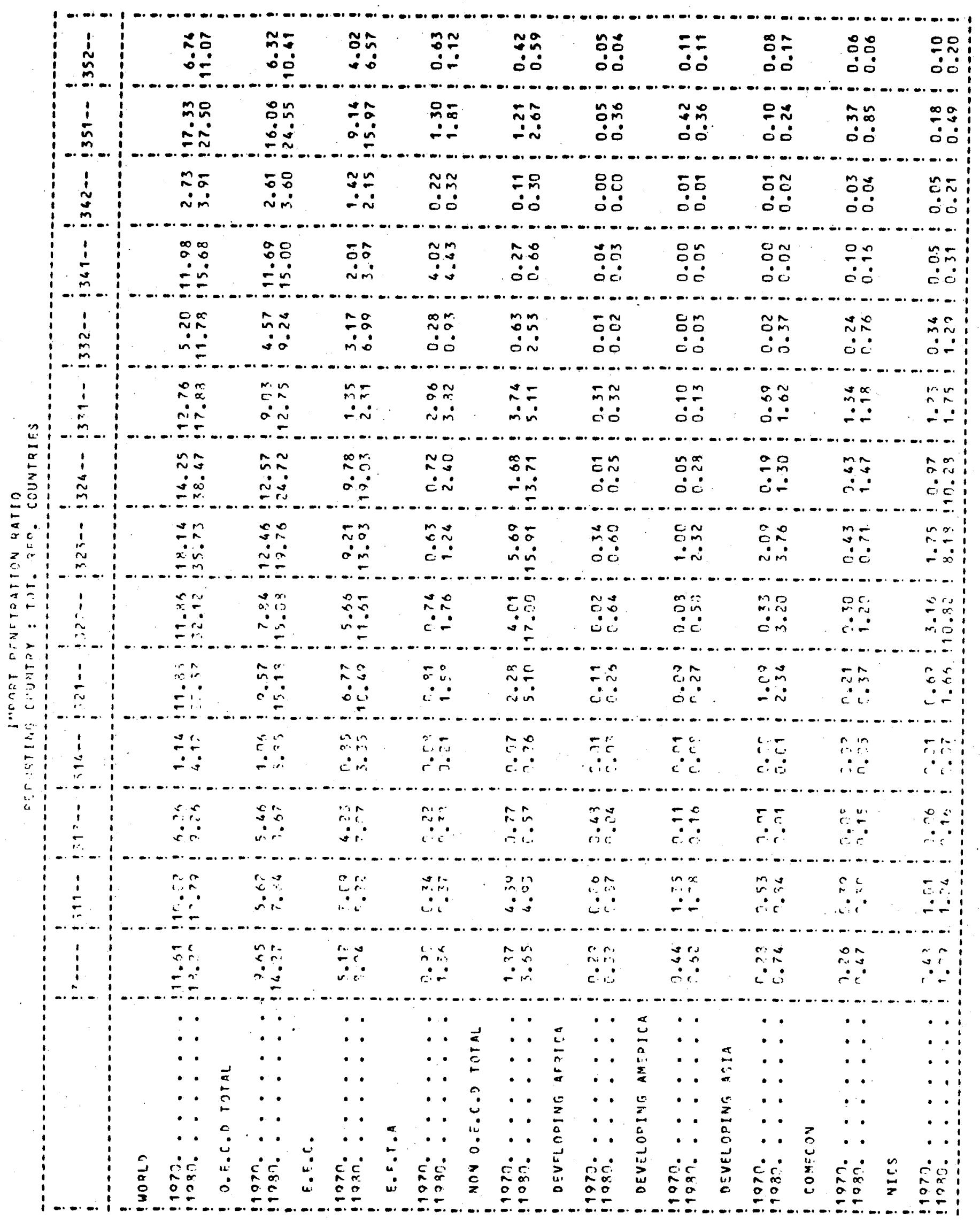




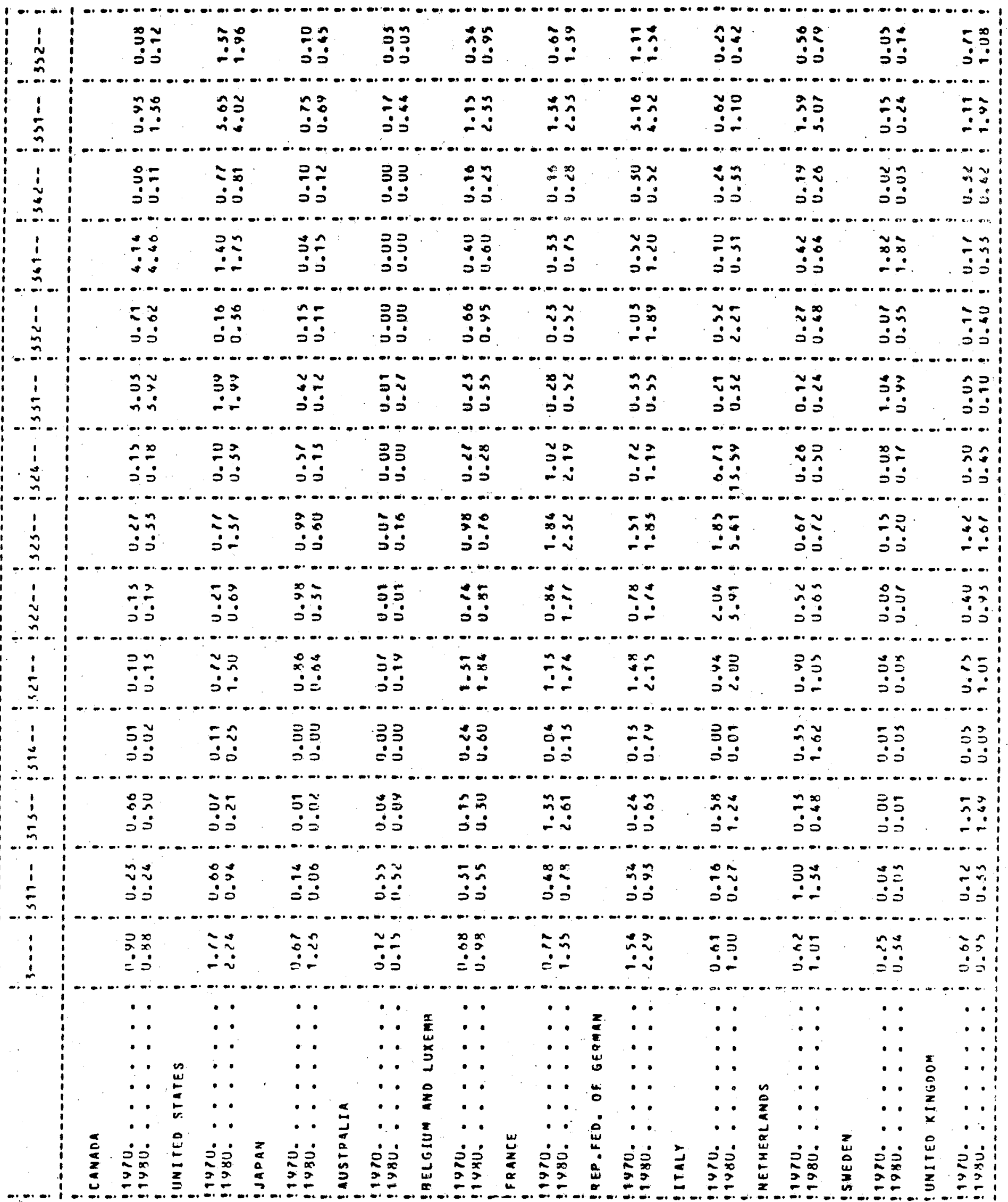




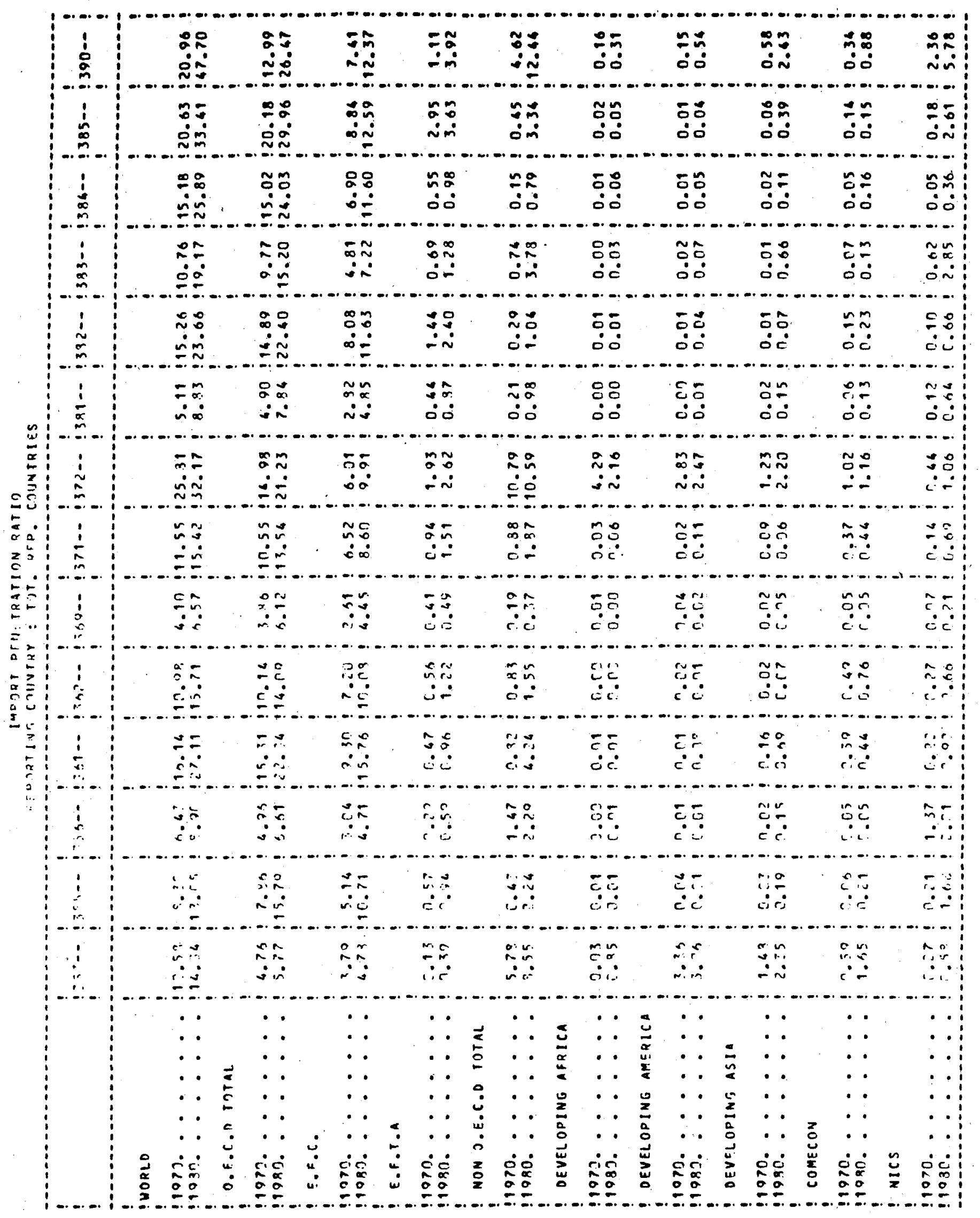




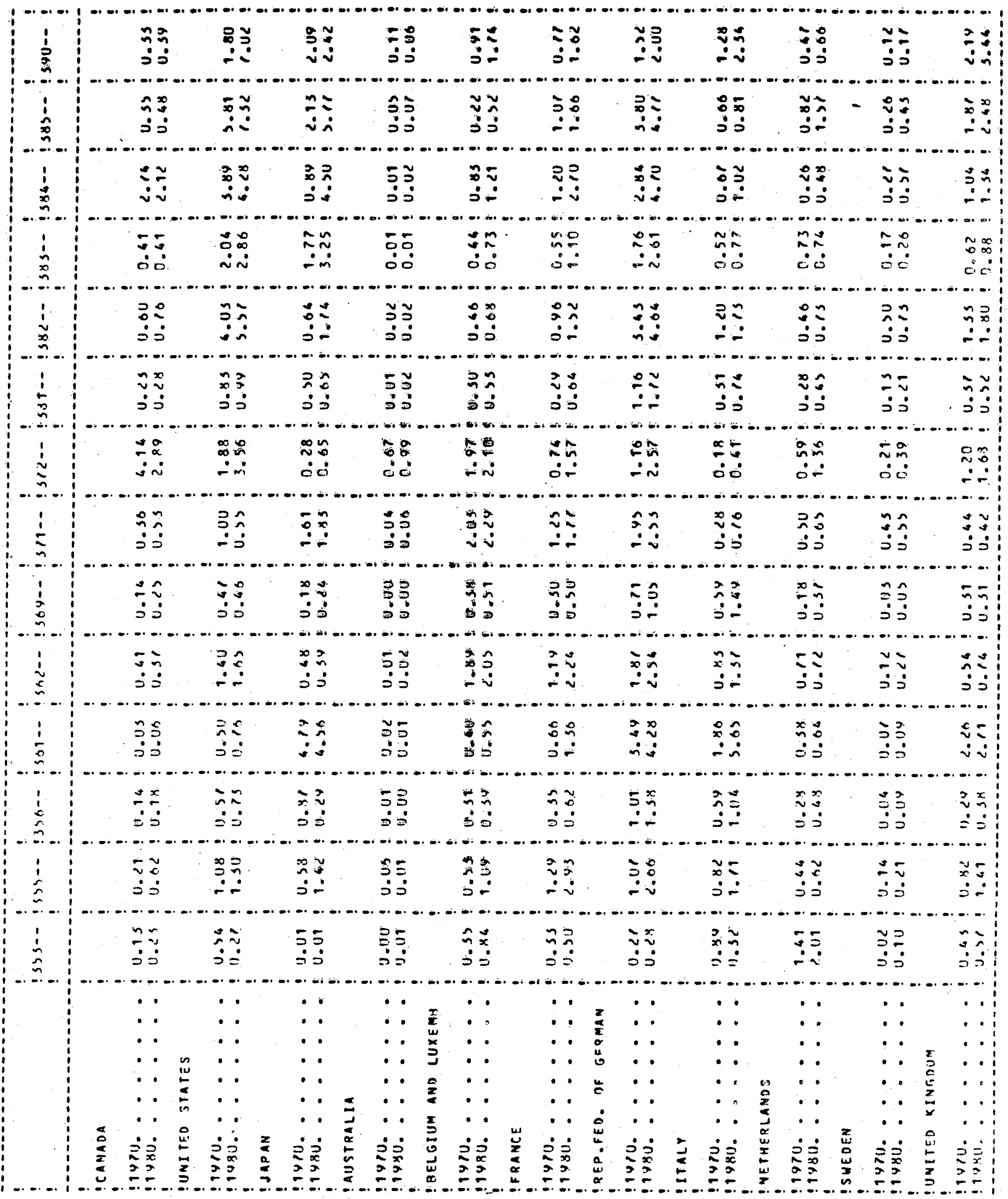

